UNIVERSIDADE DE SÃO PAULO

HOSPITAL DE REABILITAÇÃO DE ANOMALIAS CRANIOFACIAIS

\title{
AVALIAÇÃO DA QUALIDADE DE VIDA EM PACIENTES ADULTOS COM FISSURA LABIOPALATINA.
}

\section{FULVIA DE SOUZA VERONEZ}

Dissertação apresentada ao Hospital de Reabilitação de Anomalias Craniofaciais da Universidade de São Paulo, para a obtenção do título de MESTRE em Ciências da Reabilitação. Área de concentração: Distúrbios da Comunicação Humana. 
UNIVERSIDADE DE SÃO PAULO

HOSPITAL DE REABILITAÇÃO DE ANOMALIAS CRANIOFACIAIS

\section{AVALIAÇÃO DA QUALIDADE DE VIDA EM PACIENTES ADULTOS COM FISSURA LABIOPALATINA.}

\section{FULVIA DE SOUZA VERONEZ \\ Orientador: Prof. Dr. José Alberto de Souza Freitas}

Dissertação apresentada ao Hospital de Reabilitação de Anomalias Craniofaciais da Universidade de São Paulo, para a obtenção do título de MESTRE em Ciências da Reabilitação. Área de concentração: Distúrbios da Comunicação Humana. 


\section{UNIVERSIDADE DE SÃO PAULO \\ HOSPITAL DE REABILITAÇÃO DE ANOMALIAS \\ CRANIOFACIAIS}

Rua Silvio Marchione, 3-20.

Caixa postal: 1501

17043-900 Bauru/SP - Brasil

(14) $3235-8000$

Profa. Dra. Sueli Vilela - Reitora da USP

Prof. Dr. José Alberto de Souza Freitas - Superintendente HRAC/USP

Autorizo, exclusivamente, para fins acadêmicos e científicos, a reprodução total ou parcial deste trabalho.

Fulvia de Souza Veronez

Bauru, de de 2007.

VERONEZ, Fulvia de Souza

V599a Avaliação da qualidade de vida em pacientes adultos com fissura labiopalatina./ Fulvia de Souza Veronez.

Bauru, 2007.

102 fl.: il.; $31 \mathrm{~cm}$

Dissertação (Mestrado - Ciências da Reabilitação: Distúrbios da Comunicação Humana) - HRAC/USP.

Cópia revisada em

Orientador: Dr. José Alberto de Souza Freitas

Descritores: 1.Qualidade de Vida 2.Fissura Labiopalatina 3.Psicologia 


\section{FOLHA DE APROVAÇÃO}

Dissertação apresentada e defendida por

\section{FULVIA DE SOUZA VERONEZ}

e aprovada pela Comissão Julgadora em

Prof.(a) Dr.(a)

Instituição

Prof.(a) Dr.(a)

Instituição

Prof.(a) Dr.(a)

Instituição:

Prof.(a) Dr.(a) Inge Elly Kiemle Trindade

Presidente da Comissão de Pós-Graduação do HRAC-USP

Data de depósito da dissertação junto à SPG : 07/05//2007. 


\section{FULVIA DE SOUZA VERONEZ}

15 de julho de 1980

Nascimento

Adamantina - SP

\section{FORMAÇÃO ACADÊMICA}

$1999-2003$

$2003-2004$

$2004-2005$

$2005-2007$

Curso de Graduação em Psicologia: Licenciatura e Formação de Psicólogo - Universidade do Sagrado Coração. Bauru/SP.

Curso de Capacitação Psicólogo Perito Examinador - Universidade do Sagrado Coração. Bauru/SP.

Curso de Especialização em Psicologia Clínica Hospital de Reabilitação de Anomalias Craniofaciais (HRAC) USP - Bauru/SP.

Curso de Pós Graduação em Ciências da Reabilitação, ao nível de Mestrado, no Hospital de Reabilitação de Anomalias Craniofaciais (HRAC) USP - Bauru.

\section{ATIVIDADES PROFISSIONAIS}

$2005-$

$2007-$
Psicóloga Docente do Curso de Psicologia das Faculdades Adamantinenses Integradas. Adamantina - SP.

Chefe de Departamento do Curso de Psicologia das Faculdades Adamantinenses Integradas. Adamantina - SP.

\section{ASSOCIAÇÕES}

CRP - Conselho Regional de Psicologia

2006
ABEP - Associação Brasileira de Ensino em Psicologia. 
DEDICATÓRIA 
Aos meus amores:

Meu pai Renério,

Minha mãe Nilza e Meu esposo Alexandre. 
AGRADECIMENTOS 
A Deus, fonte de bondade sem a qual nada seria possível.

Aos meus pais, pelo amor infinito, apoio e incentivo percebidos nos seus olhos, que brilham de orgulho a cada conquista.

Ao meu marido, por ter acompanhado com toda paciência e com muito amor todo o processo.

Aos meus sogros, meus tios e todos os familiares, pela torcida, pelas preocupações, pelos favores.

Aos amigos que, mesmo distantes, jamais deixaram de me confortar e me apoiar.

Aos colegas da FAI, em especial à coordenadora do curso de Psicologia Ana Vitória, pelo acompanhamento e constante incentivo.

À amiga Marlene Menconi por todas as vezes que foi tão solícita com minhas necessidades e meus sentimentos.

À amiga Márcia Ferro, pela colaboração na coleta de dados.

Ao setor de Psicologia do HRAC, em especial à Dra. Liliam que me aconselhou na decisão mais importante: a de não desistir de tentar. 
Às admiradas professoras Dra. Maria Inês Gândara Graciano e Dra. Olga Maria Piacentin Rolin Rodrigues pelas valiosas contribuições na qualificação da pesquisa.

À Dra. Ana Cristina Musa Minervino-Pereira pela expressiva contribuição com suas orientações, disponibilidade, dedicação e grandes ensinamentos. Meus profundos agradecimentos.

À Silvana Maziero pela colaboração com os dados e importantes cooperações.

Ao amigo Marcelo Taga pela análise estatística e matemática computacional dos dados desta pesquisa.

Aos professores Dr. Eymar Sampaio Lopes e Dr. José Roberto Pereira Lauris, pelos esclarecimentos na área estatística.

À Dra. Inge Kiemle Trindade, pela tarefa de coordenar a pós-graduação sempre em favor do crescimento de seus alunos.

Aos amigos funcionários da pós-graduação, Andréia, Rogério, Maria José, e saulo cujos favores foram tão incontáveis quanto a simpatia com que faziam cada um deles.

Aos alunos amigos da pós-graduação, pelas horas divertidas, apoio e encorajamento nos momentos mais difíceis. 
À UEP e todos os seus funcionários, por toda acessoria para o desenvolvimento deste trabalho.

Aos funcionários do HRAC cuja amizade e companheirismo já ultrapassaram cargos e posições.

Aos pacientes, meu obrigada de coração e meu desejo de que este trabalho possa contribuir verdadeiramente com a qualidade de suas vidas.

Meus agradecimentos especiais ao Prof. Dr. José Alberto de Souza Freitas, orientador deste trabalho, pela confiança e oportunidade. Muito Obrigada! 
"Trate um homem como ele é, e ele assim permanecerá; trate-o da forma que poderia e deveria ser e ele se tornará aquilo que pode e deve ser."

Johann Wolfgang Goethe (1749-1832). 


\section{SUMÁRIO}

LISTA DE FIGURAS $\quad \mathrm{x}$

LISTA DE TABELAS - xi

LISTA DE SIGLAS xii

RESUMO xiv

SUMMARY Xvi

1 - INTRODUÇÃO 2

2 - REVISÃO DE LITERATURA 8

2.1 - A fissura labiopalatina e o HRAC 8

2.2 - Fatores psicossociais do sujeito com fissura 13

2.3 - Saúde e condições gerais de vida 25

2.4 - Qualidade de vida 29

2.5 - Qualidade de vida e fissura labiopalatina 38

3 - OBJETIVOS 43

4 - MATERIAL E MÉTODO 45

4.1 Casuística 45

4.2 Procedimentos 46

4.3 Análise dos Dados $\quad 48$

5 - RESULTADOS 52

6 - DISCUSSÃO 67

6.1 - Fatores sociodemográficos 69

6.2 - Qualidade de vida 74

6.3 - Qualidade de vida e fatores sociodemográficos 85

7 - CONCLUSÕES 90

8 - REFERÊNCIAS 92

ANEXOS 


\section{LISTA DE FIGURAS}

Figura 1 Esquema ilustrativo dos diferentes tipos de fissura

Figura 2 Gráfico Boxplots e Média \pm 2 EP do WHOQOL-BREF

Figura 3 Gráfico WHOQOL e Idade

60 


\section{LISTA DE TABELAS}

Tabela 1 Caracterização da Amostra

Tabela 2 Relação das questões do WHOQOL-BREF e seus respectivos domínios

Tabela 3 Freqüências das respostas às questões do WHOQOL-BREF

Tabela 4 Medidas-resumo do WHOQOL-BREF

Tabela 5 Medidas-resumo WHOQOL - Físico

Tabela 6 Medidas-resumo WHOQOL - Psicológico

Tabela 7 Medidas-resumo WHOQOL - Relações Sociais

Tabela 8 Medidas-resumo WHOQOL - Meio ambiente

Tabela 9 Modelo de regressão da variável WHOQOL - Meio Ambiente 


\section{LISTA DE SIGLAS}

CPD Central de Processamento de Dados

DIEESE Departamento Intersindical de Estatística e Estudos Socioeconômicos

HRAC Hospital de Reabilitação de Anomalias Craniofaciais

IBGE Instituto Brasileiro de Geografia e Estatística

OMS Organização Mundial da Saúde

WHOQOL World Health Organization Quality of Life 
RESUMO 


\section{RESUMO}

VERONEZ FS. Avaliação da qualidade de vida de pacientes adultos com fissura labiopalatina [dissertação]. Bauru: Hospital de Reabilitação de Anomalias Craniofaciais, Universidade de São Paulo; 2007.

Objetivo: A pesquisa objetivou avaliar a qualidade de vida de pacientes adultos com fissura labiopalatina, analisando-a a partir das condições sociodemográficas dos mesmos e do instrumento WHOQOL-BREF.

Modelo: $\mathrm{O}$ estudo engloba a pesquisa de campo sobre a qualidade de vida de pacientes adultos com fissura labiopalatina.

Local de Execução: Setor de Psicologia, Hospital de Reabilitação de Anomalias Craniofaciais (HRAC) USP.

Participantes: 120 pacientes de ambos os gêneros, com idade entre 18 e 30 anos. Todos em fase final de tratamento, sem nenhuma síndrome ou outra patologia associada.

Variáveis: gênero, idade, origem, situação conjugal, filhos, moradia, interesse vocacional e escolaridade; e resultados dos domínios do instrumento de avaliação da qualidade de vida WHOQOL-BREF.

Resultados: os resultados apontaram um índice de qualidade de vida no geral de bom a muito bom. Todos os domínios da qualidade de vida estavam acima da média; o domínio relações sociais ficou em primeiro, seguido do psicológico, físico e meio ambiente. Não houve correlações estatisticamente significativas entre os domínios da qualidade de vida e as variáveis sociodemográficas levantadas.

Conclusões: os pacientes adultos atendidos pelo HRAC possuem índices gerais de qualidade de vida acima da média. Embora não tenha havido correlação entre a qualidade de vida e os aspectos sociodemográficos, os dados apontam que os pacientes têm boa qualidade de vida e condições de vida correspondentes à população em geral. Descritores: Qualidade de Vida, Fissura Labiopalatina, Psicologia. 


\section{SUMMARY}




\section{SUMMARY}

VERONEZ FS. Quality of life assessment on cleft lip and cleft palate adult patients. [dissertação]. Bauru: Hospital de Reabilitação de Anomalias Craniofaciais, Universidade de São Paulo; 2007.

Objective: The research aimed to assess the quality of life on cleft lip and cleft palate adult patients from their sociodemographic perspective and the results of WHOQOLBREF.

Model: This study involves a field research on cleft palate and cleft lip adult patients quality of life.

Setting: Psychology Department, Hospital de Reabilitação de Anomalias Craniofaciais (HRAC) USP.

Participants: 120 male and female patients, aged between 18 e 30. All subjects were about to end treatment, without any other associated syndrome or disease.

Variables: sex, age, origin, marital status, children, housing, vocational interest and educational level; and the results of life quality assessment WHOQOL-BREF.

Results: the results showed a quality of life level ranging from good to very good. All the quality of life domains were above the average. Social relationships came first, followed by psychological, physical and environmental domain. It has not been established significant correlation concerning quality of life domains and the sociodemographic variables gathered.

Conclusions: the adult patients admitted at HRAC have quality of life general aspects above the average. Although was not found any relationship between quality of life and sociodemographics aspects, the data gathered suggest that patients have quality of life good and life conditions as of the general population.

Key Words: Quality of life, cleft lip, cleft palate, psychology. 
INTRODUÇÃO 


\section{1 - INTRODUÇÃ̃.}

A partir do contato diário com a realidade do Hospital de Reabilitação de Anomalias Craniofaciais (HRAC) e das suas atividades vinculadas ao curso de pósgraduação, esta pesquisadora sentiu-se mobilizada e responsável, mesmo que indiretamente, pelo processo de reabilitação vivido pelo paciente desta instituição e o seu resultado final. Desde sua chegada ao hospital, o paciente mostra-se frágil, inseguro, com um número imenso de variáveis adversas à sua condição de ser e estar. Por isso, até chegar à condição de pessoa com um repertório ampliado, pronta para se apresentar ao mundo como um ser pleno nos seus aspectos biopsicossociais, existe um longo caminho a percorrer.

O HRAC atende pessoas que o procuram para tratamento de diferentes malformações craniofaciais, em especial as fissuras labiopalatinas - resultantes da falta de fechamento completo dos tecidos que compõem o lábio e o palato, ainda na fase do desenvolvimento embrionário. Essa abertura pode envolver o lábio até as estruturas posteriores do palato, acarretando vários comprometimentos (Abdo e Machado 2005).

Os estudos sobre o impacto da fissura labiopalatina na vida das pessoas acometidas por ela, apontam os prejuízos estéticos e funcionais que, mesmo reparados, podem incidir em toda a vida do sujeito (Pegoraro-Krook 1995, Aiello et al 2000, Sinko et al 2005, Capelozza Filho e Silva Filho 2002 e Hunt et al 2005). Tais condições sugerem uma maior atenção à criança e ao adolescente com fissura, considerando os fatores que interferem no seu desenvolvimento global e sua inserção no meio social, tendo em vista a deformidade (Bachega 2000, Minervino-Pereira 2000, Stephan 2003, Tavano 2000 e Marques 2004). 
O objetivo do HRAC é promover a reabilitação do paciente. O termo reabilitação foi brilhantemente descrito por Matilde Neder, a primeira psicóloga hospitalar do Brasil, há quase meio século:

$$
\begin{aligned}
& \text { "reabilitação é a ação conjunta de profissionais } \\
& \text { especializados, com o intento de apoiar a pessoa com } \\
& \text { dificuldades físicas e mentais nas questões físicas, psíquicas, } \\
& \text { sociais e profissionais de modo que ela possa ter um maior } \\
& \text { domínio sobre si mesma e sobre o ambiente, enfrentando a } \\
& \text { realidade da vida" (Angerami et al } 1998 \text { p.10). }
\end{aligned}
$$

Amaral (1997) aproxima a reflexão acima para a realidade da reabilitação das deformidades faciais. Segundo o autor, a reabilitação envolve:

“a união de esforços de uma equipe de profissionais que, por meio de uma ação interdisciplinar, preventiva e curativa, junto à pessoa dom defeito facial, seus familiares e comunidade, procure minimizar seus problemas, favorecendo as condições para o pleno desenvolvimento de suas capacidades físicas, psicológicas, afetivas e sociais" (Amaral 1997 p.513).

A definição destes autores ecoa em todas as ciências preocupadas com a qualidade de vida do ser humano, exigindo o envolvimento das diversas áreas que visem à reabilitação e à promoção da saúde.

A idéia de qualidade de vida está, para a maioria das pessoas, relacionada ao bem-estar físico e emocional, bem como às boas condições de moradia e de bens materiais, incluindo: hábitos saudáveis, cuidados com o corpo, atenção para a qualidade dos relacionamentos, balanço entre vida pessoal e profissional, considerando também vivências de felicidade e de amor.

Impossível citar qualidade de vida sem refletir sobre a subjetividade desse conceito, visto que o significado de tal expressão se confunde no compartilhamento da 
dimensão cultural que vai constituir a experiência histórica e coletiva dos grupos e populações. Portanto, qualidade de vida não é definível exclusivamente a partir de critérios objetivos ou técnicos. Muito mais que isso, a expressão compreende uma diversidade de emoções e sentimentos particulares, só possíveis de serem apreendidos pelo próprio sujeito.

Minayo e Hartz (2000) propuseram um aprofundado debate sobre as relações entre saúde e qualidade de vida. Em seu discurso, descreveram as várias modalidades de entendimento do termo e afirmaram que enquanto conceito, qualidade de vida trata de uma representação social criada a partir de parâmetros subjetivos (bem-estar, felicidade, amor, prazer, realização pessoal) e também objetivos, cujas referências são a satisfação das necessidades básicas e daquelas criadas pelo grau de desenvolvimento econômico e social de determinada sociedade. Considera-se, ainda, a proposta de promoção da saúde como a mais relevante estratégia para evitar o reducionismo médico e realizar um diálogo intersetorial.

A conceituação de saúde está relacionada à capacidade de viver sem doenças ou de superar as dificuldades dos estados ou condições de morbidade. Fora do marco referencial do sistema médico que domina a reflexão e a prática do campo da saúde pública, sua conceituação corre o risco de perder o sentido teórico e epistemológico. Torna-se reducionista dizer que restabelecida a saúde, o indivíduo terá qualidade de vida. A qualidade de vida depende também de seriedade na economia e nas políticas de saúde pública, planejamento, desenvolvimento sustentável e do próprio sujeito que a tem ou a deseja.

Muito se vê sobre a teoria do bem-estar, que explora as reações subjetivas das experiências de vida, buscando a competência do indivíduo para minimizar sofrimentos 
e aumentar a satisfação pessoal e de seu entorno. Ao citar qualidade de vida, acredita-se na relevância de aproximá-la da saúde e, principalmente, do comprometimento dos sistemas de saúde para com a população (Casas 2005). As pesquisas sobre a qualidade de vida e saúde das pessoas, nas mais diversificadas situações, são de interesse de todas as ciências relacionadas à saúde e ao bem-estar do indivíduo. É preocupação geral que as técnicas empregadas num ou noutro tratamento somadas ao acompanhamento oferecido pelos serviços de apoio técnico-hospitalar estejam resultando numa condição na qual o sujeito possa viver bem.

São poucas as unidades de saúde que podem oferecer mais do que os cuidados técnicos, ou seja, a assistência médica imediata que alivia os sintomas e resolve o problema do ponto de vista funcional.

No entanto, é preciso ressaltar que a eficiência de um hospital ou de qualquer outra instituição de saúde não está somente na sua capacidade de proporcionar às pessoas a ausência de doenças. Um hospital deve ter equipes preocupadas com o paciente na sua totalidade, ou seja, com a habilidade de compreender o sistema humano como um todo; suas particularidades, expectativas e receios que possam interferir nos resultados finais.

O ser humano que procura recursos profissionais para tratar de uma deficiência na saúde está buscando, além da cura física propriamente dita, a aceitação, compreensão, suporte para suas condições emocionais, sociais e de afeto. Assim, no ambiente hospitalar, a equipe profissional se depara com uma diversidade de emoções e sentimentos oriundos não apenas dos pacientes como também de seus familiares, intensificadas pela própria situação de hospitalização, bem como das vivências de cada um (Romano 1999). 
Em tratamentos reabilitadores, como o da fissura labiopalatina, têm-se um paciente que evidencia a necessidade de uma abordagem holística, pois seu processo reabilitador acontece na maioria das vezes por longos períodos, incluindo idas e vindas à instituição de saúde, internações e, muitas vezes, várias cirurgias. O hospital, neste caso, torna-se um lugar especial, pois nele são firmados laços de afeto e cumplicidade, além de vivências de confiança entre paciente e profissional de saúde.

É sobre este paciente que se estenderam os objetivos deste estudo. Considerando-se toda carga emocional e todas as dificuldades às quais o sujeito com fissura é submetido, o presente trabalho pretendeu investigar a qualidade de vida de pacientes adultos em relação às suas condições de vida e saúde.

Espera-se que a partir deste referencial, seja evidenciada a realidade dos pacientes atendidos e, assim, possa ser oferecido um tratamento ainda mais completo, de forma a favorecer sempre melhores condições de vida e saúde aos atendidos. Estes dados ainda devem proporcionar aos profissionais da equipe reabilitadora, a possibilidade de maior entendimento quanto às necessidades de cada um, bem como ampliar a compreensão de possíveis insatisfações.

Até porque, parafraseando Bertold Brecht: a melhor, senão a única, finalidade da ciência é aliviar a canseira da existência humana. (Brecht 1990) 
REVISÃO DE LITERATURA 


\section{2 - REVISÃO DE LITERATURA.}

Para se atingir os objetivos propostos, é necessário primeiramente uma revisão a respeito da fissura labiopalatina, sua incidência, evolução e o tratamento oferecido, referenciando o Hospital de Reabilitação de Anomalias Craniofaciais, local de realização do estudo. Em seguida, estão apresentadas as implicações psicossociais do sujeito com fissura a partir da análise de autores que examinaram os diversos fatores desde a infância, passando pela adolescência até a idade adulta. Uma reflexão da saúde e da relevância da qualidade dos serviços oferecidos para sua promoção foi feita considerando-se, inclusive, um breve panorama da condição de vida e saúde da população do estado de São Paulo, escolhida para este estudo. Em seguida, um levantamento sobre a definição de qualidade de vida e suas formas de avaliação visa facilitar o entendimento desse assunto tão amplo. E, finalmente, apoiada numa literatura específica, buscou-se trabalhos que procuraram entender como a fissura labiopalatina pode refletir na qualidade de vida das pessoas acometidas por ela.

\section{1 - A fissura labiopalatina e o HRAC}

A fissura labiopalatina é uma anomalia congênita resultante da falta de fusão, na linha mediana, dos processos bilaterais do maxilar por volta da décima segunda semana de vida intra-uterina. Sua incidência é de um caso para cada 650 nascidos vivos; na raça amarela têm-se uma maior predominância seguida pela raça branca e com menor taxa na raça negra. Por vezes, podem ocorrer fissuras atípicas que envolvem outras áreas, 
além do lábio superior e palato, como as regiões orais, nasais, ocular e craniana (Capelozza Filho e Silva Filho 1992).

Entre as malformações que acometem o homem, as fissuras labiopalatinas representam as mais comuns. Surgem na vida intra-uterina, durante a formação da face e sua alta prevalência é explicada pela complexidade do desenvolvimento embrionário humano; sua origem é atribuída a fatores filogenéticos e ontogenéticos. Embora a etiologia ainda não esteja totalmente comprovada, Abdo e Machado (2005) apontam para diversos fatores. Dentre eles estão as questões ambientais, sociais e nutricionais; fatores teratrogênicos, como o uso de medicamentos e drogas na gestação, além de exposição a radiações, rubéola, varíola e toxoplasmose, estresse e hipervitaminose A; fatores endocrinológicos como diabetes e hipotireoidismo na mãe. Mesmo não se sabendo ainda como a fissura seria transmitida de uma geração a outra, os fatores hereditários são considerados, pois a probabilidade de transmissão de pais para filhos aumenta conforme a ocorrência de fissura na família. Os autores também apontam a existência de fatores múltiplos combinados que poderiam causar a fissura labiopalatina como: suprimento vascular deficiente ou distúrbio motor (quando o feto posiciona a língua no local de desenvolvimento das estruturas).

Para que a comunidade científica tivesse uma visão esclarecida quanto à tipologia das fissuras, Spina et al (1972) propuseram uma classificação em quatro grupos, usando como referência o forame incisivo, local em que ocorre o fechamento de toda área do lábio e palato:

Grupo I - fissura pré-forame incisivo. Refere-se à formação do lábio e rebordo alveolar. Pode ser classificada como completa ou incompleta, podendo ser unilateral, bilateral ou mediana conforme o lado comprometido. 
Grupo II - fissura transforame incisivo. Refere-se à que tem início no lábio ou rebordo alveolar e prossegue até o palato mole, atravessando o forame. Classificada em unilateral ou bilateral.

Grupo III - fissura pós-forame incisivo. São as fissuras isoladas de palato. Sua maior incidência envolve a região posterior da úvula até o forame incisivo. É classificada como completa se atinge o forame incisivo e incompleta se não chega até ele.

Grupo IV - são as fissuras faciais raras. Estas compreendem outras fissuras na face além do lábio e palato.

A figura 1 ilustra a classificação das fissuras labiopalatinas, de acordo com Spina et al (1972), apresentada por Pini e Peres (2001). 


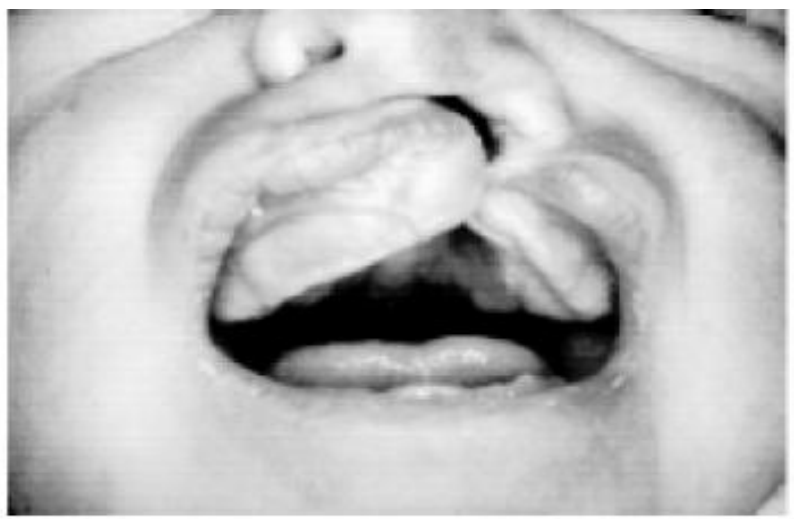

FISSURA PRE-FORAME INGSIVO UNILATERAL

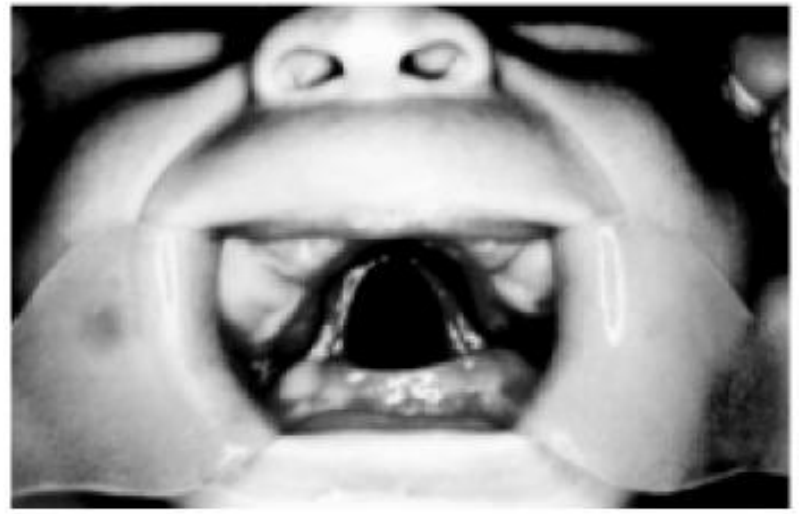

FISSURA PÓS. FORAME INCISNO TOTAL

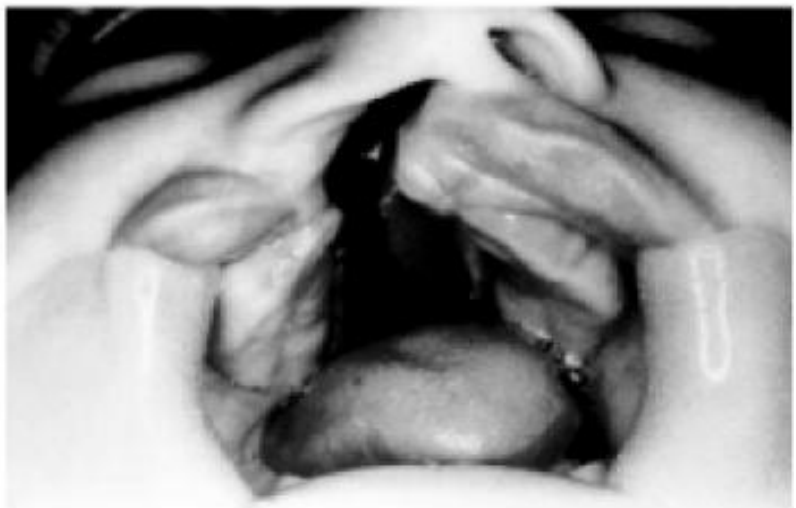

FISSURA TRANSFORAME INCISIVO UNILATERAL

Fonte: Pini JG, Peres SPBA. Alimentação do lactente portador de lesão lábio-palatal: aleitamento e introdução alimentar. Rev Nutr 2001; 14:195-9.

Figura 1: Esquema ilustrativo dos diferentes tipos de fissura. De cima para baixo: Fissura pré-forame incisivo unilateral; Fissura pós-forame incisivo e fissura transforame incisivo unilateral. 
Em um levantamento realizado por Freitas et al (2004), o tipo mais freqüente de fissura é a Transforame Incisivo Completa de Lábio e Palato (37,1\%) cuja ocorrência é maior em indivíduos do gênero masculino. Na seqüência, têm-se a fissura isolada de palato conhecida como Pós-forame Incisivo $(31,7 \%)$ e a isolada de lábio, denominada Pré-forame Incisivo $(28,4 \%)$. Estes autores citam também uma pequena porcentagem de pacientes $(3,8 \%)$ com outras combinações de fissuras, denominadas Fissuras Faciais Raras.

Baroneza et al (2005) encontraram em seus estudos com 377 pacientes com fissura atendidos por uma instituição no interior do estado do Paraná, a predominância da fissura transforame, seguida de pré-forame e pós-forame, além de verificar maior prevalência de fissuras em indivíduos do gênero masculino.

O Hospital de Reabilitação de Anomalias Craniofaciais (HRAC-USP), localizado em Bauru, trabalha com pacientes com malformações craniofaciais; em grande parte dos casos fissuras labiopalatinas. Trata-se de um centro multidisciplinar, especializado em malformações craniofaciais, que além de ser reconhecido como referência internacional pela Organização Mundial da Saúde (OMS), ainda integra os 14 centros de atendimento do Estado de São Paulo, região de maior concentração de hospitais deste tipo segundo Monlleó e Lopes (2006).

O HRAC tem como objetivo principal atender o paciente em todas as suas necessidades físico-estético-funcionais. Com um arquivo de mais de 40 mil pacientes matriculados somente nesta área de atuação, realiza com o apoio do Sistema Único de Saúde (SUS) cerca de 90 cirurgias por semana em pessoas que em sua maioria são crianças e adolescentes. Possui uma equipe preocupada com a total reabilitação do paciente, que chega ao hospital pela primeira vez, na maioria dos casos, ainda bebê, e 
permanece em tratamento até a sua alta definitiva que pode ocorrer somente na idade adulta (Loffredo et al 1994).

Conforme Abdo e Machado (2005), o tratamento desta malformação tem início logo nos primeiros meses de vida com as cirurgias primárias de lábio e palato. Após este processo inicial, o paciente é acompanhado ao longo dos anos por equipe multidisciplinar que atua em todas as áreas que envolvam a reabilitação total do indivíduo, além do apoio à família. As cirurgias secundárias visam à melhora estética e funcional e ocorrem a partir da adolescência até a idade adulta. Estima-se que por volta dos 20 anos o paciente, que iniciou o tratamento logo nos primeiros meses de vida, esteja em fase final, refinando a oclusão e aprimorando a fala.

2.2 - Fatores psicossociais do sujeito com fissura.

Muitos estudos ressaltam a influência dos fatores psicossociais em pessoas com fissuras labiopalatinas. Portanto, torna-se pertinente buscar na literatura dados que demonstrem como a malformação pode vir a ser um complicador na vida do sujeito que a possui. Serão levantados alguns estudos que exemplifiquem os implicadores psicossociais que são enfrentados pelo indivíduo nas diversas fases do desenvolvimento e quais as estratégias para a superação de dificuldades.

Os fatores psicossociais englobam as formas de relação da pessoa com o mundo a sua volta, sua habilidade nos relacionamentos interpessoais, as questões emocionais, além das condições socioeconômicas e de sobrevivência; são apontados na literatura como prováveis agravantes da condição daquele que tem fissura, pelo impacto que produzem na qualidade de vida do sujeito. 
Aiello et al (2000), num capítulo sobre todo o processo reabilitador do sujeito com fissura labiopalatina oferecido pelo HRAC, relataram que os pacientes com fissuras labiopalatinas encontram problemas psicossociais complexos, pois em decorrência das alterações morfológicas e funcionais, carregam desde a infância um estigma marcante que pode alterar seu comportamento no futuro.

Hunt et al (2005), numa revisão sistemática de pesquisas sobre os efeitos psicossociais em crianças e adultos com fissura de lábio e palato, observaram dificuldades em classificar o que seriam problemas psicológicos e sociais. No levantamento, destacaram que, em sua maioria, crianças e adultos com fissura não parecem ter mais problemas psicológicos em relação as pessoas sem malformação, embora alguns problemas específicos tenham sido observados como distúrbios comportamentais, insatisfação com aparência facial, depressão e ansiedade, em casos isolados. Considerando os diferentes tipos de fissura, poucas diferenças foram encontradas em relação ao auto-conceito, nível de satisfação com aparência facial, depressão, problemas de aprendizagem e relacionamentos interpessoais. Com poucas exceções, a idade dos sujeitos com fissura pareceu não influenciar na ocorrência ou severidade de problemas psicossociais relativos a esta condição.

Para Graciano et al (2007 p.311): “não reabilitamos um paciente sem o conhecermos totalmente". As autoras reuniram em um capítulo os aspectos psicossociais considerados na reabilitação que vão desde o impacto do nascimento de uma criança com fisssura labiopalatina na família até a constituição desta na idade adulta. Afirmaram ainda que as fissuras não determinam diferenças significativas em termos de desenvolvimento de personalidade. Contudo, as diversas contingências físicas, psicológicas, afetivas e sociais envolvidas na dinâmica da pessoa com fissura, 
podem conduzir ao desajustamento caso os pacientes e familiares não sejam apoiados por uma equipe interdisciplinar.

A aparência parece ser o fator mais agravante para a consolidação social e emocional da pessoa com fissura. Considerando o rosto como o primeiro fator exposto num contato social, pode-se compreender os sentimentos vivenciados pelos sujeitos com fissura labiopalatina e os prejuízos decorrentes da deformidade facial. Nos países ocidentais onde se têm uma cultura de valorização do belo, da juventude e da capacidade produtiva do indivíduo, a malformação facial acaba sendo associada a sentimentos negativos, de malogro pessoal, impotência, falta de confiança e insegurança.

Investigando a relação entre a aparência facial da criança com fissura e a avaliação dos professores quanto à sua capacidade intelectual, Richman (1978) concluiu que quanto mais evidente for a malformação, mais esta estará associada ao déficit cognitivo, embora já fosse de conhecimento científico que a malformação não acarreta danos neuropsicológicos. No estudo destes autores, ficou evidente que os professores classificaram a capacidade intelectual das 87 crianças com fissuras, com idade entre 9 e 14 anos, que apresentavam desfiguramento mais perceptível, com menos cuidado do que as crianças com fissuras que apresentam aparência facial relativamente normal.

Percebendo a dificuldade dos pais que se sentem vítimas de preconceitos juntamente com seus filhos com fissura labiopalatina, no tocante ao ambiente acadêmico e social, Tavano (1994), através do método de observação direta e registro cursivo, acompanhou as interações sociais de um aluno de sete anos na escola com a professora e os colegas. Diante das dificuldades encontradas por este aluno, a autora observou que, à medida que a criança sem comprometimentos cresce, mais intransigente 
se torna às deformidades encontradas na aparência e na alteração da fala do colega, sentindo-se mais inclinada a atormentar, provocar ou ridicularizar, influenciada pelo sentimento de rejeição a tudo que esteja fora do conceito generalizado de normalidade. Para a autora, a escola é considerada como o primeiro ambiente fora do seio familiar a ser freqüentado pela pessoa com fissura, e este ambiente proporciona condições que também podem gerar timidez, retraimento social, indiferença ou agressividade. As respostas emocionais da sociedade em relação à pessoa com fissura variam de piedade a repugnância, podendo mobilizar tanto a ação social quanto o isolamento. $\mathrm{O}$ aspecto marcante da crítica social altera de certo modo o auto-conceito das pessoas, resultando em uma auto-avaliação negativa da própria capacidade. Esta percepção pode influir no seu desenvolvimento acadêmico, social e emocional, refletindo negativamente na idade adulta.

Omote (1997) afirma que a aparência física de uma pessoa influencia diretamente no julgamento e nas relações que se mantém com ela. Levando-se em conta os padrões estéticos valorizados e aceitos pela nossa cultura, pode-se ter uma idéia do quanto o paciente com fissura se sente rejeitado, inadequado e não aceito socialmente pelo estigma que se instala em decorrência da deformidade.

Com o objetivo de analisar a influência do estigma físico nas relações interpessoais em indivíduos com fissura labiopalatina, Pereira e Mota (1997) abordaram o tema com 71 adolescentes e adultos com fissura labiopalatina operada recentemente. Os resultados mostraram que o estigma físico parece ser um aspecto que prejudica e interfere negativamente nas relações interpessoais e na construção de uma identidade positiva. Os pacientes entrevistados relataram ter dificuldades em encontrar alguém para namorar; reconheceram ainda ter a fala pouco compreensível, aparência e estigmas 
físicos; sentimentos de medo, insegurança e timidez, como também dificuldades de aproximação com o outro. Mesmo assim, a maioria pensa em se casar; aqueles que não pensam nisto justificam tal posição pela própria condição da fissura com as implicações do preconceito e do medo de não serem aceitos pelo outro, bem como pela dedicação exclusiva ao processo de reabilitação, além do medo de gerarem filhos com a mesma condição. As autoras ressaltaram a importância e a necessidade de um trabalho multidisciplinar, priorizando uma abordagem psicoterapêutica para melhora da condição de vida dessa população.

Pessoas com fissura labiopalatina mesmo tratada, por vezes, permanecem com dificuldades de comunicação que podem inclusive afetar a percepção, o que impacta diretamente sobre o seu comportamento psicossocial.

Pegoraro-Krook (1995), ao pesquisar 22 pacientes com inadequação velofaríngea com idade entre 8 e 71 anos, observou grande melhora na inteligibilidade da fala e ressonância após tratamento protético de palato. A autora ressalta a importância central da fala na vida individual e coletiva do homem, importância também amplamente reconhecida pelos estudiosos do comportamento humano. As alterações nas estruturas do palato que não foram passíveis de correção, podem acarretar distúrbios de fala específicos como a hipernasalidade (fala fanhosa) e as alterações articulatórias decorrentes do escape de ar nasal durante a produção da fala. Isso gera comprometimentos consideráveis quanto à inteligibilidade de fala e pode levar o indivíduo ao desajuste psicossocial.

A malformação, por sua vez, pode afetar a educação que repercute na questão do emprego. Além do julgamento que o indivíduo com fissura faz de si mesmo e do resultado do julgamento dos outros pela sua aparência ou déficit funcional, o estigma 
ainda traz repercussões maiores na sua vida social, como dificuldades com os relacionamentos afetivos, estudo e trabalho.

Peter et al (1974) compararam os aspectos econômicos e vocacionais de 196 sujeitos adultos com fissura e 209 pessoas do grupo controle. Em relação ao emprego de pessoas com fissura, observaram que os adultos trabalham normalmente em empregos formais, contudo com renda mais baixa que pessoas sem fissura. Foi identificado que a sociedade parece valorizar menos o trabalho e o interesse vocacional de pessoas com fissura. Em 1975, estes mesmos autores avaliaram a integração social dos mesmos sujeitos do estudo anterior e revelaram que os adultos com fissura tendem a confiar mais em seus familiares para cuidados de modo geral, tendendo a participar pouco de atividades sociais. Quanto à vida marital, os autores encontraram em suas pesquisas um grande número de adultos com fissura tendendo a viver na companhia de familiares ou sozinhos, quando comparados com pessoas sem fissura na mesma faixa etária. Os problemas referentes ao relacionamento com o sexo oposto parecem estar relacionados à baixa auto-estima e prejuízo na aparência. Adultos com fissura tendem a casar mais tarde que os adultos sem fissura (Peter et al 1975).

Ramstad et al (1995a) investigaram a educação, emprego e vida conjugal de 233 noruegueses adultos (168 homens e 65 mulheres) com fissura labiopalatina após o tratamento. Encontraram níveis educacionais semelhantes em grupos de sujeitos com e sem fissura. Em contrapartida, os indivíduos com fissura freqüentemente trabalhavam afastados daqueles sem fissura. Quanto às relações conjugais, foi detectado que eles namoravam menos e se casavam mais tarde do que as pessoas sem fissura.

Num estudo com 104 adolescentes e adultos com fissura labiopalatina transforame, advindos das regiões sul, sudeste e centro-oeste do Brasil, sobre a 
colocação da pessoa com fissura no mercado de trabalho, Blatner (2000) observou que a maioria dos entrevistados trabalhava no setor terciário; eles estavam inseridos socialmente, não sofrendo discriminação ou estigmatização no ambiente de trabalho.

Tavano (2000) investigou o desempenho psicossocial de 32 pacientes do HRAC com idade entre 15 e 21 anos. Os resultados demonstraram que todos eram solteiros, tinham bom relacionamento social com seus familiares, colegas e professores e apresentavam desempenho escolar normal. Embora estivessem muito satisfeitos consigo e com o tratamento, pediam mais cirurgias estéticas. Em relação ao emprego, tinham ocupações circunstanciais que não eram condizentes com seus projetos de vida. Para conseguir um trabalho, uns tinham dificuldades de fazê-lo pela própria malformação ou pelo preconceito que ela acarretava, outros eram beneficiados pela malformação à medida que aderiam a programas de inclusão profissional. A autora sugere uma avaliação subjetiva e objetiva do tratamento, além da possibilidade de atendimento psicoterapêutico no hospital com os objetivos de minimizar o sofrimento provocado pela malformação e de discutir os danos que ela acarreta.

Há uma preocupação evidente sobre o impacto da fissura no âmbito emocional, posicionando a fissura labiopalatina como agente implicador de distúrbios psicológicos complexos, que afetariam diretamente a vida do sujeito com a malformação, necessitando este de apoio psicológico ao longo do tratamento.

Ramstad et al (1995b) descreveram a ocorrência de problemas psicológicos comuns em 233 noruegueses adultos com fissura e observaram uma diferença expressiva entre pacientes com fissura e o grupo controle em relação às questões psicológicas. Os participantes do gênero masculino pareceram ser menos ajustados que os participantes do gênero feminino e as queixas de ansiedade, depressão e palpitações 
apareceram duas vezes mais nos sujeitos com fissura. Tais problemas foram fortemente associados com a aparência, dentição, fala comprometida e desejo da continuidade do tratamento. Os achados atestaram danos psicológicos em pacientes com fissura e levantaram questões para pesquisas futuras.

Garcia et al (1999) verificaram a tendência à estruturação e configuração da auto-imagem de 20 pacientes com fissura, com idade entre 18 e 30 anos. Os resultados mostram que a maioria dos pacientes apresentou auto-imagem desfavorável, dificuldades nos contatos sociais e elevado índice de dependência emocional, principalmente de familiares. Embora reconheçam mudanças no final do tratamento, os pacientes ainda tinham expectativa de melhoras, confirmando que a reabilitação cirúrgica não garante a reestruturação da auto-imagem, impondo-se como necessário uma ajuda psicológica.

Preocupada com a constituição do auto-conceito e da auto-estima de 80 pacientes com mais de 16 anos, considerando o tipo de fissura e o tempo de convivência com ela, Minervino-Pereira (2000) observou que quanto maior o tempo de convivência com a fissura não tratada, mais negativo era o auto-conceito. Todos os pacientes pesquisados apresentaram uma auto-estima mediana e o fator tipo de fissura foi mais determinante na formação da auto-estima positiva do que o tempo de convivência com a mesma. Diante dos resultados obtidos, a autora sugere uma reflexão sobre o estigma mantido pela própria equipe hospitalar e a sociedade em geral, que continua denominando como "fissurada", a pessoa que passa por um longo processo reabilitador.

Broder (2001), numa revisão dos estudos que examinam as questões psicológicas de pacientes com fissura labiopalatina, como resiliência e estratégias terapêuticas para a promoção do bem-estar, reforça a necessidade de intensificação de 
aconselhamentos, suporte e treino de pais para a intervenção terapêutica no processo de reabilitação, de modo a intervir diretamente nas questões psicossociais que influenciam na qualidade de vida.

$\mathrm{Na}$ fase final do tratamento, surge a necessidade de se medir a satisfação com os resultados obtidos além das habilidades do paciente em relação à sua adequação no mundo. A literatura expõe que existe em muitos casos a necessidade de mais cirurgias pelos pacientes e alguns estudos apontam que a satisfação não é sempre completa.

Noar (1991) investigou os problemas e interesses percebidos por 28 pacientes com fissura labiopalatina, com idade entre 16 e 25 anos, e seus pais. Os resultados demonstraram satisfação com o tratamento recebido, com sua aparência de forma geral e com as condições de fala. Entretanto, algumas áreas específicas foram citadas com baixa satisfação (nariz, boca e dentes), além de dificuldades sociais, especialmente com o sexo oposto. Os pais também perceberam que seus filhos foram social e emocionalmente afetados pelo fato de terem fissura labiopalatina.

Em relação à aparência facial, Thomas et al (1997) examinaram a satisfação de 111 pacientes com fissura, na faixa etária de 10,15 e 20 anos, e seus pais. O estudo enfocou a relação entre satisfação, aparência e funcionamento psicossocial. Os resultados apontaram que os pacientes com 20 anos, cuja deformidade era menos visível, estavam mais satisfeitos com sua aparência; enquanto aqueles cuja deformidade era mais visível demonstraram maiores índices de insatisfação com a aparência facial. Para os autores, as medidas de auto-satisfação com a aparência podem ser úteis na indicação de problemas de ajustamento.

Marcusson et al (2002) compararam 68 adultos suecos com fissura de lábio e palato com 66 adultos sem fissuras. As questões permearam os temas de auto-imagem, 
qualidade de vida em geral, qualidade de vida em relação à saúde, somatização e depressão. Muitos adultos esperavam melhores resultados das cirurgias. O grupo com fissura respondeu insatisfação com sua aparência facial, incluindo nariz, lábios e boca. Diante disso um grupo de profissionais avaliou os participantes da pesquisa e concordou com os entrevistados, sugerindo mais cirurgias secundárias como a rinoplastia. A satisfação com a aparência foi fortemente correlacionada com a qualidade de vida e depressão em ambos os grupos. Embora insatisfeitos com sua aparência, eles pareciam bem ajustados psicologicamente.

Em estudos mais recentes, há autores que afirmam que o paciente com fissura labiopalatina pode superar as dificuldades advindas da malformação por meio de um tratamento reabilitador multidisciplinar adequado.

Amaral (1997) concluiu, após revisão de literatura, que as variáveis como família, amigos, escola e vida adulta não se diferenciam enquanto formadoras da personalidade de indivíduos com e sem fissura. Mesmo reconhecendo que a fissura acarreta uma série de conseqüências físicas e sociais e que estas podem afetar o desenvolvimento emocional do paciente, é enfatizada a importância do acompanhamento multidisciplinar em todo processo reabilitador, promovendo $\mathrm{o}$ ajustamento do paciente com fissura ao seu meio social.

Numa revisão da literatura psicológica sobre fissura de lábio e palato e outras anomalias craniofaciais, Endriga e Kapp-Simon (1999) levantaram questões sobre aceitação familiar, competência social, auto-conceito, ajustamento emocional e funcionamento cognitivo. A pesquisa cumulativa revelou que muitas crianças são resilientes em relação às questões psicológicas; entretanto, boa parte denuncia distúrbios 
de aprendizagem e dificuldades com a competência social. Os estudos também evidenciaram adultos sem transtornos psicológicos aparentes.

Bachega (2000), com o objetivo de identificar, descrever e avaliar os indicadores psicossociais e a repercussão destes na qualidade de vida de 67 adolescentes com fissura em comparação com 67 adolescentes sem fissura, ambos com idade entre 10 e 19 anos, relatou limitações dos indivíduos com fissura labiopalatina para o desenvolvimento de uma carreira profissional devido à baixa freqüência escolar. Os sujeitos estudados apresentaram indisciplina e isolamento social, sendo necessário construir uma identidade positiva, incorporando sua malformação a sua auto-imagem, sendo o conhecimento das próprias limitações igualmente importante na definição da identidade. Todavia, concluiu que apesar do estigma, os pacientes superaram os limites da deficiência e apresentaram-se satisfeitos com a vida.

Strauss (2001) sugeriu uma mudança de olhar pelos pesquisadores a respeito da saúde e resiliência de pessoas com anomalias craniofaciais. O impacto psicológico de uma condição não precisa estar relacionado com o efeito do dano biológico. Para ele, os clínicos deveriam considerar que a decisão pelo tratamento deve envolver mais o paciente e a família, tornando-os mais responsáveis por suas escolhas e seu próprio destino. A modernidade da ciência tem condições de maximizar o potencial humano, enfatizando a resiliência e o otimismo, mudando o foco do estudo da doença para a saúde. O autor sugeriu também futuros estudos com foco na psicologia positiva e na adaptação social fazendo uso das medidas e escalas psicológicas existentes.

Stephan (2003), numa revisão de literatura sobre o desenvolvimento psicossocial e educacional de indivíduos com anomalias, analisou a capacidade de superação de indivíduos brasileiros com anomalias faciais em relação aos problemas inerentes à sua 
condição e de que maneira essa capacidade pode ser potencializada. Dados sobre o assunto, de natureza multidisciplinar, relataram uma tendência a um tratamento focado não somente no restabelecimento funcional e anatômico, mas no desenvolvimento de uma pessoa saudável emocional, social e profissionalmente.

Ainda de acordo com Stephan (2003), essa condição pode ser possível por três dimensões: o desenvolvimento educacional dos indivíduos afetados; a conscientização de pais e responsáveis com relação à desestigmatização da diferença facial, às formas de tratamento e às implicações conseqüentes; e, a familiarização de educadores em relação às condições craniofaciais e às suas implicações, para que se sintam preparados para receber na sociedade indivíduos com malformação, incluindo-os em classes regulares.

Num estudo sobre a influência da dificuldade de fala nos aspectos psicossociais de 13 sujeitos com média de idade de 24 anos e fissura já reparada, Marques (2004) detectou melhora nas relações interpessoais e nas habilidades sociais após a faringoplastia.

Veronez e Tavano (2005) observaram significativa melhora na aceitação de si mesmo, disposição para planejar o futuro e grande repercussão nas relações sociais em 30 pacientes adultos submetidos à cirurgia ortognática; 15 deles com fissura labiopalatina e 15 sem fissura. Isso demonstra que o tratamento adequado e a segurança do paciente na equipe hospitalar geram bons resultados e favorecem a adaptação do indivíduo na sociedade.

Os dados referentes ao estudo social dos pacientes com fissura atendidos no hospital ainda são incipientes, impossibilitando um levantamento das condições socioeconômicas e sua correlação com a fissura para esta população. Graciano et al (2006), com o objetivo de analisar e reconstruir os indicadores do protocolo do estudo 
social se propuseram a reformular todo o levantamento, construindo um novo modelo de relatório social informatizado, interdisciplinar capaz de atender aos critérios de classificação social, emocional e econômico da população atendida.

Os aspectos psicossociais negativos podem agravar a situação do paciente que vivencia a fissura labiopalatina, influenciando diretamente o seu desempenho global. Por outro lado, muitos estudos apontam a capacidade de superação das dificuldades advindas da malformação e os aspectos psicossociais como agentes positivos na estruturação da vida do sujeito. É importante ressaltar que os referidos aspectos são um dos fatores considerados para a vida do sujeito e que tão relevante quanto eles são as condições de vida e saúde que compõe a rotina diária das pessoas.

2.3 - Saúde e condições gerais de vida.

O estado de saúde repercute em todos os aspectos da vida do indivíduo. Este estado, aliado às condições de vida predizem a capacidade para realização de tarefas e a possibilidade de uma vida em plenitude.

A Lei Orgânica da Saúde no .8080 de 19 de setembro de 1990 dispõe:

Art. $3^{\circ}$ A saúde tem como fatores determinantes e condicionantes, entre outros, a alimentação, a moradia, o saneamento básico, o meio ambiente, o trabalho, a renda, a educação, o transporte, o lazer e o acesso aos bens e serviços essenciais; os níveis de saúde da população expressam a organização social e econômica do País.

Parágrafo único. Dizem respeito também à saúde as ações que, por força do disposto no artigo anterior, se destinam a garantir às pessoas e à coletividade condições de bem-estar físico, mental e social (Brasil 2006). 
Esta denominação evidencia o conceito de saúde como o reflexo de boas condições sociais e de provimento do país.

Para a Organización Mundial de la Salud (1994), a definição de saúde refere-se à situação de perfeito bem-estar físico, mental e social da pessoa. Segre e Ferraz (1997) questionam a atual definição, pois a consideram ultrapassada por visar uma perfeição inatingível, considerando-se as próprias características da personalidade. Segundo os autores, quando se fala em "bem-estar" já se englobam todos os fatores que influem sobre o homem; dentre eles, os aspectos biopsicossociais, pois o homem é uma integração subjetiva de seus estados físico, emocional e social. Portanto, somente a própria pessoa pode afirmar ser saudável quando sentir bem-estar, considerando-se suas condições de vida.

Diante de um tratamento para restabelecimento da saúde, toda a carga emocional que acompanha o paciente desde o diagnóstico deve ser considerada (Alves 1995). Desse modo, o estado emocional do paciente repercute em fatores favoráveis ou desfavoráveis na sua reabilitação. É importante que a equipe hospitalar tenha informações sobre as condições emocionais dos pacientes e, mais ainda, das suas próprias, criando dessa maneira condições para que uma intervenção possa ser realizada em perfeita harmonia com os princípios disciplinadores de um correto tratamento.

Observando a importância da qualidade dos serviços prestados na promoção da saúde, Lemme et al (1991), num estudo exploratório realizado num Hospital Universitário do Rio de Janeiro, com 158 usuários de baixa renda e com pouca escolaridade, ficou demonstrada a capacidade dos usuários de, ao expressarem a sua satisfação/insatisfação com os diversos setores e serviços do hospital, identificar a origem dos obstáculos que impedem um atendimento de melhor qualidade. Contudo, os 
autores perceberam a necessidade de uma adaptação dos instrumentais utilizados para levantamento, visto que a maioria dos métodos é internacional.

É necessário também atentar para o fato de que já foi comprovada uma tendência por parte dos usuários dos serviços de saúde, advindos de classes sociais menos favorecidas, de avaliar positivamente os serviços que lhe são prestados, independentemente das suas reais opiniões a respeito, comprometendo os resultados finais (Ware 1978).

O nosso país difere muito de uma região a outra no tocante às condições de vida e saúde. O desenvolvimento sociocultural e econômico de cada parte determina evidentes discrepâncias. Um estado que se destaca é o de São Paulo, considerado o mais desenvolvido em relação à promoção de saúde e de variáveis que facilitam a vida em sociedade. Como os participantes deste estudo são todos oriundos deste Estado, foi realizada uma busca dos principais aspectos socioeconômicos que o compõem.

O censo demográfico do Instituto Brasileiro de Geografia e Estatística (2000) (IBGE) apresentou dados definitivos do universo da pesquisa, que abrangem as características da população, das pessoas responsáveis pelos domicílios e dos domicílios e seus respectivos moradores, relativos ao total do país, grandes regiões, unidades da federação e municípios. No estado de São Paulo, em relação à nupcialidade e fecundidade, o censo confirmou que $74 \%$ das pessoas com idade entre 19 e 24 anos eram solteiras e sem filhos. Quanto à escolaridade, a maior proporção de adultos do Estado possuía o ensino médio completo.

Segnini (2000), com o objetivo de chamar a atenção para a relação educação, trabalho e desenvolvimento, percorrendo caminhos na contra-corrente dos discursos e políticas formulados pelos organismos internacionais reguladores, destacou que os 
adultos jovens aptos para o mercado de trabalho do Brasil constituem o grupo social mais escolarizado e mais desempregado, ou mesmo, inserido em trabalhos precários.

Cesar et al (2005) apresentaram um amplo estudo sobre as condições de vida e saúde da população do estado de São Paulo. As piores condições de vida foram encontradas nos municípios periféricos da Grande São Paulo, onde havia maior proporção de habitação e entorno com condições inadequadas, maior freqüência de chefes de família desempregados em relação aos pontos levantados no interior do Estado. Os autores revelaram também a importância do SUS na utilização de serviços de saúde, principalmente para a população de baixa escolaridade, desempenhando importante papel no atendimento dos problemas de saúde nas áreas com piores condições de vida.

Também sobre o trabalho e suas relações, o Departamento Intersindical de Estatística e Estudos Socioeconômicos (DIEESE) publicou uma pesquisa que retrata a situação do estado de São Paulo em relação ao emprego e desemprego. Foi possível observar que boa parte da população total jovem em idade ativa encerrou o ano de 2005 desempregada, enquanto que outra parte tinha aderido aos empregos informais, que exigem pouca ou nenhuma qualificação, para garantir o próprio sustento. (Departamento Intersindical de Estatística e Estudos Socioeconômicos 2006)

O estado de saúde e as condições gerais de vida estão inter-relacionados. Para o seu julgamento deve-se considerar mais fatores do que simplesmente a ausência de doença, como os aspectos sociais e de sobrevivência. Pois quanto melhor as condições gerais de vida melhor a perspectiva de qualidade de vida para uma determinada população. 
2.4 - Qualidade de vida.

Acredita-se que mesmo antes de ter sido considerada pela comunidade científica, a qualidade de vida já era comentada e muito se fazia em vista dela. Por exemplo, para Fleck et al (1999) a expressão foi citada pela primeira vez pelo presidente dos Estados Unidos, Lyndon Johnson, em 1964, quando declarou que a qualidade de vida das pessoas não poderia ser medida somente pelos balanços financeiros dos bancos.

Os primeiros conceitos sobre qualidade de vida enfatizavam os aspectos materiais como bens adquiridos, salário e carreira profissional. (Nahas 2001). Com a modernização da sociedade, sua denominação foi ampliada, servindo como indicador social de uma população como crescimento econômico, educação, saúde e lazer (Farquhar 1995, Minayo e Hartz 2000, Paschoal 2000 e Nucci 2003).

A definição da expressão qualidade de vida atualmente tem várias vertentes, que reúnem desde parâmetros como sentimentos e emoções, relações pessoais, eventos profissionais, propagandas da mídia, política, sistemas de saúde, atividades de apoio social, até a perspectiva científica, com vários significados na literatura médica. A seguir, estão as principais pontuações e questionamentos a respeito da conceituação da qualidade de vida.

Para Bednar (1990 p.223), “somente o paciente e sua família podem informarnos sobre a natureza de sua qualidade de vida. O que os profissionais melhor podem fazer é ouvir os pacientes e familiares e caminhar conforme o ritmo das circunstâncias".

Bullinger et al (1993) consideraram que qualidade de vida é mais geral e inclui uma variedade potencial maior de condições que podem afetar a percepção do indivíduo, seus sentimentos e comportamentos relacionados com o seu funcionamento 
diário, incluindo, mas não se limitando, a sua condição de saúde e as intervenções médicas.

Gill e Feinstein (1994 p.20), após realizarem uma revisão de literatura sobre o conceito de qualidade de vida, concluíram que a qualidade de vida é a "reflexão do modo com que o paciente percebe e reage a sua saúde e a outros aspectos não-médicos da sua vida".

Morton (1995) e Paschoal (2000) conceituaram qualidade de vida numa perspectiva que valoriza a opinião dos indivíduos sobre si mesmos, sendo esta a medida da percepção que a pessoa tem entre a diferença da sua realidade e suas necessidades ou desejos.

Minayo e Hartz (2000) afirmaram que a noção de qualidade de vida depende de três fatores: a referência histórica que se modifica ao longo do tempo; a referência cultural que acompanha e altera os valores de uma sociedade; e as desigualdades sociais que fazem com que classes menos favorecidas relacionem a idéia de qualidade de vida ao bem-estar dos mais ricos.

De acordo com Arnold et al (2004), o julgamento que cada indivíduo faz de sua qualidade de vida global deve ser considerado. Teoricamente, espera-se que o indivíduo combine diferentes aspectos de sua vida e os resuma em uma avaliação geral de sua qualidade de vida. Sobre esta avaliação, os autores se preocupam com a possibilidade dos indivíduos realmente fazerem um resumo de tudo que compreenda a qualidade de suas vidas, ou incluírem apenas aspectos que os perturbem recentemente.

Sendo um constructo, as pesquisas sobre qualidade de vida vêm contribuindo para a evolução do entendimento do processo saúde-doença, além dos paradigmas biomédicos que negligenciam aspectos socioeconômicos, psicológicos e culturais. A 
avaliação da qualidade de vida é um indicador do "impacto físico e psicossocial que as enfermidades, disfunções ou incapacidades podem acarretar nas pessoas acometidas, permitindo um melhor conhecimento do paciente e de sua adaptação à condição" (Seidl e Zanon 2004 p.581). As autoras pontuaram as dificuldades em se medir qualidade de vida num país como o Brasil, com realidades tão diferentes de uma região para outra. Além de evidenciar que, a partir da década de 90, os pesquisadores concordaram que a avaliação deve considerar a perspectiva do próprio sujeito e não ficar restrita à visão de cientistas e profissionais da saúde sobre o sujeito.

Para Casas (2005 p.17), a qualidade de vida "é um fenômeno que articula condições materiais de vida e condições psicossociais de vida em relação a qualquer pessoa ou grupo, comunidade ou sociedade humana". Qualidade de vida aparece como um conceito entre os mais prototípicos dos denominados valores pós-materiais, ao longo dos anos de 1960, no eixo dos interesses para estudar os processos sociais de mudança positiva. Sendo assim, ao estudo da qualidade de vida interessa tanto a objetividade como as percepções, avaliações e aspirações subjetivas das pessoas em relação ao contexto social e sociocultural no qual vivem. $\mathrm{O}$ autor ainda adverte que não se pode falar de qualidade de vida de nenhum grupo humano ou população sem ter também em conta o ponto de vista de todos os agentes sociais implicados, incluindo os destinatários dos serviços.

Dentre os entendimentos sobre a definição de qualidade de vida, destaca-se o modelo relacionado à saúde, uma vez que seria esta a medida do estado de capacidade para a realização de tarefas, ou seja, com saúde a pessoa teria condições de realizar as atividades do dia-a-dia, trabalhar e promover relações interpessoais, favorecendo sua 
qualidade de vida (Organización Mundial de la Salud 1994, Minayo e Hartz 2000, Lima 2002 e Casas 2005).

A preocupação com o conceito de qualidade de vida reflete-se num movimento das ciências direcionadas ao bem-estar humano, no sentido de valorizar parâmetros mais amplos que o controle de sintomas físicos, a diminuição da mortalidade ou o aumento da expectativa de vida.

A Organização Mundial da Saúde, a partir do início dos anos 90, constatou que as medidas de qualidade de vida revestem-se de particular importância na avaliação de saúde, tanto numa perspectiva individual como social. O desenvolvimento desses elementos conduziu a formação de um grupo para estudos sobre qualidade de vida denominado WHOQOL-Group. Em 1994, este grupo apresentou uma definição de qualidade de vida subjetiva, multidimensional e que inclui elementos positivos e negativos:

\footnotetext{
"a percepção do indivíduo de sua posição na vida no contexto da cultura e sistema de valores nos quais ele vive e em relação aos seus objetivos, expectativas, padrões e preocupações" (WHOQOL-Group 1994 p.42).
}

Trata-se de um conceito amplo e complexo, que engloba a saúde física, o estado psicológico, o nível de independência, as relações sociais, as crenças pessoais e a relação com as características do meio ambiente (Organización Mundial de la Salud 1994).

Considerada a melhor definição de qualidade de vida aquela que é declarada pelo próprio sujeito, surge a questão de como avaliá-la respeitando-se a subjetividade de cada um, e ao mesmo tempo determinando padrões que possam orientar pesquisas e melhorias da condição de vida da população em geral. 
Há múltiplas escalas de avaliação de qualidade de vida. Todavia, existem diferenças em relação aos aspectos conceituais, bem como à natureza e ao peso de cada domínio para avaliação de qualidade de vida como recurso gerador de conceitos pertinentes à população em questão a serem posteriormente averiguados sob enfoque psicométrico (Farquhar 1995).

A busca de um instrumento que avaliasse qualidade de vida dentro de uma perspectiva abrangente fez com que a OMS desenvolvesse um projeto multicêntrico. $\mathrm{O}$ resultado deste projeto foi a elaboração do WHOQOL-100, um instrumento de avaliação de qualidade de vida, composto por 100 itens (Fleck et al 1999).

A necessidade de instrumentos curtos que demandem pouco tempo para seu preenchimento, mas com características psicométricas satisfatórias, fez com que o Grupo de Qualidade de Vida da OMS desenvolvesse uma versão abreviada do WHOQOL-100, o WHOQOL-BREF (WHOQOL-Group 1998). Este instrumento pressupõe a avaliação da qualidade de vida no geral e em quatro domínios: físico, psicológico, relações sociais e meio ambiente.

Essa proposta da OMS tem sido usada em populações de diversos países com diferentes diagnósticos. Skevington et al (2004) avaliaram as propriedades psicométricas do instrumento de avaliação da qualidade de vida da Organização Mundial da Saúde, o WHOQOL-BREF, em adultos de 23 países. Foram consideradas as variáveis socioeconômicas bem como condições de saúde e reabilitação. As análises indicaram que o WHOQOL-BREF possui excelentes propriedades psicométricas.

O WHOQOL-BREF é um dos instrumentos mais adequados para avaliação da qualidade de vida para Seidl e Zanon (2004), pois ele considera a subjetividade e a multidimensionalidade que compõe a vida das pessoas. O uso disseminado e sistemático 
do WHOQOL-BREF em pesquisas com pessoas em situações específicas diversas permitem evidências sobre a qualidade psicométrica do instrumento.

Desde que validado no Brasil por Fleck et al (1999), houve um grande interesse no uso desse instrumento que parece abranger boa parte das dificuldades encontradas por pesquisadores para levantarem dados que correspondam fortemente à qualidade de vida das pessoas e à avaliação dos sistemas de saúde. O levantamento dos estudos já realizados no país com o WHOQOL-BREF em populações com condições específicas é descrito a seguir. Estes achados serão relevantes para a contraposição com os dados do presente estudo no capítulo de discussão.

Fleck et al (2000) avaliaram o WHOQOL-BREF numa amostra de 300 brasileiros no Rio Grande do Sul. O Instrumento mostrou características satisfatórias de consistência interna, validade discriminante, validade de critério, validade concorrente e fidedignidade teste-reteste. O WHOQOL-BREF alia um bom desempenho psicométrico com praticidade de uso, o que lhe coloca como uma alternativa útil para ser usado em estudos que se propõem a avaliar qualidade de vida no Brasil.

Lima (2002), relacionando a gravidade de dependência do álcool e a qualidade de vida de 36 pacientes do sexo masculino com o WHOQOL-BREF, observou que quanto maior o estado de dependência, pior os índices de qualidade de vida em todos os domínios. A autora ainda denunciou uma crise consensual sobre a denominação do que seria qualidade de vida. Com o levantamento de vários estudos, concluiu que se trata de uma condição subjetiva, e que depende da integração de características físicas, psicológicas e sociais do indivíduo. Visando ao bem-estar, salienta que a saúde é a variável que mais determina a qualidade vida. 
Boery (2003) aplicou o WHOQOL-BREF em 72 pacientes adultos com câncer de pulmão durante tratamento quimioterápico em São Paulo. Após o primeiro ciclo de quimioterapia, o autor observou diferença estatisticamente significante para piora da qualidade de vida no domínio psicológico em todos os pacientes estudados.

Nucci (2003) comparou a qualidade de vida de 50 pacientes com diferentes diagnósticos de câncer e 70 pessoas do grupo controle no interior de São Paulo, utilizando o WHOQOL-BREF. Os grupos não apresentaram diferenças estatisticamente significativas em relação aos aspectos: psicológico, satisfação com a saúde e qualidade de vida.

Berlim et al (2003) investigaram o impacto da depressão na qualidade de vida de 43 pacientes brasileiros diagnosticados em tratamento. Embora não tenham encontrado correlações significativas entre o WHOQOL-BREF e os fatores psicossociais, a análise identificou que pacientes com depressão mais severa tinham piores níveis de qualidade de vida.

Bittencourt et al (2004) aplicaram o WHOQOL-BREF em pacientes transplantados renais, sendo 100 deles com enxerto funcionante e 32 em tratamento dialítico, no interior do estado de São Paulo. Os resultados apontaram melhor qualidade de vida nos domínios físico e psicológico para todos os participantes. Além disso, os autores afirmam a eficácia do instrumento, pois privilegia a opinião dos pacientes, permitindo uma abordagem multidisciplinar do problema.

Michelone e Santos (2004), analisando e comparando a qualidade de vida de 48 doentes com câncer colorretal atendidos pelo SUS no interior do estado de São Paulo, conforme ausência e presença de estoma, através do WHOQOL-BREF, perceberam 
escores médios menores em todos os domínios para as pessoas ostomizadas, porém sem diferenças significativas na comparação com o grupo de pessoas sem ostomia.

Berlim et al (2005) avaliaram as propriedades psicométricas do WHOQOLBREF em 89 brasileiros adultos com diagnóstico de depressão. A análise contou com a comparação com outros instrumentos adequados para o diagnóstico e demonstrou que o instrumento está apropriado para avaliar a qualidade de vida, uma vez que os achados apontaram piores índices no domínio psicológico para os sujeitos pesquisados.

Kluthcovsky (2005), investigando a qualidade de vida de agentes comunitários de saúde, do interior do estado do Paraná, utilizando-se do WHOQOL-BREF, detectou índices maiores para o domínio relações sociais, seguidos do físico, psicológico e meio ambiente. No geral, os escores estiveram acima da média. Isso pressupõe a utilização do instrumento para análise, considerando-se todos os domínios ou cada um separadamente. O que garante maior consistência aos resultados.

Com o objetivo de avaliar a qualidade de vida das pessoas que tiveram hanseníase e estão curadas, porém não retornaram ao convívio familiar e social, Quaggio (2005) aplicou o WHOQOL-BREF em 36 moradores do Instituto Lauro de Souza Lima, em Bauru. Dos quatro domínios, o único que apresentou qualidade de vida abaixo da média foi o meio ambiente. A autora sugere a aplicação de outros instrumentos de qualidade de vida para mais comparações.

Correlacionando os escores do WHOQOL-BREF e transtorno bipolar em 60 pacientes diagnosticados em Porto Alegre, Gazalle et al (2006) observaram que escores maiores de qualidade de vida foram encontrados entre pacientes com remissão completa dos sintomas, seguidos pelos pacientes com sintomas subsindrômicos. Os pacientes deprimidos apresentaram escores de qualidade de vida mais baixos em todos os 
domínios. A depressão bipolar e os sintomas residuais de depressão estão negativamente correlacionados com qualidade de vida em pacientes com transtorno bipolar.

Heldt et al (2006) analisaram o impacto da terapia breve com a abordagem cognitiva comportamental em 36 pacientes do Rio Grande do Sul, com transtorno de pânico a partir da sua qualidade de vida. Depois das sessões, foi observado aumento significativo em todos os domínios do WHOQOL-BREF.

Roque e Forones (2006) acompanharam 45 pacientes de São Paulo com câncer colorretal em tratamento quimioterápico e avaliaram a qualidade de vida pelo WHOQOL-BREF no início, no $3^{\circ}$ e no $6^{\circ}$ ciclo de tratamento. Os resultados mostraram que a qualidade de vida diminuiu após o início da quimioterapia com queda no estado de saúde, em relação à atividade física e psicológica. A análise do questionário não mostrou alteração de qualidade vida quando comparados os doentes em tratamento paliativo com os em adjuvância.

Em estudo transversal que avaliou qualidade de vida por meio do questionário WHOQOL-BREF em 21 pacientes brasileiros com doença de Parkinson e seus respectivos cuidadores, Schestatsky et al (2006) encontraram déficits significativos nos domínios físico e psicológico. Os autores sugerem a validação de outros questionários de aplicação curta para amostras brasileiras.

A conceituação da qualidade de vida mais aceita, vista na literatura, é aquela que valoriza os aspectos subjetivos da vida do indivíduo e os parâmetros objetivos das condições de vida e saúde.

A avaliação da qualidade de vida depende exclusivamente da percepção do sujeito; somando-se a isso as condições sociodemográficas e de saúde em que ele vive 
(Whoqol-Group 1998). Essa atividade tornou-se uma necessidade e muitos estudos em pessoas com características e diagnósticos específicos tiveram início com a permissão do uso do WHOQOL-BREF no país. Em diferentes populações, os resultados apontaram níveis de significância cada vez mais consistentes; o que faz deste instrumento um objeto confiável para a avaliação a qualidade de vida respeitando o conceito dado pela Organización Mundial de la Salud (1994).

2.5 - Qualidade de vida e fissura labiopalatina.

Patel e Ross (2003) ressaltam que a literatura sobre a qualidade de vida em pacientes com fissura labiopalatina é intensa a partir da década de 70 e tais achados não correspondem mais ao contexto do novo século. Vários métodos de investigação, muitos elaborados pelos próprios autores, foram aplicados considerando-se faixa etária, tipo de fissura, questões psicossociais e aspectos gerais de vida e saúde. Diante de tantas definições e metodologias de pesquisa diferentes encontradas na literatura, fez-se necessário revisar as publicações mais recentes que trataram especificamente da qualidade de vida de pacientes adultos com fissura, com amostras semelhantes à do presente estudo.

Pruzinsky (1992), discutindo a literatura sobre as experiências sociais e psicológicas de pacientes com as mais severas deformidades faciais, valorizou a ênfase nos aspectos subjetivos para avaliação da qualidade de vida de pessoas com deformidades faciais e de seus familiares. Salientou que, embora os indivíduos tenham sofrido impactos sociais e psicológicos negativos pela experiência da fissura labiopalatina, a maioria não desenvolveu psicopatologia e apresentava bom índice de 
qualidade de vida em razão de intervenções da equipe multidisciplinar que resultaram em excelente trabalho de tratamento e prevenção, além do apoio familiar.

Marcusson et al (2001) avaliaram a qualidade de vida de 80 pacientes adultos com fissura de lábio e palato em comparação com 80 adultos sem fissura, com média de idade de 24 anos. Foi observado que o grupo com fissura teve de maneira geral, um impacto negativo em suas vidas, relacionado ao bem-estar e vida social. Entretanto, a maioria dos aspectos práticos da vida diária não diferiu muito do grupo controle, o que indica uma boa capacidade de ajustamento à situação.

Patel e Ross (2003) avaliaram a percepção sobre a qualidade de vida de 20 adultos com fissura labiopalatina da África do Sul em relação à comunicação, educação, emprego, família, vida social e questões emocionais. Apontaram a relevância do convívio e as formas de preconceito às quais o sujeito com fissura está exposto. De todos os entrevistados, a maioria colocou-se satisfeita com sua qualidade de vida em geral, dizendo que a fissura não afetou sua vida social. Mesmo assim, os entrevistados reconheceram a recepção negativa das pessoas em relação à malformação, indicando ainda que indivíduos com fissura estivessem insatisfeitos com seu trabalho em termos de habilidade e remuneração justa. Eles também reconheceram que um tratamento multidisciplinar realçou a qualidade de suas vidas.

Sinko et al (2005) avaliaram 70 pacientes adultos com fissura em relação à qualidade de vida, questões estéticas e funcionais. Observaram que a maioria dos entrevistados pediu mais cirurgias, além das previstas, para melhora estética. As pacientes do gênero feminino estavam menos satisfeitas com os resultados do tratamento do que os do gênero masculino. Quanto à qualidade de vida, foram encontrados índices mais baixos no funcionamento social e emocional. Os autores 
concluíram que as cirurgias de reabilitação deveriam promover a qualidade de vida, conforme o levantamento das expectativas dos pacientes entrevistados e que muitos mantêm expectativas irreais sobre a reabilitação, ficando frustrados após as cirurgias, o que evidencia a necessidade de encaminhamentos ao aconselhamento psicoterápico.

Os estudos sobre a qualidade de vida em pacientes com fissura labiopalatina revelaram que os autores consideraram para sua avaliação um conjunto de componentes psicossociais que podem influenciar nas condições de vida, e poucos trataram da qualidade de vida estritamente. Foram mais encontrados levantamentos sobre os aspectos psicossociais e sua repercussão na qualidade de vida, como já explorado anteriormente.

Com base em toda literatura revisada, observou-se que a fissura labiopalatina traz comprometimentos estéticos e funcionais que podem influenciar negativamente na formação da identidade e competência social, aliada aos aspectos psicossociais agravantes. Muitos estudos pontuaram os fatores psicossociais que compõem a vida do indivíduo com fissura, evidenciando uma maior preocupação com a questão do estigma físico, relacionamentos interpessoais, educação, trabalho, satisfação com resultados e, principalmente, em relação ao aspecto psicológico. Todos estes fatores interferem na constituição do sujeito.

Porém, há a perspectiva de capacidade de superação das dificuldades por meio de uma intervenção multidisciplinar com o paciente e sua família, em centros cuja equipe se preocupe com a reabilitação global do indivíduo, como no HRAC.

Em relação à saúde, esta é a condição intrínseca para a qualidade de vida. Foi necessária uma breve categorização das condições de vida da população do estado de São Paulo, fazendo menção à amostra deste estudo, já que foi observado que este 
Estado apresenta condições satisfatórias para o desenvolvimento pleno de uma vida em sociedade e retrata na sua população, a realidade do país.

A definição de qualidade de vida deve respeitar a percepção que cada um tem a respeito de si mesmo e das condições à sua volta. Sua avaliação é possível, com um instrumento com propriedades psicométricas eficientes, como o WHOQOL-BREF, cuja aplicação já resultou em diversos estudos em populações com condições peculiares.

Os estudos mais recentes sobre a qualidade de vida do sujeito com fissura labiopalatina salientaram seus diferentes enfoques, destacando aqueles que pontuaram a satisfação dos pacientes com fissura com a qualidade de suas vidas, apesar das dificuldades enfrentadas no decorrer de suas vidas. 
OBJETIVOS 


\section{3 - OBJETIVOS.}

- Avaliar a qualidade de vida dos pacientes adultos com fissura labiopalatina atendidos no hospital.

- Investigar as condições sociodemográficas dos pacientes.

- Analisar a qualidade de vida a partir das condições sociodemográficas investigadas. 
MATERIAL E MÉTODO 


\section{4 - MATERIAL E MÉTODO.}

O estudo, aprovado pelo Comitê de Ética e Pesquisa em Seres Humanos (Ofício $n^{\circ}$. 291/2005) (anexo 1) engloba a pesquisa de campo de corte transversal sobre a qualidade de vida de pacientes adultos com fissura labiopalatina. De tipologia descritiva, "permite ao pesquisador a descrição das características de determinada população ou fenômeno, ou o estabelecimento de relações entre variáveis" (Gil 1989 p.45). Além de descrever os fatos e fenômenos de determinada realidade, é possível estabelecer relações entre variáveis (Triviños 1987).

4.1 - Casuística.

Participaram da pesquisa homens e mulheres na faixa etária de 18 a 30 anos, com fissura labiopalatina, residentes no estado de São Paulo. Essa área de abrangência foi escolhida por possuir características sociodemográficas semelhantes.

Um levantamento preliminar feito na Central de Processamento de Dados (CPD) do HRAC identificou primeiramente 2.500 pacientes aptos à participar da pesquisa. Após a verificação dos critérios de exclusão, este número foi reduzido à 2.000. A partir de cálculo estatístico de amostra para populações finitas (Gil 1989), chegou-se a um total de 130 sujeitos. Considerando as ausências dos pacientes durante o período da coleta, a amostra ficou totalizada em 120 pacientes com fissura labiopalatina, regularmente matriculados no HRAC, em fase final de tratamento, em acompanhamento fonoaudiológico e odontológico. 
Não puderam colaborar com a pesquisa os sujeitos que residiam em outros estados que não o de São Paulo, os que tivessem outras anomalias ou síndromes associadas ou não à fissura, neuropatias, doenças autoimunes ou outros diagnósticos que afetassem a função neuroautonômica. Também foram excluídos os que não apresentaram condições percepto-cognitivas para responder às questões e aqueles que urilizavam-se de antidepressivos, neurolépticos ou qualquer outro medicamento semelhante.

4.2 - Procedimentos.

Instrumento de medida

Foram utilizados dois instrumentos para a coleta de dados. Para caracterizar as condições sociodemográficas (sexo, idade, origem, situação conjugal, filhos, moradia, interesse vocacional e escolaridade), foi aplicado um questionário de identificação, com cinco questões fechadas e duas abertas (anexo 4). Este questionário foi desenvolvido pela pesquisadora especificamente para este estudo, tendo como base a literatura e as recomendações do WHOQOL-Group (1994) sobre a necessidade de levantamento dos aspectos gerais de vida para compor a avaliação da qualidade de vida.

Para a avaliação da qualidade de vida, foi aplicado o WHOQOL-BREF (anexo 5), testado e validado no Brasil por Fleck et al (2000), com 26 questões fechadas. As perguntas do WHOQOL-BREF foram formuladas com uma escala Likert de: intensidade (nada - extremamente), capacidade (nada - completamente), freqüência (nunca - sempre) e avaliação (muito insatisfeito - muito satisfeito; muito ruim - muito bom), com escores que variam de 1 a 5 (onde 1 e 2 representam uma avaliação negativa, 
3 a intermediária e 4 e 5 positiva). De todas as questões, duas são gerais de qualidade de vida e as demais 24 representam quatro domínios: físico, psicológico, relações sociais e meio ambiente. Estas questões estão diretamente correlacionadas com cada uma das facetas que compõe o instrumento original, desenvolvido pelo WHOQOL-Group (1994) e descrito na revisão de literatura. Abaixo, a relação dos domínios e suas facetas conforme Fleck et al (2000).

- Físico: impedimentos devido à deficiência, necessidade de tratamento de saúde, energia no dia-a-dia, capacidade de locomoção, satisfação com o sono, com a capacidade de desempenho nas atividades diárias e com a capacidade para o trabalho.

- Psicológico: aproveitamento e sentido da vida, capacidade de concentração e de aceitar sua aparência física, satisfação consigo mesmo.

- Relações sociais: satisfação com relações pessoais (amigos, parentes, conhecidos, colegas), vida sexual, apoio de amigos, sentimentos negativos.

- Meio ambiente: segurança na vida diária, satisfação com ambiente físico de trabalho e com a situação financeira, disponibilidade de informações, oportunidades de lazer, satisfação com as condições do local de residência, com o acesso aos serviços de saúde e meio de transporte.

Os estudos de WHOQOL-Group (1998), Fleck et al (2000), Bittencourt et al (2004), Skevington et al (2004) e Berlim et al (2005) comprovaram a eficácia do WHOQOL-BREF na avaliação da qualidade de vida, uma vez que já foi averiguado pelo enfoque psicométrico e privilegia a opinião dos pesquisados, permitindo uma abordagem multidisciplinar do tema. 
Aplicação

Os questionários foram aplicados à medida que os pacientes compareciam ao hospital para atendimentos ambulatoriais agendados, entre os meses de dezembro de 2005 e março de 2006. A coleta de dados foi realizada pela própria pesquisadora e por uma psicóloga devidamente treinada, vinculada à instituição.

Todos os participantes foram orientados sobre a pesquisa a ser realizada mediante carta de informação (anexo 2), e assinaram o termo de consentimento (anexo 3), autorizando as manobras propostas, assim como a divulgação dos resultados, conforme resolução 196/96 do Conselho Nacional de Ética em Pesquisa (CONEP) (Brasil 1996).

Os instrumentos utilizados são auto-aplicáveis, contudo, a pesquisadora utilizou a orientação direta quando o participante apresentava dificuldades de compreensão em alguma questão.

4.3 - Análise dos dados.

Os dados obtidos com o questionário de identificação foram categorizados para que pudessem ser apresentados de forma descritiva e, posteriormente, fossem correlacionados com os resultados do outro instrumento - o WHOQOL-BREF - e com a literatura pertinente.

As respostas do item ocupação foram classificadas com base na Classificação Brasileira de Ocupações (CBO) (Brasil 2002). Nela constam todas as ocupações entendidas como a agregação de empregos ou situação de trabalhos similares em relação às atividades realizadas. A classificação descreve as ocupações no nível dos 
grandes grupos ocupacionais definidos em dez grupos agregados por nível de competência e similaridade nas atividades executadas. Também foram categorizados e classificados participantes desempregados e estudantes.

As informações sobre o tipo de fissura de cada paciente foram obtidas no momento da aplicação, mediante consulta documental no prontuário do paciente, e registrado conforme a classificação de Spina et al (1972).

Para a correção do WHOQOL-BREF, foi contemplada uma abordagem quantitativa com a utilização do software SPSS for Windows, versão 10.0 (Norusis 1992). De acordo com este programa, os escores de cada domínio são calculados por uma sintaxe que considera as respostas de cada questão, entendendo que maiores escores correspondem a melhor qualidade de vida. (Fleck et al 2000)

Para se ter uma idéia mais clara do grau médio de qualidade de vida dos participantes, foram calculadas as médias de cada um dos domínios, sem levar em conta nenhum fator específico. Foram construídos gráficos de boxplot e da média \pm 2 Erropadrão, para possibilitar a comparação dos domínios entre si.

Em relação ao estudo da associação entre cada um dos domínios do WHOQOL e as variáveis (região, tipo de fissura, gênero, idade, escolaridade e profíssão) foi utilizado um modelo de regressão linear múltiplo (Neter et al 1996). Somente neste momento, optou-se pela exclusão de um participante da análise, por ser o único a apresentar a condição de analfabetismo, uma vez que os resultados seriam inconclusivos. Para obtenção do modelo final, foi adotado o método de backward (Neter et al 1996).

Para Seidl e Zanon (2004), a comparação de pesquisas diversas realizadas com o WHOQOL-BREF aumenta a confiabilidade no instrumento. 
Portanto, para maior desenvolvimento dos objetivos propostos, os resultados deste estudo foram discutidos com base em outras pesquisas com o WHOQOL-BREF em amostras brasileiras, embora tenham sido realizadas com pessoas sem fissura labiopalatina e nem todos tenham utilizado a mesma escala para cálculo estatístico dos escores obtidos.

Os dados do presente estudo foram também comparados com pesquisas encontradas na literatura nacional e internacional, sobre a qualidade de vida do paciente com fissura labiopalatina, realizadas com outros instrumentos que não o WQOQOLBREF. 


\section{RESULTADOS}




\section{5 - RESULTADOS.}

A partir dos dados coletados dos 120 pacientes, estes foram submetidos a análise estatística, obtendo-se os resultados finais. Estes são apresentados inicialmente pela categorização da amostra estudada, obtida pela aplicação do questionário de identificação.

Os resultados da avaliação da qualidade de vida por meio do instrumento WHOQOL-BREF estão dispostos numa única tabela, de modo a facilitar a visualização de todas as questões, exatamente como o questionário foi apresentado aos pacientes participantes deste estudo. As médias da qualidade de vida em geral e dos domínios físico, psicológico, relações sociais e meio ambiente são apresentadas em seguida.

Posteriormente podem ser visualizadas as tabelas com as correlações dos aspectos sociodemográficos, obtidos pelo questionário de identificação, e os domínios do WHOQOL-BREF.

Para caracterizar a amostra, foram consideradas as variáveis: região, tipo de fissura, idade, gênero, estado civil, escolaridade, convívio, filhos, moradia, profissão e motivo da escolha da profissão. Abaixo, a Tabela 1 apresenta estas variáveis. 
Tabela 1 - Caracterização da amostra

\begin{tabular}{|c|c|c|c|}
\hline Variável & Categoria & Freqüência & $(\%)$ \\
\hline \multirow{2}{*}{ Região } & Capital & 17 & 14,2 \\
\hline & Interior & 103 & 85,8 \\
\hline \multirow{3}{*}{ Tipo de fissura } & Transforame & 83 & 69,1 \\
\hline & Pré-forame & 15 & 12,6 \\
\hline & Pós-forame & 22 & 18,3 \\
\hline \multirow{2}{*}{ Idade } & 18 a 24 anos & 89 & 74,2 \\
\hline & 25 a 30 anos & 31 & 25,8 \\
\hline \multirow{2}{*}{ Gênero } & Masculino & 74 & 61,7 \\
\hline & Feminino & 46 & 38,3 \\
\hline \multirow{5}{*}{ Estado Civil } & Solteiro & 100 & 83,3 \\
\hline & Casado & 13 & 10,8 \\
\hline & União Estável & 05 & 4,3 \\
\hline & Separado & 01 & 0,8 \\
\hline & Divorciado & 01 & 0,8 \\
\hline \multirow{4}{*}{ Escolaridade } & Analfabeto & 01 & 0,8 \\
\hline & Ensino fundamental & 14 & 11,7 \\
\hline & Ensino médio & 84 & 70 \\
\hline & Ensino superior & 21 & 17,5 \\
\hline \multirow{4}{*}{ Convívio } & Pais/familiares & 97 & 80,8 \\
\hline & Com parceiro & 15 & 12,5 \\
\hline & Sozinho & 05 & 4,2 \\
\hline & Com amigos & 3 & 2,5 \\
\hline \multirow{3}{*}{ Filhos } & Nenhum & 104 & 86,6 \\
\hline & Um & 13 & 10,8 \\
\hline & Dois ou mais & 03 & 2,5 \\
\hline \multirow{3}{*}{ Moradia } & Casa própria & 82 & 68,3 \\
\hline & Aluguel & 29 & 24,2 \\
\hline & Emprestada & 09 & 7,5 \\
\hline \multirow{9}{*}{ Profissão } & Ciências e artes & 07 & 5,8 \\
\hline & Técnicos nível médio & 08 & 6,7 \\
\hline & Serviços administrativos & 16 & 13,3 \\
\hline & Comerciantes & 13 & 10,8 \\
\hline & Agropecuários & 03 & 2,5 \\
\hline & Produção industrial & 07 & 5,8 \\
\hline & Manutenção/reparação & 27 & 22,5 \\
\hline & Estudante & 08 & 6,7 \\
\hline & Desempregado & 31 & 25,8 \\
\hline \multirow{4}{*}{ Motivo escolha da profissão } & Influencia familiar & 13 & 16,2 \\
\hline & Falta de opção & 51 & 63,7 \\
\hline & Identificação com a área & 15 & 18,7 \\
\hline & Boa remuneração & 01 & 1,25 \\
\hline
\end{tabular}


A Tabela 1 aponta que a maior porcentagem dos entrevistados residia no interior do Estado (85,8\%) e apresentava fissura tipo transforame incisivo $(69,1 \%)$. A média de idade foi de 22 anos, sendo que 74,2\% dos participantes estavam entre 18 e 24 anos. O maior percentual foi do gênero masculino $(61,7 \%)$.

Observa-se que $83,3 \%$ dos sujeitos eram solteiros e grande parte da amostra (86,6\%) não tinha filhos. Sobre à escolaridade, $70 \%$ deles possuíam o ensino médio enquanto que outros 17,5\% tinham o ensino superior. Em relação à moradia, 68,3\% dos pacientes viviam em casa própria no convívio com os pais ou familiares $(80,8 \%)$.

De todos os 120 participantes, os estudantes somaram 6,7\% da amostra e $25,8 \%$ estavam desempregados. Dos 81 entrevistados que trabalhavam, 22,5\% prestavam serviços de manutenção e reparação e $63,7 \%$ escolheram a ocupação relatada por falta de opção por outra atividade.

Os dados a seguir ilustram as respostas do WHOQOL-BREF. Para uma melhor compreensão destes, a Tabela 2 mostra a relação das 26 questões e os domínios que cada uma representa, conforme a sintaxe apresentada por Fleck et al (2000).

Tabela 2 - Relação das questões do WHOQOL-BREF e seus respectivos domínios

\begin{tabular}{c|l} 
DOMÍNIOS & \multicolumn{1}{c}{ QUESTÕES } \\
\hline Geral & 1 e 2 \\
\hline Físico & $3,4,10,15,16,17$ e 18 \\
\hline Psicológico & $5,6,7,11,19$ e 26 \\
\hline Relações Sociais & 20,21 e 22 \\
\hline Meio Ambiente & $8,9,12,13,14,23,24$ e 25 \\
\hline
\end{tabular}


A freqüência das respostas à cada questão do WHOQOL-BREF é apresentada abaixo.

Tabela 3 - Freqüências das respostas às questões do WHOQOL-BREF

\begin{tabular}{|c|c|c|c|c|c|c|c|}
\hline & Questões & $\begin{array}{c}\text { Muito } \\
\text { ruim } \\
(\%)\end{array}$ & $\begin{array}{c}\text { Ruim } \\
(\%)\end{array}$ & $\begin{array}{c}\text { Nem ruim } \\
\text { nem boa } \\
(\%)\end{array}$ & $\begin{array}{l}\text { Boa } \\
(\%)\end{array}$ & $\begin{array}{c}\text { Muito } \\
\text { Boa } \\
(\%)\end{array}$ & $\begin{array}{c}\text { Total } \\
(\%)\end{array}$ \\
\hline 1 & $\begin{array}{l}\text { Como você } \\
\text { avaliaria sua } \\
\text { qualidade de vida? }\end{array}$ & $\begin{array}{c}0 \\
(0,0)\end{array}$ & $\begin{array}{c}1 \\
(0,8)\end{array}$ & $\begin{array}{c}21 \\
(17,5)\end{array}$ & $\begin{array}{c}77 \\
(64,2)\end{array}$ & $\begin{array}{c}21 \\
(17,5)\end{array}$ & $\begin{array}{c}120 \\
(100,0)\end{array}$ \\
\hline 2 & $\begin{array}{l}\text { Quão satisfeito(a) } \\
\text { você está com a } \\
\text { sua saúde? }\end{array}$ & $\begin{array}{c}1 \\
(0,8) \\
\end{array}$ & $\begin{array}{c}7 \\
(5,8) \\
\end{array}$ & $\begin{array}{c}8 \\
(6,7) \\
\end{array}$ & $\begin{array}{c}83 \\
(69,2) \\
\end{array}$ & $\begin{array}{c}21 \\
(17,5) \\
\end{array}$ & $\begin{array}{c}120 \\
(100,0)\end{array}$ \\
\hline & Questões & $\begin{array}{l}\text { Nada } \\
(\%)\end{array}$ & $\begin{array}{c}\text { Muito } \\
\text { pouco } \\
(\%)\end{array}$ & $\begin{array}{c}\text { Mais ou } \\
\text { menos } \\
(\%)\end{array}$ & $\begin{array}{c}\text { Bastante } \\
(\%)\end{array}$ & $\begin{array}{c}\text { Extre- } \\
\text { mamente } \\
(\%)\end{array}$ & $\begin{array}{c}\text { Total } \\
(\%)\end{array}$ \\
\hline 3 & $\begin{array}{l}\text { Em que medida } \\
\text { você acha que sua } \\
\text { condição (física) } \\
\text { impede você de } \\
\text { fazer o que você } \\
\text { precisa? }\end{array}$ & $\begin{array}{c}90 \\
(75,0)\end{array}$ & $\begin{array}{c}12 \\
(10,0)\end{array}$ & $\begin{array}{c}12 \\
(10,0)\end{array}$ & $\begin{array}{c}5 \\
(4,2)\end{array}$ & $\begin{array}{c}1 \\
(0,8)\end{array}$ & $\begin{array}{c}120 \\
(100,0)\end{array}$ \\
\hline 4 & $\begin{array}{l}\text { O quanto você } \\
\text { precisa de algum } \\
\text { tratamento médico } \\
\text { para levar sua vida } \\
\text { diária? }\end{array}$ & $\begin{array}{c}94 \\
(78,3)\end{array}$ & $\begin{array}{c}15 \\
(12,5)\end{array}$ & $\begin{array}{c}6 \\
(5,0) \\
\end{array}$ & $\begin{array}{c}5 \\
(4,2) \\
\end{array}$ & $\begin{array}{c}0 \\
(0,0)\end{array}$ & $\begin{array}{c}120 \\
(100,0)\end{array}$ \\
\hline 5 & $\begin{array}{l}\text { O quanto você } \\
\text { aproveita a vida? }\end{array}$ & $\begin{array}{c}1 \\
(0,8)\end{array}$ & $\begin{array}{c}3 \\
(2,5)\end{array}$ & $\begin{array}{c}17 \\
(14,2)\end{array}$ & $\begin{array}{c}61 \\
(50,8)\end{array}$ & $\begin{array}{c}38 \\
(31,7)\end{array}$ & $\begin{array}{c}120 \\
(100,0) \\
\end{array}$ \\
\hline 6 & $\begin{array}{l}\text { Em que medida } \\
\text { você acha que a } \\
\text { sua vida tem } \\
\text { sentido? }\end{array}$ & $\begin{array}{c}3 \\
(2,5) \\
\end{array}$ & $\begin{array}{c}1 \\
(0,8)\end{array}$ & $\begin{array}{c}14 \\
(11,7) \\
\end{array}$ & $\begin{array}{c}33 \\
(27,5) \\
\end{array}$ & $\begin{array}{c}69 \\
(57,5) \\
\end{array}$ & $\begin{array}{c}120 \\
(100,0)\end{array}$ \\
\hline 7 & $\begin{array}{l}\text { O quanto você } \\
\text { consegue se } \\
\text { concentrar? }\end{array}$ & $\begin{array}{c}2 \\
(1,7)\end{array}$ & $\begin{array}{c}17 \\
(14,2)\end{array}$ & $\begin{array}{c}21 \\
(17,5)\end{array}$ & $\begin{array}{c}61 \\
(50,8) \\
\end{array}$ & $\begin{array}{c}19 \\
(15,8)\end{array}$ & $\begin{array}{c}120 \\
(100,0)\end{array}$ \\
\hline 8 & $\begin{array}{l}\text { Quão seguro(a) } \\
\text { você se sente em } \\
\text { sua vida diária? }\end{array}$ & $\begin{array}{c}0 \\
(0,0)\end{array}$ & $\begin{array}{c}17 \\
(14,2)\end{array}$ & $\begin{array}{c}24 \\
(20,0)\end{array}$ & $\begin{array}{c}58 \\
(48,3) \\
\end{array}$ & $\begin{array}{c}21 \\
(17,5) \\
\end{array}$ & $\begin{array}{c}120 \\
(100,0)\end{array}$ \\
\hline 9 & $\begin{array}{l}\text { Quão saudável é o } \\
\text { seu ambiente físico } \\
\text { (clima, barulho, } \\
\text { poluição, } \\
\text { atrativos)? }\end{array}$ & $\begin{array}{c}6 \\
(5,0)\end{array}$ & $\begin{array}{c}17 \\
(14,2)\end{array}$ & $\begin{array}{c}20 \\
(16,7)\end{array}$ & $\begin{array}{c}64 \\
(53,3)\end{array}$ & $\begin{array}{c}13 \\
(10,8)\end{array}$ & $\begin{array}{c}120 \\
(100,0)\end{array}$ \\
\hline
\end{tabular}


Continuação

\begin{tabular}{|c|c|c|c|c|c|c|c|}
\hline & Questões & $\begin{array}{l}\text { Nada } \\
(\%)\end{array}$ & $\begin{array}{c}\text { Muito } \\
\text { pouco } \\
(\%)\end{array}$ & $\begin{array}{c}\text { Médio } \\
(\%)\end{array}$ & $\begin{array}{l}\text { Muito } \\
(\%)\end{array}$ & $\begin{array}{c}\text { Completa } \\
\text { Mente } \\
(\%)\end{array}$ & $\begin{array}{l}\text { Total } \\
(\%)\end{array}$ \\
\hline 10 & $\begin{array}{l}\text { Você tem energia } \\
\text { suficiente para seu } \\
\text { dia-a- dia? }\end{array}$ & $\begin{array}{c}4 \\
(3,3) \\
\end{array}$ & $\begin{array}{c}6 \\
(5,0) \\
\end{array}$ & $\begin{array}{c}17 \\
(14,2)\end{array}$ & $\begin{array}{c}59 \\
(49,2) \\
\end{array}$ & $\begin{array}{c}34 \\
(28,3)\end{array}$ & $\begin{array}{c}120 \\
(100,0)\end{array}$ \\
\hline 11 & $\begin{array}{l}\text { Você é capaz de } \\
\text { aceitar sua } \\
\text { aparência física? }\end{array}$ & $\begin{array}{c}7 \\
(5,8) \\
\end{array}$ & $\begin{array}{c}6 \\
(5,0) \\
\end{array}$ & $\begin{array}{c}22 \\
(18,3) \\
\end{array}$ & $\begin{array}{c}55 \\
(45,8) \\
\end{array}$ & $\begin{array}{c}30 \\
(25,0) \\
\end{array}$ & $\begin{array}{c}120 \\
(100,0)\end{array}$ \\
\hline 12 & $\begin{array}{l}\text { Você tem dinheiro } \\
\text { suficiente para } \\
\text { satisfazer suas } \\
\text { necessidades? }\end{array}$ & $\begin{array}{c}72 \\
(60,0) \\
\end{array}$ & $\begin{array}{c}7 \\
(5,8) \\
\end{array}$ & $\begin{array}{c}24 \\
(20,0) \\
\end{array}$ & $\begin{array}{c}11 \\
(9,2) \\
\end{array}$ & $\begin{array}{c}6 \\
(5,0) \\
\end{array}$ & $\begin{array}{c}120 \\
(100,0)\end{array}$ \\
\hline 13 & $\begin{array}{l}\text { Quão disponíveis } \\
\text { para você estão as } \\
\text { informações que } \\
\text { precisa no seu dia- } \\
\text { a-dia? }\end{array}$ & $\begin{array}{c}10 \\
(8,3)\end{array}$ & $\begin{array}{c}17 \\
(14,2)\end{array}$ & $\begin{array}{c}18 \\
(15,0)\end{array}$ & $\begin{array}{c}56 \\
(46,7) \\
\end{array}$ & $\begin{array}{c}19 \\
(15,8)\end{array}$ & $\begin{array}{c}120 \\
(100,0) \\
\end{array}$ \\
\hline 14 & $\begin{array}{l}\text { Em que medida } \\
\text { você tem } \\
\text { oportunidades de } \\
\text { atividade de lazer? }\end{array}$ & $\begin{array}{c}8 \\
(6,7) \\
\end{array}$ & $\begin{array}{c}21 \\
(17,5)\end{array}$ & $\begin{array}{c}16 \\
(13,3)\end{array}$ & $\begin{array}{c}33 \\
(27,5)\end{array}$ & $\begin{array}{c}42 \\
(35,0)\end{array}$ & $\begin{array}{c}120 \\
(100,0)\end{array}$ \\
\hline & Questões & $\begin{array}{c}\text { Muito } \\
\text { ruim } \\
(\%)\end{array}$ & $\begin{array}{c}\text { Ruim } \\
(\%)\end{array}$ & $\begin{array}{c}\text { Nem ruim } \\
\text { nem bom } \\
(\%)\end{array}$ & $\begin{array}{l}\text { Bom } \\
(\%)\end{array}$ & $\begin{array}{c}\text { Muito bom } \\
(\%) \\
\end{array}$ & $\begin{array}{c}\text { Total } \\
(\%)\end{array}$ \\
\hline 15 & $\begin{array}{l}\text { Quão bem você é } \\
\text { capaz de se } \\
\text { locomover? }\end{array}$ & $\begin{array}{c}0 \\
(0,0)\end{array}$ & $\begin{array}{c}0 \\
(0,0)\end{array}$ & $\begin{array}{c}2 \\
(1,7)\end{array}$ & $\begin{array}{c}4 \\
(3,3) \\
\end{array}$ & $\begin{array}{c}114 \\
(95,0)\end{array}$ & $\begin{array}{c}120 \\
(100,0)\end{array}$ \\
\hline 16 & $\begin{array}{l}\text { Quão satisfeito(a) } \\
\text { você está com o } \\
\text { seu sono? }\end{array}$ & $\begin{array}{c}1 \\
(0,8)\end{array}$ & $\begin{array}{c}4 \\
(3,3) \\
\end{array}$ & $\begin{array}{c}9 \\
(7,5) \\
\end{array}$ & $\begin{array}{c}14 \\
(11,7)\end{array}$ & $\begin{array}{c}92 \\
(76,7)\end{array}$ & $\begin{array}{c}120 \\
(100,0)\end{array}$ \\
\hline 17 & $\begin{array}{l}\text { Quão satisfeito(a) } \\
\text { você está com sua } \\
\text { capacidade de } \\
\text { desempenhar as } \\
\text { atividades do seu } \\
\text { dia-a-dia? }\end{array}$ & $\begin{array}{c}1 \\
(0,8) \\
\end{array}$ & $\begin{array}{c}3 \\
(2,5) \\
\end{array}$ & $\begin{array}{c}13 \\
(10,8) \\
\end{array}$ & $\begin{array}{c}72 \\
(60,0) \\
\end{array}$ & $\begin{array}{c}31 \\
(25,8) \\
\end{array}$ & $\begin{array}{c}120 \\
(100,0) \\
\end{array}$ \\
\hline 18 & $\begin{array}{l}\text { Quão satisfeito(a) } \\
\text { você está com sua } \\
\text { capacidade para o } \\
\text { trabalho? }\end{array}$ & $\begin{array}{c}2 \\
(1,7) \\
\end{array}$ & $\begin{array}{c}3 \\
(2,5) \\
\end{array}$ & $\begin{array}{c}11 \\
(9,2) \\
\end{array}$ & $\begin{array}{c}68 \\
(56,7) \\
\end{array}$ & $\begin{array}{c}36 \\
(30,0) \\
\end{array}$ & $\begin{array}{c}120 \\
(100,0) \\
\end{array}$ \\
\hline 19 & $\begin{array}{l}\text { Quão satisfeito(a) } \\
\text { você está consigo } \\
\text { mesmo? }\end{array}$ & $\begin{array}{c}1 \\
(0,8)\end{array}$ & $\begin{array}{c}2 \\
(1,7)\end{array}$ & $\begin{array}{c}19 \\
(15,8) \\
\end{array}$ & $\begin{array}{c}57 \\
(47,5) \\
\end{array}$ & $\begin{array}{c}41 \\
(34,2) \\
\end{array}$ & $\begin{array}{c}120 \\
(100,0) \\
\end{array}$ \\
\hline 20 & $\begin{array}{l}\text { Quão satisfeito(a) } \\
\text { você está com suas } \\
\text { relações pessoais } \\
\text { (amigos, parentes, } \\
\text { conhecidos, } \\
\text { colegas)? }\end{array}$ & $\begin{array}{c}2 \\
(1,7)\end{array}$ & $\begin{array}{c}5 \\
(4,2)\end{array}$ & $\begin{array}{c}9 \\
(7,5)\end{array}$ & $\begin{array}{c}31 \\
(25,8)\end{array}$ & $\begin{array}{c}73 \\
(60,8)\end{array}$ & $\begin{array}{c}120 \\
(100,0)\end{array}$ \\
\hline
\end{tabular}


Continuação

\begin{tabular}{|c|c|c|c|c|c|c|c|}
\hline 21 & $\begin{array}{l}\text { Quão satisfeito(a) } \\
\text { você está com sua } \\
\text { vida sexual? }\end{array}$ & $\begin{array}{c}18 \\
(15,0) \\
\end{array}$ & $\begin{array}{c}7 \\
(5,8) \\
\end{array}$ & $\begin{array}{c}14 \\
(11,7) \\
\end{array}$ & $\begin{array}{c}44 \\
(36,7) \\
\end{array}$ & $\begin{array}{c}37 \\
(30,8) \\
\end{array}$ & $\begin{array}{c}120 \\
(100,0) \\
\end{array}$ \\
\hline 22 & $\begin{array}{l}\text { Quão satisfeito(a) } \\
\text { você está com } \\
\text { o apoio que você } \\
\text { recebe de seus } \\
\text { amigos? }\end{array}$ & $\begin{array}{c}1 \\
(0,8)\end{array}$ & $\begin{array}{c}8 \\
(6,7)\end{array}$ & $\begin{array}{c}10 \\
(8,3)\end{array}$ & $\begin{array}{c}65 \\
(54,2)\end{array}$ & $\begin{array}{c}36 \\
(30,0)\end{array}$ & $\begin{array}{c}120 \\
(100,0)\end{array}$ \\
\hline 23 & $\begin{array}{l}\text { Quão satisfeito(a) } \\
\text { você está com } \\
\text { as condições do } \\
\text { local onde mora? }\end{array}$ & $\begin{array}{c}2 \\
(1,7)\end{array}$ & $\begin{array}{c}4 \\
(3,3)\end{array}$ & $\begin{array}{c}13 \\
(10,8)\end{array}$ & $\begin{array}{c}74 \\
(61,7)\end{array}$ & $\begin{array}{c}27 \\
(22,5)\end{array}$ & $\begin{array}{c}120 \\
(100,0)\end{array}$ \\
\hline 24 & $\begin{array}{l}\text { Quão satisfeito(a) } \\
\text { você está com o } \\
\text { seu acesso aos } \\
\text { serviços de saúde? }\end{array}$ & $\begin{array}{c}8 \\
(6,7)\end{array}$ & $\begin{array}{c}25 \\
(20,8)\end{array}$ & $\begin{array}{c}12 \\
(10,0)\end{array}$ & $\begin{array}{c}44 \\
(36,7)\end{array}$ & $\begin{array}{c}31 \\
(25,8)\end{array}$ & $\begin{array}{c}120 \\
(100,0)\end{array}$ \\
\hline 25 & $\begin{array}{l}\text { Quão satisfeito(a) } \\
\text { você está com } \\
\text { o seu meio de } \\
\text { transporte? }\end{array}$ & $\begin{array}{c}6 \\
(5,0) \\
\end{array}$ & $\begin{array}{c}18 \\
(15,0) \\
\end{array}$ & $\begin{array}{c}10 \\
(8,3) \\
\end{array}$ & $\begin{array}{c}62 \\
(51,7) \\
\end{array}$ & $\begin{array}{c}24 \\
(20,0) \\
\end{array}$ & $\begin{array}{c}120 \\
(100,0)\end{array}$ \\
\hline & Questões & $\begin{array}{c}\text { Nunca } \\
(\%)\end{array}$ & $\begin{array}{c}\text { algumas } \\
\text { vezes } \\
(\%) \\
\end{array}$ & $\begin{array}{c}\text { Freqüente- } \\
\text { mente } \\
(\%)\end{array}$ & $\begin{array}{c}\text { Muito } \\
\text { frequentemente } \\
(\%)\end{array}$ & $\begin{array}{c}\text { Sempre } \\
(\%)\end{array}$ & $\begin{array}{l}\text { Total } \\
(\%)\end{array}$ \\
\hline 26 & $\begin{array}{l}\text { Com que } \\
\text { freqüência você } \\
\text { tem sentimentos } \\
\text { como mau humor, } \\
\text { desespero, } \\
\text { ansiedade, } \\
\text { depressão? }\end{array}$ & $\begin{array}{c}51 \\
(42,5)\end{array}$ & $\begin{array}{c}52 \\
(43,3)\end{array}$ & $\begin{array}{c}13 \\
(10,8)\end{array}$ & $\begin{array}{c}4 \\
(3,3)\end{array}$ & $\begin{array}{c}\mathbf{0} \\
(\mathbf{0}, \mathbf{0})\end{array}$ & $\begin{array}{c}120 \\
(100,0)\end{array}$ \\
\hline
\end{tabular}

Pela Tabela 3, observa-se que as respostas às questões sobre qualidade de vida permearam os escores mais altos na quase totalidade dos dados. As questões de qualidade de vida no geral pontuaram que $64,2 \%$ dos entrevistados consideraram sua qualidade de vida boa enquanto $17,5 \%$ deles acharam-na muito boa. Bem satisfeitos com sua saúde estavam $69,2 \%$ dos entrevistados.

Relacionando as questões respondidas no WHOQOL-BREF aos domínios correspondentes, nota-se que no domínio físico, por exemplo, $75 \%$ dos pesquisados colocaram que sua condição física não os impede de fazer nada e a capacidade para as atividades da vida diária foi reconhecida por $60 \%$ dos entrevistados. No domínio 
psicológico, a satisfação consigo mesmo apareceu em 47,5\% das respostas, a freqüência de sentimentos como tristeza e depressão foi citada por apenas $10,8 \%$ e a aceitação da aparência física estava presente para $45,8 \%$ dos pacientes.

A satisfação com o apoio que recebe dos amigos no domínio relações sociais foi relatada por $54,2 \%$ dos pesquisados e $60 \%$ deles também disseram estar satisfeitos com os relacionamentos entre amigos e familiares. Sobre o domínio meio ambiente, $36,7 \%$ dos sujeitos estavam bem satisfeitos com o acesso aos serviços de saúde e 50,8\% da amostra consideraram as condições do local onde moram muito boas.

O estudo das médias de cada um dos domínios sem correlacioná-los a nenhum fator específico, pode ser visto na Tabela 4.

Tabela 4 - Medidas-resumo do WHOQOL-BREF

\begin{tabular}{ccccccc}
\hline Domínios & N & Média & $\begin{array}{c}\text { Desvio- } \\
\text { padrão }\end{array}$ & Mínimo & Mediana & Máximo \\
\hline Geral & 120 & 71 & 11 & 31 & 72 & 94 \\
Físico & 120 & 62 & 8 & 32 & 61 & 82 \\
Psicológico & 120 & 66 & 12 & 17 & 67 & 88 \\
Relações & & & & & & \\
Sociais & 120 & 76 & 21 & 0 & 83 & 100 \\
Meio ambiente & 120 & 61 & 16 & 19 & 59 & 97 \\
\hline
\end{tabular}

$\mathrm{Na}$ avaliação das questões gerais de qualidade de vida, a média do grupo foi 71 , o que representou um índice de qualidade de vida de bom a muito bom. Os pacientes apresentaram valores médios maiores no domínio relações sociais (76). O domínio meio ambiente teve os índices mais baixos (61), seguidos do físico (62) e psicológico (66). 
A Figura 2 mostra a avaliação dos domínios isoladamente. Observa-se que, quando comparados entre si, todos os domínios da qualidade de vida apresentaram valores acima da média.

Média $\pm 2 \mathrm{EP}$
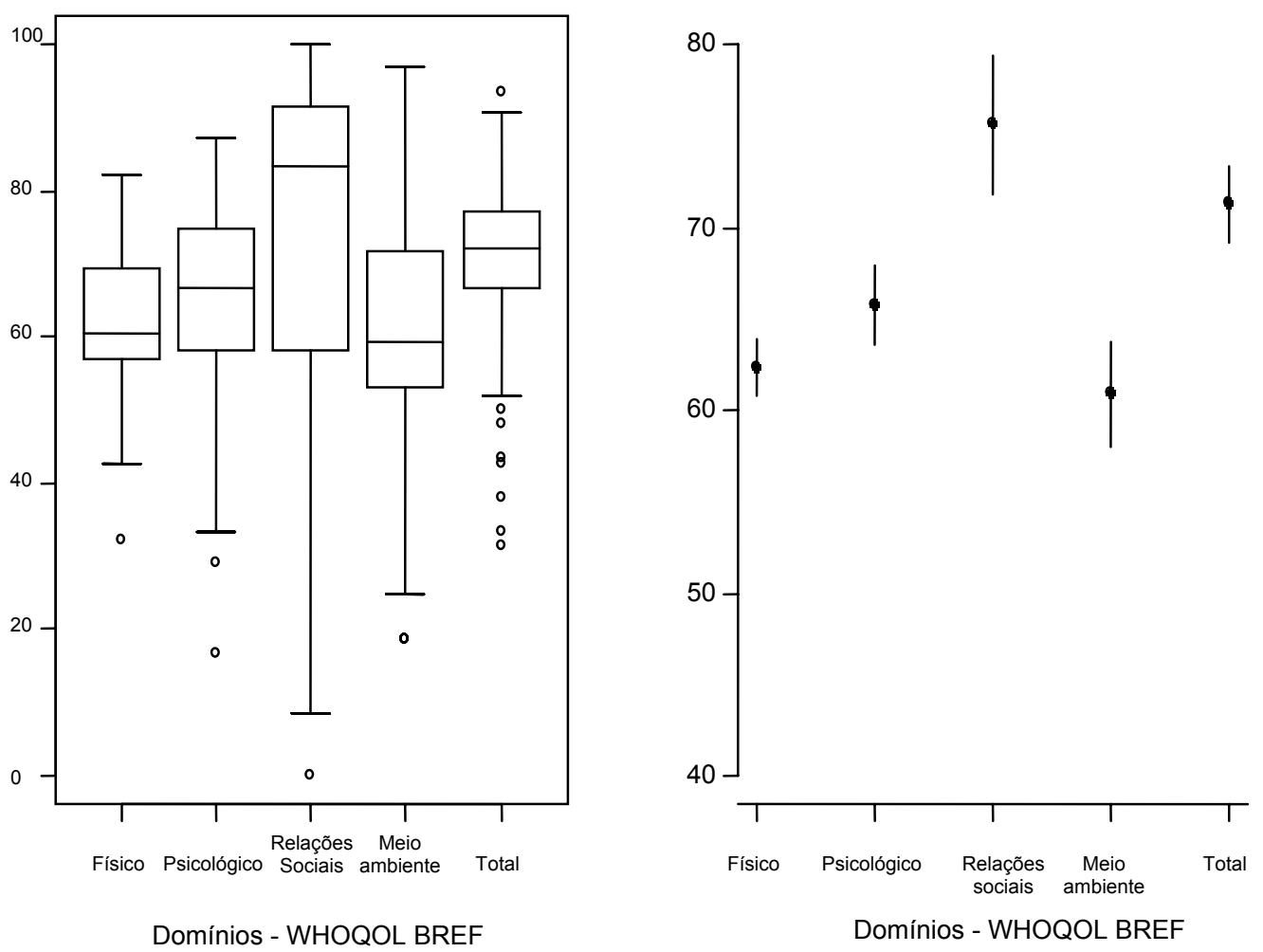

Figura 2 - Gráfico Boxplots* e Média \pm 2EP do WHOQOL-BREF

* ver interpretação no anexo 6. 
Diante da possibilidade de interferência positiva ou negativa dos fatores obtidos pelo questionário de identificação, na qualidade de vida dos pacientes pesquisados, estes foram correlacionados com os resultados do WHOQOL-BREF.

Para o item idade foram construídos gráficos de dispersão entre cada domínio do WHOQOL-BREF (Figura 3) onde se percebe que não houve indícios de associação em todos os casos nos quatro domínios.
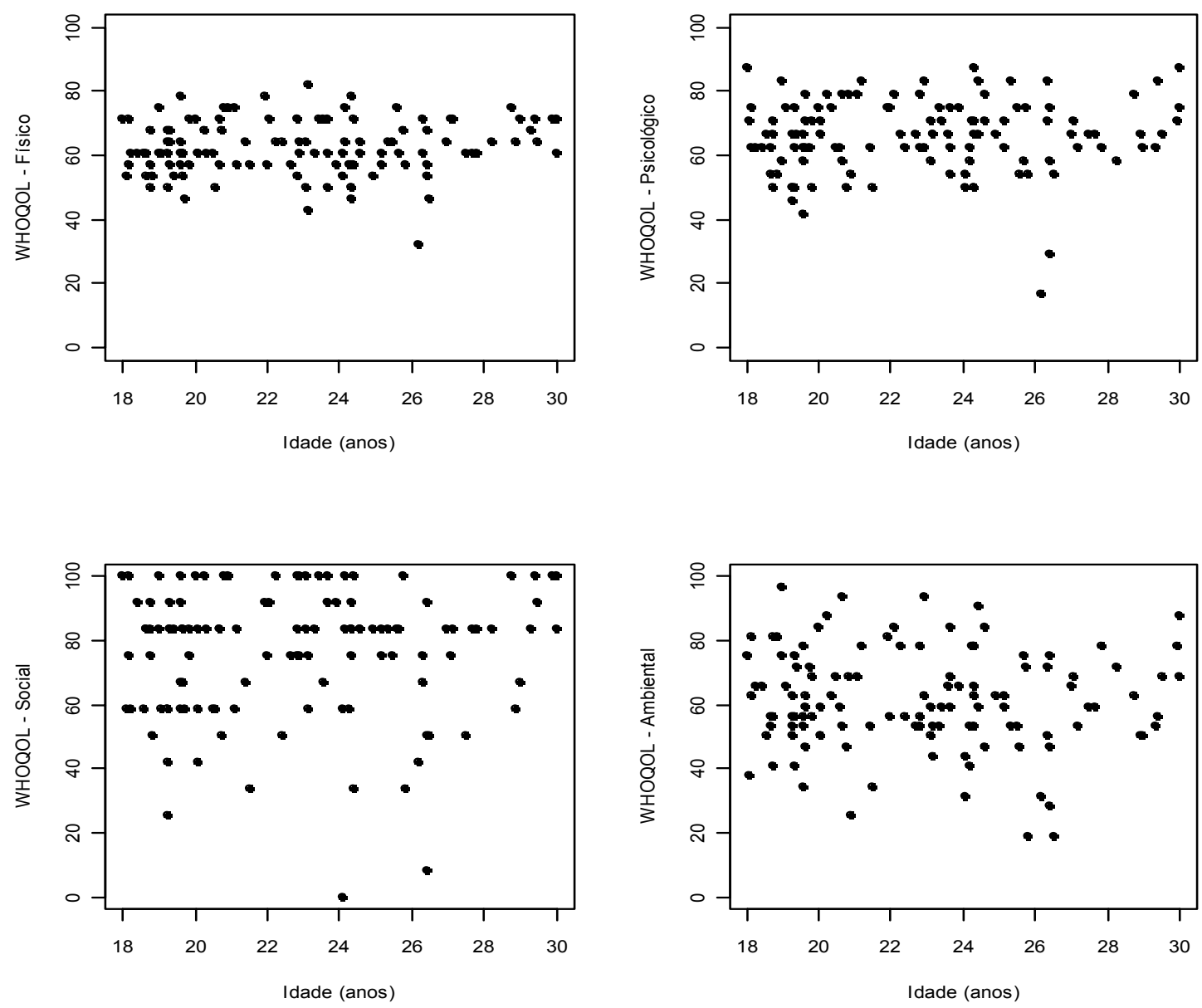

Figura 3 - Gráfico WHOQOL e Idade 
As tabelas de $\mathrm{n}^{\mathrm{o}} .: 5,6,7,8$ e 9 foram construídas para demonstrar a possível correlação dos fatores: região, tipo de fissura, gênero, escolaridade e profissão com cada domínio específico do WHOQOL-BREF.

Tabela 5 - Medidas-resumo WHOQOL - Físico

\begin{tabular}{|c|c|c|c|c|c|c|c|}
\hline Fatores & Categorias & $\mathbf{N}$ & Média & $\begin{array}{l}\text { Desvio- } \\
\text { padrão }\end{array}$ & Mínimo & Mediana & Máximo \\
\hline \multirow{2}{*}{ Região } & Capital & 17 & 63 & 10 & 46 & 61 & 82 \\
\hline & Interior & 102 & 62 & 8 & 32 & 61 & 79 \\
\hline \multirow{3}{*}{ Tipo de fissura } & Transforame & 82 & 62 & 9 & 32 & 61 & 82 \\
\hline & Pré-forame & 15 & 65 & 6 & 57 & 64 & 79 \\
\hline & Pós-forame & 22 & 61 & 7 & 50 & 61 & 71 \\
\hline \multirow[t]{2}{*}{ Gênero } & Masculino & 74 & 63 & 8 & 43 & 61 & 79 \\
\hline & Feminino & 45 & 62 & 9 & 32 & 61 & 82 \\
\hline \multirow{3}{*}{ Escolaridade } & Ensino fundamental & 14 & 63 & 9 & 46 & 66 & 71 \\
\hline & Ensino médio & 84 & 63 & 9 & 32 & 61 & 82 \\
\hline & Ensino superior & 21 & 61 & 8 & 46 & 61 & 75 \\
\hline \multirow{9}{*}{ Profissão } & Ciências e artes & 7 & 61 & 12 & 46 & 64 & 75 \\
\hline & Técnicos nível médio & 8 & 64 & 8 & 54 & 63 & 75 \\
\hline & Serv. Administrativos & 16 & 64 & 6 & 54 & 64 & 79 \\
\hline & Comerciantes & 13 & 63 & 8 & 50 & 64 & 79 \\
\hline & Agropecuários & 3 & 67 & 8 & 57 & 71 & 71 \\
\hline & Produção industrial & 7 & 56 & 8 & 43 & 57 & 68 \\
\hline & Man.reparação & 27 & 63 & 10 & 32 & 64 & 82 \\
\hline & Estudante & 8 & 56 & 6 & 46 & 59 & 61 \\
\hline & Desempregado & 30 & 63 & 8 & 50 & 61 & 79 \\
\hline
\end{tabular}

Observa-se na Tabela 5, que não houve associação significativa no domínio físico com os fatores do questionário de identificação, pois as médias representadas em cada fator não foram destoantes o suficiente para serem consideradas pela análise estatística. 
Tabela 6 - Medidas-resumo WHOQOL - Psicológico

\begin{tabular}{|c|c|c|c|c|c|c|c|}
\hline Fatores & Categorias & $\mathbf{N}$ & Média & $\begin{array}{l}\text { Desvio- } \\
\text { padrão }\end{array}$ & Mínimo & Mediana & Máximo \\
\hline \multirow{2}{*}{ Região } & Capital & 17 & 65 & 7 & 50 & 67 & 79 \\
\hline & Interior & 102 & 66 & 12 & 17 & 67 & 88 \\
\hline \multirow{3}{*}{ Tipo de fissura } & Transforame & 82 & 66 & 12 & 17 & 67 & 88 \\
\hline & Pré-forame & 15 & 70 & 9 & 58 & 71 & 83 \\
\hline & Pós-forame & 22 & 63 & 12 & 29 & 67 & 79 \\
\hline \multirow{2}{*}{ Gênero } & Masculino & 74 & 67 & 10 & 42 & 67 & 88 \\
\hline & Feminino & 45 & 64 & 13 & 17 & 63 & 88 \\
\hline \multirow{3}{*}{ Escolaridade } & Ensino fundamental & 14 & 66 & 14 & 29 & 69 & 88 \\
\hline & Ensino médio & 84 & 65 & 12 & 17 & 67 & 88 \\
\hline & Ensino superior & 21 & 68 & 10 & 50 & 71 & 83 \\
\hline \multirow{9}{*}{ Profissão } & Ciências e artes & 7 & 70 & 9 & 54 & 71 & 79 \\
\hline & Técnicos nível médio & 8 & 67 & 8 & 54 & 67 & 83 \\
\hline & Serv. Administrativos & 16 & 66 & 10 & 50 & 67 & 83 \\
\hline & Comerciantes & 13 & 66 & 8 & 58 & 63 & 79 \\
\hline & Agropecuários & 3 & 71 & 8 & 63 & 71 & 79 \\
\hline & Produção industrial & 7 & 70 & 14 & 50 & 71 & 88 \\
\hline & Man.reparação & 27 & 65 & 14 & 17 & 67 & 88 \\
\hline & Estudante & 8 & 63 & 8 & 46 & 63 & 75 \\
\hline & Desempregado & 30 & 65 & 14 & 29 & 65 & 83 \\
\hline
\end{tabular}

Em relação ao domínio psicológico, na Tabela acima, as médias não apontaram valores que pudessem significar correlação entre os fatores ou interferência de algum deles nos resultados do WHOQOL-BREF. 
Tabela 7 - Medidas-resumo WHOQOL - Relações Sociais

\begin{tabular}{clrrrrrr}
\hline \multirow{2}{*}{ Fatores } & Categorias & N & Média & $\begin{array}{c}\text { Desvio- } \\
\text { padrão }\end{array}$ & Mínimo & Mediana & Máximo \\
\hline \multirow{2}{*}{ Região } & Capital & 17 & 77 & 18 & 50 & 75 & 100 \\
& Interior & 102 & 76 & 21 & 0 & 83 & 100 \\
\hline \multirow{2}{*}{ Tipo de fissura } & Transforame & 82 & 77 & 20 & 0 & 83 & 100 \\
& Pré-forame & 15 & 84 & 13 & 58 & 83 & 100 \\
& Pós-forame & 22 & 69 & 25 & 8 & 83 & 100 \\
\hline \multirow{3}{*}{ Gênero } & Masculino & 74 & 79 & 19 & 0 & 83 & 100 \\
& Feminino & 45 & 72 & 21 & 8 & 83 & 100 \\
\hline \multirow{5}{*}{ Escolaridade } & Ensino fundamental & 14 & 73 & 25 & 8 & 79 & 100 \\
& Ensino médio & 84 & 76 & 21 & 0 & 83 & 100 \\
& Ensino superior & 21 & 81 & 14 & 58 & 83 & 100 \\
\hline \multirow{5}{*}{ Profissão } & Ciências e artes & 7 & 82 & 15 & 58 & 83 & 100 \\
& Técnicos nível médio & 8 & 77 & 22 & 33 & 83 & 100 \\
& Serv. administrativos & 16 & 81 & 17 & 50 & 83 & 100 \\
& Comerciantes & 13 & 79 & 19 & 50 & 83 & 100 \\
& Agropecuários & 3 & 81 & 21 & 58 & 83 & 100 \\
& Produção industrial & 7 & 77 & 17 & 50 & 83 & 100 \\
& Man.reparação & 27 & 78 & 15 & 42 & 75 & 100 \\
& Estudante & 8 & 66 & 18 & 42 & 58 & 100 \\
& Desempregado & 30 & 72 & 28 & 0 & 83 & 100 \\
\hline & & & & & & &
\end{tabular}

A Tabela 7 indica os fatores do questionário de identificação correlacionados às respostas do domínio relações sociais, onde não houve nenhum valor estatisticamente significativo, como pode ser observado. 
Diferente dos dados acima, com relação ao domínio meio ambiente, a Tabela 8 mostra que houve indícios de que a média para o grupo com escolaridade superior (71) foi maior em comparação com a média dos grupos com ensino fundamental (58) e ensino médio (59). Ou seja, os participantes com escolaridade superior atribuíram melhor qualidade de vida para este domínio.

Tabela 8 - Medidas-resumo WHOQOL - Meio ambiente

\begin{tabular}{|c|c|c|c|c|c|c|c|}
\hline Fatores & Categorias & $\mathbf{N}$ & Média & $\begin{array}{l}\text { Desvio- } \\
\text { padrão }\end{array}$ & Mínimo & Mediana & Máximo \\
\hline \multirow{2}{*}{ Região } & Capital & 17 & 63 & 11 & 44 & 63 & 78 \\
\hline & Interior & 102 & 61 & 16 & 19 & 59 & 97 \\
\hline \multirow{3}{*}{ Tipo de Fissura } & Transforame & 82 & 61 & 15 & 19 & 61 & 97 \\
\hline & Pré-forame & 15 & 65 & 15 & 47 & 59 & 94 \\
\hline & Pós-forame & 22 & 58 & 18 & 19 & 59 & 84 \\
\hline \multirow{2}{*}{ Gênero } & Masculino & 74 & 63 & 15 & 19 & 63 & 97 \\
\hline & Feminino & 45 & 59 & 16 & 19 & 59 & 94 \\
\hline \multirow{3}{*}{ Escolaridade } & Ensino fundamental & 14 & 58 & 20 & 19 & 56 & 88 \\
\hline & Ensino médio & 84 & 59 & 15 & 19 & 56 & 97 \\
\hline & Ensino superior & 21 & 71 & 12 & 41 & 69 & 94 \\
\hline \multirow{9}{*}{ Profissão } & Ciências e artes & 7 & 69 & 11 & 59 & 66 & 94 \\
\hline & Técnicos nível médio & 8 & 61 & 17 & 38 & 59 & 91 \\
\hline & Serv. Administrativos & 16 & 67 & 15 & 41 & 67 & 94 \\
\hline & Comerciantes & 13 & 63 & 13 & 47 & 56 & 84 \\
\hline & Agropecuários & 3 & 63 & 14 & 53 & 56 & 78 \\
\hline & Produção industrial & 7 & 71 & 13 & 53 & 78 & 88 \\
\hline & Man.reparação & 27 & 56 & 16 & 19 & 56 & 88 \\
\hline & Estudante & 8 & 66 & 8 & 53 & 66 & 81 \\
\hline & Desempregado & 30 & 56 & 17 & 19 & 56 & 97 \\
\hline
\end{tabular}


No modelo de regressão linear múltiplo, que correlacionou os valores dos fatores sociodemográficos entre si e com cada domínio, o único em que houve associação estatisticamente significante foi no domínio meio ambiente. As mulheres demonstraram média menor $(6,16)$ que os homens $(\mathrm{p}=0,030)$ para a qualidade de vida neste domínio. $\mathrm{O}$ resultado pode ser visualizado na Tabela 9.

Tabela 9 - Modelo de regressão da variável WHOQOL - Meio ambiente

\begin{tabular}{cccccc}
\hline \multicolumn{2}{c}{ Fatores } & Coeficiente & Erro-padrão & $\mathrm{t}$ & $\mathrm{P}$ \\
& constante & 64,07 & 4,27 & 15,01 & 0,000 \\
\hline \multirow{2}{*}{ Tipo de fissura } & pré-forame & 4,81 & 4,11 & 1,17 & 0,245 \\
& pós-forame & $-3,92$ & 3,49 & $-1,12$ & 0,264 \\
\hline \multirow{2}{*}{ Gênero } & Feminino & $-6,16$ & 2,80 & $-2,2$ & 0,030 \\
\hline \multirow{2}{*}{ Escolaridade } & Médio & $-2,65$ & 4,32 & $-0,61$ & 0,541 \\
& Superior & 10,13 & 5,13 & 1,97 & 0,051
\end{tabular}




\section{DISCUSSÃO}




\section{6 - DISCUSSÃO.}

Refletir sobre a expressão qualidade de vida significa considerar diferentes vertentes amplamente exploradas por todas as ciências envolvidas com o bem-estar do ser humano. Este conceito amplo pode se referir aos sentimentos, emoções, relações pessoais, realização profissional, estado psicológico, nível de independência, às crenças pessoais e, especialmente, à saúde física, considerada a variável que mais influencia na qualidade de vida, uma vez que esta seria a medida do estado de capacidade para a realização de tarefas e a promoção de relações interpessoais (Morton 1995, Segre e Ferraz 1997, Minayo e Hartz 2000, Paschoal 2000, Lima 2002, Berlim et al 2003, Nucci 2003, Arnold et al 2004, Berlim et al 2005 e Casas 2005).

As considerações acima citadas foram observadas já no momento inicial deste estudo, pois os pacientes convidados a participar da pesquisa concordaram de prontidão, demonstrando interesse, disponibilidade para colaboração e reconhecimento da pesquisa como mais uma forma de cuidado oferecida pela equipe do hospital.

Observou-se também que, apesar de todos terem respondido com clareza o questionário de identificação feito inicialmente, a expressão dos pacientes se alterou quando questionados sobre sua qualidade de vida. Tal questionamento fez parecer que, pensar na qualidade da própria vida era novidade para muitos deles.

A avaliação da qualidade de vida pede uma reflexão madura a respeito do quão feliz ou satisfeito se está com as condições que se tem. Para tanto, entende-se que somente os adultos podem fazer uma auto-avaliação da própria qualidade de vida, em vista de uma experiência de vida que os instrumentaliza. É necessário que a pessoa tenha condições de observar o mundo a sua volta e atribuir valores positivos ou 
negativos à sua condição. Portanto, a avaliação da qualidade de vida é subjetiva, pois para cada indivíduo há uma forma de operacionalizar sua avaliação; a avaliação de um mesmo indivíduo pode variar com o tempo, com as mudanças de prioridades ao longo da vida e com as circunstâncias pelas quais a vida pode se modificar (Pruzinsky 1992, WHOQOL-Group 1994, Morton 1995, Segre e Ferraz 1997, Paschoal 2000, Lima 2002, Arnold et al 2004 e Seidl e Zannon 2004).

A literatura referente à qualidade de vida em grupos de pessoas em condições semelhantes foi intensificada à medida que o conceito de qualidade de vida evoluiu de suprimento às necessidades básicas até o completo bem-estar do sujeito na sociedade (Farquhar 1995, Minayo e Hartz 2000, Paschoal 2000, Nucci 2003). Essa ampliação deu margem a diferentes reflexões sobre o que seria necessário à qualidade de vida das pessoas em geral e, em particular, à pessoa com fissura (Bachega 2000, Marcusson et al 2001, Patel e Ross 2003 e Sinko et al 2005). Porém, como lembraram Patel e Ross (2003), a modernização da sociedade promoveu mudanças radicais na vida das pessoas, em seus hábitos e costumes. Por isso, o que era valorizado no início das pesquisas sobre qualidade de vida, a partir de 1970, hoje tem outro significado. Um exemplo desta mudança é encontrado no próprio conflito em torno daquele que tem fissura, uma vez que a deformidade na boca e o prejuízo da aparência atualmente não são tão mais importantes do que as possíveis dificuldades de comunicação. (Pegoraro-Krook 1995).

Os resultados obtidos pela presente pesquisa revelaram um panorama das condições de vida dos pacientes adultos com fissura labiopalatina do estado de São Paulo atendidos pelo HRAC. A análise dos fatores sociodemográficos dos pesquisados e a avaliação da qualidade de vida deles, pelo instrumento WHOQOL-BREF, foram os 
pilares que facilitaram uma análise do propósito deste estudo e a correlação da realidade desta Instituição com a literatura revisada.

6.1 - Fatores sociodemográficos.

Para a avaliação da qualidade de vida dos pacientes fica evidente a necessidade de um levantamento de suas condições de vida (WHOQOL-Group 1994), por serem estes aspectos considerados os melhores medidores do estado geral da pessoa.

Os participantes deste estudo apresentaram, em sua maioria, a fissura transforame incisivo, da mesma forma que prevaleceu nesta amostra o gênero masculino. Estes dados são condizentes com a literatura que aponta a predominância de fissura completa de lábio e palato na população que apresenta malformação e que afirma ser este tipo de fissura a mais propicia neste gênero (Freitas et al 2004 e Baroneza et al 2005).

Em centros como o HRAC, onde o processo reabilitador ocorre por um longo tempo, o paciente é acompanhado durante todo o período por diferentes profissionais de uma equipe multidisciplinar (Aiello et al 2000 e Abdo e Machado 2005). O sujeito que iniciou o tratamento da fissura labiopalatina na infância, vivencia, em meio ao processo reabilitador, todas as fases de desenvolvimento até sua idade adulta (Graciano et al 2007). Os relacionamentos interpessoais experienciados neste processo são intrínsecos à estruturação da identidade, favorecendo a reabilitação naturalmente de modo positivo.

Dos participantes deste estudo, $83,3 \%$ estavam solteiros e não tinham filhos. Desde Peter et al (1975), as dificuldades de relacionamentos interpessoais foram atribuídas em decorrência da fissura labiopalatina. Ramstad et al (1995a) e Pereira e 
Mota (1997) também apontaram que o estigma vivenciado por eles dificulta namoro e casamento, fazendo com que namorem menos e casem mais tarde em comparação aos que não têm fissura. Outras afirmativas foram de que o tratamento longo inibiria envolvimentos sérios, além do medo de gerarem filhos com fissura. Entretanto, considerando a amostra com 74,2\% de pacientes com idade entre 18 e 24 anos, recorreu-se ao Censo do Instituto Brasileiro de Geografia e Estatística (2000), que confirmou que $74 \%$ das pessoas com idade pareada a dos pesquisados também estavam solteiros e sem filhos. Desta forma, infere-se que esses sujeitos podem ainda não ter se casado porque são jovens demais, sugerindo consequentemente um estudo que abranja adultos com mais idade em grupos pareados, para que seja possível medir se ainda continuam solteiros e quais os motivos disso.

A mesma análise pode ser feita em relação à convivência familiar. Na presente pesquisa, a maioria dos pacientes vivia com os pais ou familiares. Estudos de Peter et al (1975), Noar (1991) e Garcia et al (1999) consideraram a pessoa com fissura emocionalmente dependente dos familiares por mais tempo, uma vez que eles confiam mais nos seus familiares para receber cuidados e apoio. Novamente fazendo uma reflexão sobre o adulto jovem na atualidade, observou-se que sua independência socioeconômica acontece mais tarde, sendo que a vida em família garante a eles benefícios como conforto e segurança. Os dados do Instituto Brasileiro de Geografia e Estatística (2000) confirmaram esta realidade no estado de São Paulo. Portanto, os sujeitos deste estudo também podem ser inseridos nesta variável.

A educação é premissa básica para o desenvolvimento e independência. Ao contrário de algumas décadas atrás, a comunidade em geral já admite o estudo como ferramenta para alcançar a sobrevivência digna. O levantamento deste estudo apontou 
que $70 \%$ dos pacientes tinham o ensino médio completo, e somente $17,5 \%$ possuíam o ensino superior. Bachega (2000) constatou que a comunicação falha e o tratamento longo afetam a educação, principalmente no que se refere ao interesse pelos estudos. Outra condição que poderia interferir no segmento escolaridade foi evidenciada por Richman (1978), e mais tarde, por Tavano (1994) que afirmaram que os professores e colegas julgam mal as crianças com fissura, atribuindo dificuldades cognitivas em concomitância à gravidade da malformação e conseqüentemente, influenciando no autoconceito e no desenvolvimento acadêmico. Marques (2004) e Veronez e Tavano (2005) evidenciaram que as aspirações à profissionalização se tornaram mais freqüentes em pacientes que, além das cirurgias funcionais, foram submetidos às cirurgias estéticofaciais. Com a melhora da auto-estima destes pacientes, eles identificaram maior disposição para continuar seus estudos, tentar uma vaga na universidade e/ou realizar um curso técnico profissionalizante.

Pode-se considerar que a malformação seja ainda inibidora da capacidade de realização acadêmica do sujeito, mas outras dificuldades, como a condição financeira necessária para o ensino superior são consideradas tão ou mais agravantes que a fissura labioplatina. Pesquisas de Ramstad et al (1995a) e Patel e Ross (2003) encontraram níveis educacionais semelhantes em pacientes com e sem fissura. O Instituto Brasileiro de Geografia e Estatística (2000) também revelou uma maior proporção de adultos com a mesma idade da amostra estudada somente com o ensino médio completo. De posse de todas essas afirmações, conclui-se que as pessoas deste estudo correspondem à população em geral quanto à escolaridade, e as dificuldades em continuar os estudos não parecem ser apenas pertinentes à malformação. 
A capacidade para o trabalho, muitas vezes, é erroneamente confundida com as oportunidades de trabalho. São poucos os que conseguem trabalhar no que gostam, pois as chances de se conseguir um emprego que garanta sua subsistência e ao mesmo tempo lhes recompense emocionalmente são remotas. A concorrência da atualidade impede até mesmo que se consiga um trabalho, seja no que for. O presente estudo levantou que $25,8 \%$ dos pesquisados estavam desempregados. Levando em consideração a questão da aparência física, as dificuldades de fala e o tratamento intensivo ao qual o paciente com fissura é submetido, a situação de desemprego pode se agravar pelo preconceito em relação a pessoa com fissura (Ramstad et al 1995a, Tavano 2000 e Graciano et al 2006). Contudo, são muitas as questões que dificultam o emprego não somente para os pacientes, mas para toda a população. A desqualificação pela baixa escolaridade é uma delas. Em estudo com adolescentes, Bachega (2000) relatou limitações dos indivíduos com fissura labiopalatina para o desenvolvimento de carreira profissional devido à baixa freqüência à escola; porém, como visto, os níveis de escolaridade dos pacientes pesquisados estão equiparados aos das demais pessoas com a mesma idade de todo país. Numa pesquisa do Departamento Intersindical de Estatística e Estudos Socioeconômicos (2006) foi revelado que boa parte da população total em idade ativa no estado de São Paulo encerrou o ano de 2005 desempregada. Segnini (2000) relatou que os jovens no Brasil representam o grupo social mais escolarizado e mais desempregado, ou, mesmo, inserido em trabalhos precários.

Esta é outra situação que atingiu os pacientes entrevistados. Dos que estão empregados, 22,5\% exercem funções que, segundo Brasil (2002), exigem pouca ou nenhuma qualificação; e 63,7\% deles não tiveram opção na hora da escolha da ocupação. Peter et al (1974) e Ramstad et al (1995a) observaram que a sociedade parece 
valorizar menos o trabalho de pessoas com fissura, dificultando a contratação em empregos formais, embora eles tivessem iguais condições para o exercício de funções laborativas. Estes autores também afirmaram que os sujeitos com fissura normalmente ficavam isolados em seus locais de trabalho e tinham renda mais baixa quando comparada com a renda de sujeitos sem fissura. Contudo, Blatner (2000) observou que a maioria dos pacientes com fissura, por ela pesquisados, trabalha no setor terciário e não sofre qualquer discriminação por causa da malformação. Além disso, em conformidade com os dados pesquisados, o Departamento Intersindical de Estatística e Estudos Socioeconômicos (2006) revelou que a maioria dos empregados em geral desenvolve atividades nos setores de serviços como comércio e manutenção. A referida instituição de pesquisa atribuiu a evidente desigualdade de oportunidades no mercado de trabalho aos fatores culturais, sociais e econômicos, ou seja, os filhos de famílias com poder aquisitivo menor têm pior inserção no mercado de trabalho.

As questões do desemprego e do subemprego são problemas sociais que avançam as fronteiras de uma condição ou outra. Em todo o país existem sujeitos como os pesquisados, sentindo as mesmas dificuldades que ultrapassam os possíveis agravantes como a fissura labiopalatina.

Com o intuito de levantar as condições de vida e saúde dos pacientes pesquisados, foi possível observar que eles têm relacionamentos interpessoais e convívio familiar de acordo com o esperado para a sua idade e que as dificuldades encontradas nos setores educacional e profissional são condizentes com a população em geral. 
6.2 - Qualidade de vida.

A preocupação com a qualidade de vida de pacientes com fissura labiopalatina repercute o interesse observado na literatura por parte das instituições, em proporcionar, concomitantemente ao tratamento, melhora nas condições gerais de vida e saúde aqueles que buscam os serviços assistenciais (Organización Mundial de la Salud 1994, Minayo e Hartz 2000 e Brasil 2006).

Outras avaliações de qualidade de vida já foram realizadas em sujeitos com fissura labiopalatina nas diversas idades, e com instrumentos desenvolvidos pelos próprios autores. Porém, não foi encontrado na literatura nenhum estudo semelhante a este que avalie a qualidade de vida de pacientes adultos com fissura, através de um instrumento mundialmente padronizado como o WHOQOL-BREF.

O referido instrumento respeita as colocações de Bednar (1990), Pruzinsky (1992), Bullinger et al (1993), Gill e Feinstein (1994), Morton (1995), Segre e Ferraz (1997), Organización Mundial de la Salud (1994), Fleck et al (1999), Lima (2002) e Casas (2005) que valorizam a mistura de objetividade e subjetividade para a avaliação de qualidade de vida; resultante do julgamento que cada um faz das suas próprias condições incluindo os aspectos psicossociais.

Conforme apresentado no capítulo Material e Método, o WHOQOL-BREF, instrumento utilizado neste estudo, busca avaliar a qualidade de vida da pessoa a partir de concepções subjetivas que se referem a sua saúde e sua própria qualidade de vida. Este instrumento, além de avaliar a qualidade de vida em geral, também considera a qualidade de vida em quatro áreas específicas denominadas de domínios: físico, psicológico, relações sociais e meio ambiente. 
A qualidade de vida no geral se traduz na avaliação subjetiva da própria qualidade de vida e das condições de saúde percebidas pelo sujeito. Para os pacientes deste estudo, o reconhecimento de sua qualidade de vida esteve acima da média do grupo pesquisado com índices bom $(64,2 \%)$ e muito bom $(17,5 \%)$. Considerando outros estudos realizados com populações com condições diferentes da malformação craniofacial, somente o estudo de Kluthcovsky (2005) obteve bom nível de qualidade de vida no geral em agentes comunitários de saúde. No entanto, com dependentes de álcool, Lima (2002) observou déficit na qualidade de vida à medida que a gravidade da dependência aumentava. Michelone e Santos (2004), em seus estudos, obtiveram resultados indicativos de índice baixo de qualidade de vida em pacientes ostomizados. Estes dados aludem à questão do comprometimento da saúde nas atividades diárias, uma vez que, quanto maior a existência de sintomas físicos e/ou psicológicos, pior a qualidade de vida (Marcusson et al 2001, Michelone e Santos 2004, Gazalle et al 2006, Roque e Forones 2006 e Schestatsky et al 2006).

Em pessoas com fissura, Sinko et al (2005) encontraram baixos índices de qualidade de vida no geral. Por outro lado, Bachega (2000), Marcusson et al (2001) e Patel e Ross (2003) identificaram que os pacientes com fissura estavam satisfeitos com sua qualidade de vida e, mesmo reconhecendo o impacto da fissura em suas vidas, eles tiveram uma boa capacidade de ajustamento à situação.

Percebe-se que, ao contrário dos casos de pacientes com câncer ou com dependência química que são submetidos a tratamentos que prejudicam a vida diária do sujeito, as cirurgias reabilitadoras capacitam o paciente com fissura a viver sem comprometimentos, a menos que tenham alguma patologia correlacionada. 
Os valores acima da média para a qualidade de vida no geral encontrados no presente estudo, mostraram uma realidade positiva, diferente da esperada, e podem ser atribuídos à capacidade de superação das dificuldades advindas da fissura por meio de um processo reabilitador multidisciplinar eficiente, com uma equipe envolvida com as questões que compreendem o paciente dentro e fora do hospital, capaz de prevenir problemas psicossociais (Noar 1991, Pruzinsky 1992, Alves 1995, Amaral 1997, Pereira e Mota 1997, Bachega 2000, Marcusson et al 2001, Patel e Ross 2003, Marques 2004 e Graciano et al 2007).

A superação das dificuldades e boa qualidade de vida podem ainda estar relacionadas, de acordo com Stephan (2003), à boa educação e ao trabalho de familiarização de pais e educadores na formação da pessoa com fissura labiopalatina.

Considerando a saúde a variável que mais determina a qualidade de vida, (Minayo e Hartz 2000, Lima 2002 e Casas 2005), foi possível investigar a satisfação dos pacientes pesquisados em relação à sua saúde, com os instrumentos utilizados por este estudo. Dos 120 entrevistados, ressalta-se que 69,2\% estavam bem satisfeitos com sua saúde. Embora a fissura labiopalatina não prediga um déficit na saúde de modo geral, os trabalhos de Thomas et al (1997) e Veronez e Tavano (2005) apontam que os pacientes associam seu estado de saúde ao processo reabilitador; o que torna os resultados obtidos no presente estudo ainda mais consistentes, uma vez que tais autores perceberam maior satisfação com a saúde em pacientes com fissura, à medida que a deformidade ficava menos visível com o tratamento oferecido.

Segre e Ferraz (1997) e Brasil (2006) pontuaram que é importante considerar na saúde todas as condições de vida do sujeito. Não foi o propósito deste trabalho, realizar uma avaliação específica sobre todos os aspectos que se referem à saúde dos 
pesquisados. Portanto, mesmo que a satisfação com a saúde esteja alta, é necessário uma investigação mais aprofundada sobre o assunto para que seja considerada a plena satisfação com a saúde.

Após a análise da qualidade de vida em geral dos participantes deste estudo, foi feita uma análise dos dados que se referem a cada domínio separadamente. Eles estão apresentados e discutidos por ordem de classificação da maior para a menor média, como observado nos resultados.

O domínio relações sociais compreende todas as formas de relacionamento interpessoal necessárias ao bem-estar do sujeito e à vida em sociedade. É por intermédio das relações com o outro que a pessoa adquire indicadores da percepção de si mesmo e de sua participação no mundo. No presente estudo, este foi o domínio que mais se destacou em relação aos demais, com uma pontuação média de 76 , salientando que $60 \%$ dos participantes estavam satisfeitos com os relacionamentos com amigos e familiares. Em estudos com o WHOQOL-BREF, Roque e Forones (2006) observaram menores escores no domínio social em pacientes com câncer, provavelmente devido às limitações que a doença acarreta. Contudo, Kluthcovsky (2005) e Gazalle et al (2006) obtiveram índices semelhantes aos do presente estudo neste domínio em suas pesquisas com agentes comunitários de saúde e pacientes com transtorno bipolar, respectivamente.

Em pacientes com fissura, Tavano (2000), Patel e Ross (2003), Marques (2004) e Veronez e Tavano (2005) observaram que a malformação não afetou a vida social e os pacientes detectaram significativa melhora nos relacionamentos sociais após as cirurgias reabilitadoras, porque, com a aparência e fala melhoradas, sentiam um aumento da probabilidade de serem aceitos num grupo social. No entanto, Peter et al (1974), Tavano 
(1994), Pegoraro-Krook (1995), Omote (1997), Pereira e Mota (1997), Aiello et al (2000) e Sinko et al (2005) atribuíram às alterações morfológicas e funcionais os problemas nas relações sociais. Para eles, a malformação faz com que as pessoas com fissura participem pouco de atividades sociais, temendo a crítica social que pode alterar de certo modo o auto-conceito destes, resultando em uma auto-avaliação negativa da própria capacidade. Ressalta-se que a diferença de resultados observada na colocação dos autores acima sobre as relações sociais da pessoa com fissura, pode estar relacionada ao momento do processo reabilitador em que os estudos foram realizados.

Por isso, embora os autores acima apontem a malformação como algo que atrapalha o convívio social, vale lembrar que o grupo estudado concluiu as cirurgias primárias e secundárias e está em fase final de tratamento, não sendo mais tão visíveis os comprometimentos na aparência e, conseqüentemente, os prejuízos no contato com o outro.

Diante dos dados analisados, parece que não se pode mais considerar a pessoa que nasceu com fissura e está reabilitada, como possuidora de déficit nos relacionamentos sociais, uma vez que os entrevistados se consideram bem relacionados socialmente, com bom convívio entre amigos e familiares.

O domínio psicológico enfatiza o aproveitamento da vida, a capacidade de concentração, satisfação consigo mesmo e com sua aparência. Sobre esta última condição, 45,8\% dos pacientes pesquisados apresentaram boa aceitação. Todavia, há uma questão relevante observada nas entrevistas de rotina do hospital: os pacientes, embora satisfeitos, esperam ainda mais cirurgias com melhores resultados estéticos (Noar 1991, Tavano 2000 e Marcusson et al 2002). Isso pode ser decorrente da necessidade constante de melhora da aparência, em virtude de uma vida em convívio 
com a deformidade pela malformação. Sinko et al (2005) e Veronez e Tavano (2005) constataram que a expectativa do paciente pelos resultados da cirurgia nem sempre estão de acordo com o que o cirurgião pode oferecer. Diante de tal afirmativa, surge a necessidade de estudos mais pertinentes à questão da aparência, de forma a ampliar a compreensão de possíveis insatisfações dos pacientes.

O bem-estar psicológico repercute em todas as dimensões da vida, proporcionando possibilidades de atuação positiva e encorajamento frente às adversidades. A preocupação com a influência da fissura no âmbito psicológico revestese de fundamental importância para os estudiosos do comportamento, pois a saúde emocional contribui efetivamente para a boa qualidade de vida, como afirmam Berlim et al (2003).

Os pacientes estudados apresentaram bons escores no domínio psicológico (média 66), ressaltando-se que somente 10,8\% deles relataram ter experienciado sentimentos negativos como tristeza ou depressão nas últimas semanas e outros $47,5 \%$ afirmaram estarem muito satisfeitos consigo mesmo. Em pacientes com câncer, Boery (2003) e Schestatsky et al (2006) encontraram déficit considerável neste domínio, principalmente em decorrência da gravidade do quadro de doença terminal. Contudo, os escores do WHOQOL-BREF para transplantados renais tiveram resultados positivos no estudo de Bittencourt et al (2004), uma vez que o transplante restabeleceu seu estado de saúde. Isso pode ser igualmente estendido ao caso do paciente com fissura reabilitado, que não tem mais a malformação visível, considerada um possível agravante ao domínio psicológico.

Em estudos com outros instrumentos, com pacientes com fissura labiopalatina Richman (1978), Tavano (1994), Ramstad et al (1995b), Garcia et al (1999), e Sinko et 
al (2005) encontraram danos psicológicos e distúrbios psicossomáticos como ansiedade, depressão e palpitações, além de uma auto-imagem desfavorável e elevado índice de dependência emocional. Os autores apontaram que o sujeito com fissura tem questões complexas que conduzem ao desajuste psicossocial desde a infância, refletindo negativamente na idade adulta. Por outro lado, (Pruzinsky 1992, Amaral 1997, Endriga e Kapp-Simon 1999, Minervino-Pereira 2000, Marcusson et al 2002 e Hunt et al 2005), encontraram em suas pesquisas adultos sem transtornos emocionais aparentes, com auto-estima mediana e bem ajustados psicologicamente.

Apesar de um bom número de autores afirmarem a presença de danos psicológicos advindos das conseqüências da fissura, incluindo déficits psicossomáticos, os bons índices neste domínio contrapõem esta afirmativa, conduzindo à compreensão de que a malformação, após as cirurgias reabilitadoras, não repercute mais como um fator depreciativo da auto-estima.

Pode-se considerar que vários fatores devem ter levado aos valores acima da média no domínio psicológico obtidos neste estudo, como, por exemplo, o resultado de um bom trabalho de tratamento e prevenção do setor de psicologia do HRAC numa abordagem multidisciplinar em meio às cirurgias reabilitadoras, a participação da família e a conscientização da sociedade para que a fissura não seja um agravante emocional na vida do sujeito (Garcia et al 1999, Bachega 2000, Marcusson et al 2001 e Broder 2001). Uma prova dos benefícios do apoio psicológico na reabilitação está nos achados de Heldt et al (2006) que observaram aumento da qualidade de vida em todos os domínios do WHOQOL-BREF em pacientes com transtorno de pânico, após sessões de psicoterapia breve. 
Vale lembrar, que a presença de desajustamento psicológico depende de uma série de fatores aos quais as pessoas estão sujeitas e não somente à condição de ter fissura. Concordando, com esta afirmativa, cita-se Strauss (2001) que diz que o impacto psicológico de uma condição não precisa estar relacionado com o efeito do dano biológico.

O domínio físico reúne as questões gerais de saúde e capacidade para realização de tarefas do dia-a-dia. A qualidade de vida pode ficar severamente prejudicada, caso o sujeito esteja impossibilitado de atuar no mundo por uma deficiência na saúde ou por um comprometimento físico. Considerando que os pacientes atendidos no hospital, em particular os do presente estudo, apresentam em geral boas condições de saúde, o aspecto físico reportou-se diretamente à questão da fissura labiopalatina e aos comprometimentos advindos dela. Os resultados para este domínio tiveram média igual a 62 pontos, valor acima da média como nos demais domínios; salientando que $60 \%$ dos entrevistados disseram ser plenamente capazes para a realização de atividades diárias e $75 \%$ dos pacientes afirmaram que a sua condição física não os impede de fazer nada. Em estudos com pacientes com Parkinson e câncer, com o WHOQOL-BREF, Nucci (2003), Roque e Forones (2006) e Schestatsky et al (2006) observaram baixa nos escores do domínio físico, que pode ser compreensível pelo diagnóstico de doença crônica, enquanto que, Bittencourt et al (2004) mostraram melhores resultados no domínio físico em pacientes após o transplante renal. Evidencia-se que, quanto mais grave for uma patologia, maiores as limitações físicas em decorrência dela; ao passo que com a reabilitação do estado de saúde, há a melhora no domínio físico.

Em relação à fissura labiopalatina, não foram encontrados na literatura relatos de comprometimentos físicos em pacientes adultos que passaram ou estão passando pelo 
processo reabilitador, além de questões relacionadas ao comprometimento da fala naqueles que, em alguns casos, principalmente quando a fissura de palato não pôde ser totalmente reparada, continuaram com dificuldades de comunicação (Pegoraro-Krook 1995).

Diante do exposto para o domínio físico, conclui-se que a fissura labiopalatina tratada não pode ser considerada um dano físico de forma generalizada, visto que, com a reabilitação, a grande maioria não permanece com comprometimentos à saúde diretamente, nem à capacidade para realização de tarefas.

Relacionado ao domínio meio ambiente, as condições, das quais as pessoas dependem e vivem, dizem muito sobre a qualidade de suas vidas. As percepções do sujeito sobre o grau de higiene, segurança, economia, moradia, lazer e acesso aos serviços de saúde são necessárias para que se possa fazer uma avaliação de quanto isto pode interferir nas condições gerais de vida (Brasil 2006).

Neste domínio a amostra teve média de 61 pontos, valor que, mesmo baixo em relação aos outros domínios, é também superior à média do grupo. Dos pesquisados neste estudo, 50,8\% consideraram as condições do local onde moram bastante saudáveis. Em pesquisa com o WHOQOL-BREF com pacientes hansenianos recuperados que continuavam a residir na instituição que os acolheu para tratamento, Quaggio (2005) encontrou o domínio meio ambiente em menor índice em relação aos outros domínios. Porém, considerando que a grande maioria dos pesquisados neste estudo tem casa própria e convive com familiares, não é possível compará-los com a realidade dos sujeitos com hanseníase reabilitados, que evidenciaram condições desfavoráveis para a moradia. 
Também não foram encontrados na literatura estudos sobre as condições do meio ambiente de pacientes com fissura labiopalatina especificamente. Uma justificativa para a avaliação satisfatória do domínio meio ambiente pelos pacientes pesquisados poderia ser o fato de $85,8 \%$ deles estarem residindo no interior. Pode-se inferir que os dados reflitam as características de pessoas que vivem em cidades que, conforme Cesar et al (2005), têm melhores índices de saúde e condições ambientais se comparadas com a capital do estado de São Paulo.

Embora Bullinger et al (1993) e Gill e Feinstein (1994) tenham detectado que a qualidade de vida reproduz um aglomerado de condições que pode afetar a percepção do indivíduo, o seu funcionamento diário e não somente as questões médicas, Casas (2005) e Brasil (2006) evidenciaram a necessidade de incluir os serviços oferecidos e as intervenções médicas na avaliação da qualidade de vida. Uma questão do domínio meio ambiente relevante foi sobre a satisfação com os serviços de saúde, onde um total de $36,7 \%$ dos pacientes entrevistados referiu estar bem satisfeitos e $25,8 \%$ deles muito satisfeitos com os serviços de saúde do qual se utilizam. Como os pacientes pesquisados dependem do tratamento específico das fissuras, oferecido pelo HRAC, a avaliação dos serviços de saúde foi direcionada ao hospital.

Romano (1999) e Strauss (2001) afirmaram que os pacientes, uma vez inseridos como ativos no processo reabilitador, participando das decisões sobre si mesmo e o tratamento, são capazes de avaliar a satisfação com os serviços de forma responsável. Tal condição é própria dos pacientes do HRAC em função das etapas e condutas terapêuticas aplicadas (Bachega 2000) e da convivência intensiva entre a equipe, o paciente e sua família, que proporciona um maior conhecimento de suas inquietações e insatisfações (Alves 1995). Contudo, referente ao critério de avaliação de satisfação 
com o serviço oferecido, é preciso considerar as opiniões de Ware (1978), Lemme et al (1991) e Cesar et al (2005), quando pontuaram que os pacientes tendem a avaliar positivamente os serviços prestados gratuitamente, dificultando a investigação de obstáculos que estariam impedindo um atendimento melhor. Portanto, mesmo com dados indicativos da satisfação com os serviços de saúde prestados, são necessárias pesquisas que lidem particularmente com os níveis de satisfação com o tratamento das fissuras e tudo o que o compõe, uma vez que informações obtidas somente por algumas questões dentro do instrumento de qualidade de vida impossibilitam o oferecimento de resultados mais consistentes a este respeito.

Diante do exposto, observa-se que os pacientes pesquisados avaliaram a própria qualidade de vida, de modo geral, acima da média. Este resultado clarifica a necessidade da mudança de olhar sobre o paciente com fissura após a reabilitação, colocando-o como ser humano completo, independente, com plena capacidade de realização e não mais como o "portador" de fissura que sofre limitações e precisa de cuidados especiais por toda a vida, como já evidenciaram Minervino-Pereira (2000) e Strauss (2001).

Como visto, a avaliação dos quatro domínios separadamente também mostrou que todos os pacientes entrevistados estão acima da média do grupo. Em primeiro lugar está o domínio de relações sociais, seguido do psicológico, físico e meio ambiente. Embora todos os resultados estejam satisfatórios, existe a necessidade de pesquisas, principalmente quanto aos domínios físico e meio ambiente, uma vez que foram encontrados mais estudos voltados para os domínios relações sociais e psicológico para pacientes com fissura labiopalatina, de forma a contribuir com mais subsídios ao conhecimento das condições de vida e saúde da população de interesse, inclusive abrangendo amostras de pessoas advindas de todas as regiões do país. 
6.3 - Qualidade de vida e fatores sociodemográficos.

De acordo com a literatura estudada, a qualidade de vida deve ser medida a partir dos fatores que compõem a vida e as percepções dos sujeitos a respeito de si mesmos (WHOQOL-Group 1994, Segre e Ferraz 1997, Arnold et al 2004 e Berlim et al 2005). Para tanto, foi feita a análise dos resultados da qualidade de vida com a utilização do WHOQOL-BREF e do questionário de identificação que trouxe os dados referentes às condições sociodemográficas dos sujeitos pesquisados. Porém, a correlação destes dois instrumentos mostrou que as variáveis levantadas não interferiram significativamente nos domínios da qualidade de vida. Os resultados não permitiram, então, a afirmação de que os fatores levantados favoreceram ou não a qualidade de vida dos pacientes adultos com fissura labiopalatina. Berlim et al (2003) também não encontraram correlações significativas dos aspectos sociodemográficos em seu grupo de pacientes com diagnóstico de depressão, estudado através do WHOQOLBREF.

Mesmo entendendo que os fatores sociodemográficos sejam complementares à avaliação da qualidade de vida, no presente estudo a qualidade de vida dos participantes parece não ter sido afetada pelos fatores idade, região, tipo de fissura, gênero, escolaridade e profissão levantados, particularmente em relação aos domínios físico, psicológico e relações sociais.

Somente no domínio meio ambiente, a análise estatística identificou os fatores escolaridade e gênero com valores clinicamente relevantes.

Dos pacientes pesquisados, aqueles que tinham o ensino superior atribuíram melhor qualidade de vida para o domínio meio ambiente. A educação, como fator 
preponderante na qualidade de vida, tem a capacidade de ampliar na pessoa a visão a respeito de si mesmo e das condições ao seu redor. Por isso, é justificável que os participantes com ensino superior apresentem melhores condições de avaliar os aspectos ambientais. Porém, como os demais participantes também atribuíram bom índice para este domínio mesmo com valores mais baixos em comparação aos sujeitos com ensino superior, outra hipótese seria visualizada na interpretação do Departamento Intersindical de Estatística e Estudos Socioeconômicos (2006) de que as pessoas com mais escolaridade advém de famílias com melhores condições socioeconômicas como: local de moradia, lazer, transporte e serviços de saúde. Sendo assim, o ambiente dessas pessoas favorece melhor qualidade de vida.

O outro achado apareceu na comparação entre homens e mulheres controlandose as variáveis tipo de fissura e escolaridade. A análise demonstrou que as mulheres creditaram média menor para a qualidade de vida no domínio meio ambiente. Contudo, esse resultado não parece ser clinicamente consistente, uma vez que nos demais domínios tal diferença não foi encontrada. A literatura também não apresenta estudos que correlacionem diretamente a opinião das mulheres quanto ao seu ambiente, muito menos, mulheres com malformações como a fissura labiopalatina.

Mesmo não havendo correlações significativas entre os resultados do questionário de identificação e do WHOQOL-BREF, estes dois instrumentos, analisados separadamente, mostraram que os fatores sociodemográficos levantados posicionaram o paciente com fissura num parâmetro igual ao das demais pessoas e sua qualidade de vida em geral pôde ser considerada boa. A avaliação dos domínios da qualidade de vida isoladamente apontou bons índices para todos os participantes do presente estudo, salientando os domínios relações sociais e psicológico. No entanto, 
Hunt et al (2005) ressaltaram que há muita variedade sobre o que seriam fatores psicológicos e sociais, dificultando a classificação de problemas advindos deles. A literatura revisada mostra que, mesmo havendo estudos recentes que avaliaram as questões psicossociais de pacientes com fissura em diferentes idades e condições, os resultados destes estudos apresentaram uma ampla relação de variáveis, impossibilitando o destaque para os fatores psicossociais realmente pertinentes. Ou seja, os autores que estudaram os aspectos psicossociais de pacientes com fissura labiopalatina escolheram, utilizando de diferentes normas, o que seria relevante dentre tantos fatores a serem considerados.

A própria pesquisadora deste estudo desenvolveu o questionário de identificação com base na literatura existente e nas recomendações do WHOQOL-Group (1994) de que, sendo a qualidade de vida um constructo, seria necessário o conhecimento da realidade sociodemográfica dos pesquisados para a avaliação da mesma. Contudo, não foram encontrados critérios efetivos sobre o que pesquisar em relação a aspectos psicossociais.

Portanto, se houvessem informações mais efetivas sobre os fatores psicossociais de interesse talvez fosse possível encontrar relações mais consistentes com a qualidade de vida dos pacientes com fissura.

O estudo de Graciano et al (2006) apontou a necessidade de reestruturar o modelo de relatório social que servirá como indicador fidedigno das condições sociais e econômicas dos pacientes atendidos no HRAC.

Mais do que isso, surge à necessidade do desenvolvimento de um protocolo de avaliação psicossocial padronizado e validado para a população com fissura labiopalatina, que abranja as condições sociais e emocionais do indivíduo e de sua 
família. Desta forma, poderia se estabelecer uma rotina de avaliação de qualidade de vida, que atendesse aos interesses científicos e práticos dos serviços assistenciais oferecidos pelo HRAC e que contribuísse para o aprimoramento constante da já efetiva proposta de reabilitação. 
CONCLUSÕES 


\section{7 - CONCLUSÕES.}

A avaliação da qualidade de vida dos pacientes adultos com fissura labiopalatina demonstrou que eles têm índices de qualidade de vida no geral e em cada domínio acima da média do grupo, sendo que nos domínios relações sociais e psicológico, os índices foram ainda superiores em comparação aos domínios físico e meio ambiente. Esta afirmativa sugere a existência de uma boa capacidade de ajustamento do paciente com fissura e superação das possíveis dificuldades, resultantes de um processo reabilitador eficiente que o capacita para uma vida com qualidade.

Ao investigar as condições sociodemográficas, conclui-se os pacientes pesquisados estão adequados às condições normais de vida da população em geral.

A análise da qualidade de vida a partir das condições sociodemográficas não demonstrou correlações significativas que comprovassem a influência direta dos fatores do questionário de identificação levantados e os resultados do WHOQOL-BREF. Contudo é de consenso que quanto melhor as condições de vida que se tem melhor a qualidade de vida que se leva.

Sugere-se mais pesquisas sobre a qualidade de vida nos domínios físico e meio ambiente para sujeitos com fissura labiopalatina. Evidencia-se também a necessidade de um protocolo de avaliação das condições psicossociais do indivíduo com fissura que se torne parte de uma rotina de avaliação da qualidade de vida dos mesmos, recurso que ofereceria aos profissionais da equipe de reabilitação informações fidedignas sobre as condições gerais de vida e saúde dos atendidos. 


\section{REFERÊNCIAS}




\section{8 - REFERÊNCIAS}

Abdo RCC, Machado MAAM. Odontopediatria das fissuras labiopalatais. São Paulo: Editora Santos; 2005.

Aiello CA, Silva Filho OG, Freitas JAS. Fissuras labiopalatais: uma visão contemporânea do processo reabilitador. In: Mugayar LRF, coord. Pacientes portadores de necessidades especiais: manual de odontologia e saúde oral. São Paulo: Pancast; 2000. p. 111-39.

Alves MCR. Aspectos psicológicos das intervenções cirúrgicas na área odontológica. Odont Mod 1995; 12:48-52.

Amaral VLAR. Aspectos psicossociais. In : Altman EBC. Fissuras labiopalatinas. 4a. ed. Carapicuíba: Pró-Fono; 1997. p.501-14.

Angerami VA, Nicoletti EA, Chiatone BC, organizadores. $O$ doente a psicologia e $O$ hospital. 3a. ed. São Paulo: Pioneira;1998.

Arnold R, Ranchor AV, Sanderman R, Kempen GI, Ormel J, Suurmeijer TP. The relative contribution of domains of quality of life to overall quality of life for different chronic diseases. Qual Life Res 2004; 13:883-96.

Bachega MI. Indicadores psicossociais e repercussões na qualidade de vida de adolescentes com fissura labiopalatal [tese]. Botucatu: Faculdade de Medicina de Botucatu, Universidade Estadual Paulista; 2000.

Baroneza JE, Faria MJSS, Kuasne H, Carneiro JLV, Oliveira JC. Dados epidemiológicos de portadores de fissuras labiopalatinas de uma instituição especializada de Londrina, Estado do Paraná. Acta Sci Health Sci 2005; 27:31-5. Bednar EA. Self-help for the facially disfigured: commentary on "the quasimodo complex". J Clin Ethics 1990; 1:222-3. 
Berlim MT, Mattevi BS, Fleck MPA. Depression and quality of life among depressed Brazilian outpatients. Psychiatr Serv 2003; 54:254.

Berlim MT, Pavanello DM, Caldieraro MAK, Fleck MPA. Reliability and validity of the WHOQOL BREF in a sample of Brazilian outpatients with major depression. Qual Life Res 2005; 14:561-4.

Bittencourt ZZLC, Alves Filho G, Mazzali M, Santos NR. Qualidade de vida em transplantados renais: importância do enxerto funcionante. Rev Saúde Pública 2004; 38:732-4.

Blatner SHB. Portadores de lesões lábio-palatais e suas relações no trabalho: estigma e realidade [dissertação]. Franca: Faculdade de História, Direito e Serviço Social, Universidade Estadual Paulista “Júlio de Mesquita Filho"; 2000.

Boery EN. Qualidade de vida de pacientes adultos com câncer de pulmão, submetidos a quimioterapia ambulatorial [tese]. São Paulo: Universidade Federal de São Paulo, Escola Paulista de Medicina; 2003.

Brasil. Ministério da Saúde. Conselho Nacional de Saúde. Resolução 196/96 sobre pesquisas envolvendo seres humanos. Brasília: Ministério da Saúde; 1996.

Brasil. Ministério do Trabalho e Emprego. Classificação brasileira de ocupações. [online] 2002 [consultado em 31 maio 2006]; [14 telas]. Disponível: URL: http://www.mtecbo.gov.br/informacao.asp. 
Brasil. Presidência da Republica. Lei n. 8080, de 19 de setembro de 1990. Dispõe sobre as condições para a promoção, proteção e recuperação da saúde, a organização e o funcionamento dos serviços correspondentes e dá outras providências. [online]. 2006 [consultado em 2 nov 2006]: [38 telas]. Disponível: url: http://www.planalto.gov.br/CCIVIL/LEIS/L8080.htm.

Brecht B. Poemas: 1913-1956. São Paulo: Brasiliense; 1990.

Broder HL. Using psychological assessment and therapeutic strategies to enhance wellbeing. Cleft Palate Craniofac J 2001; 38:248-54.

Bullinger M, Anderson R, Cella D, Aaronson N. Developing and evaluating crosscultural instruments from minimum requirements to optimal models. Qual Life Res $1993 ; 2: 451-9$.

Capelozza Filho L, Silva Filho OG. Fissuras lábio-palatais. In: Petrelli E, coordenador. Ortodontia para fonoaudiologia. Curitiba: Lovise; 1992. p.195-239.

Casas F. Desafios atuais da psicologia na intervenção social. Psicol Soc [online]. 2005, v.17 n2 [consultado em 29 jan. 2007] [8 telas]. Disponível:

URL:http://www.scielo.br/scielo.php?script=sci_arttext\&pid=S0102$71822005000200007 \& \operatorname{lng}=\mathrm{pt} \& \mathrm{nrm}=\mathrm{iso}>$.

Cesar CLG, Carandina L, Alves MCGP, Barros MBA, Goldbaum M. Saúde e condição de vida em São Paulo: inquérito multicêntrico de saúde no Estado de São Paulo, ISA/SP. [São Paulo]: Faculdade de Saúde Pública, Universidade de São Paulo: [2005].

Departamento Intersindical de Estatística e Estudos Socioeconômicos. A ocupação dos jovens nos mercados de trabalho metropolitanos. Estudos e pesquisas [online]. 2006, v.3,n.24 [consultado em 27 fev. 2007] [17 telas]. Disponível: URL: http://www.dieese.org.br/esp/estpesq24_jovensocupados.pdf. 
Endriga MC, Kapp-Simon KA. Psychological issues in craniofacial care: state of the art. Cleft Palate Craniofac J 1999; 36:3-9.

Farquhar M. Elderly people's definitions of quality of life. Soc Sci Méd 1995; 41:143946.

Fleck MPA, Leal OF, Louzada S, Xavier M, Chachamovich E, Vieira G, et al.

Desenvolvimento da versão em português do instrumento de avaliação de qualidade de vida da OMS (WHOQOL-100). Rev Bras Psiquiatr 1999; 21:19-28.

Fleck MPA, Louzada S, Xavier M, Chachamovich E, Vieira G, Santos L, et al. Aplicação da versão em português do instrumento abreviado de avaliação de qualidade de vida WHOQOL-BREF. Rev Saúde Pública 2000; 34:178-83.

Freitas JAS, Dalben GS, Santamaría Júnior M, Freitas PZ. Current data on the characterization of oral cleft in Brasil . Braz Oral Res 2004; 18:128-33.

Garcia JR, Neme CMB, Chinelatto MCMP. Body-image in adult patients with cleft lip palate: an analysis through human figure drawing . Braz J Dysmorphol Speech Hear Disord 1999; 2:17-26.

Gazalle FK, Andreazza AC, Hallal PC, Kauer-Sant'anna M, Ceresér KM, Soares JC, et al. Bipolar depression: the importance of being on remission. Rev Bras Psiquiatr 2006; 28:93-6.

Gil AC. Métodos e técnicas de pesquisa social. 3a. ed. São Paulo: Atlas; 1989.

Gill TM, Feisntein AR. A critical appraisal of the quality of quality-of-life measurements. JAMA 1994; 272:619-26. 
Graciano MIG, Pavão APAR, Blattner SHB. Os indicadores de estudo sócio econômico na construção do relatório social no Hospital de Reabilitação de Anomalias Craniofaciais. Serv Social Saúde 2006; 5:183-216.

Graciano MIG, Tavano LDA, Bachega MI. Aspectos psicossociais da Reabilitação. In: Trindade IEK, Silva Filho OG, coords. Fissuras Labiopalatinas: uma abordagem interdisciplinar. São Paulo: Santos Editora; 2007. p.311-33.

Heldt E, Blaya C, Isolan L, Kipper L, Teruchkin B, Otto MW, et al. Quality of life and treatment outcome in panic disorder: cognitive behavior Group therapy effects in patients refractory to medication treatment. Psychother Psychosom 2006; 75:183-6.

Hunt O, Burden D, Hepper P, Johnston C. The psychosocial effects of cleft lip and palate: a systematic review. Eur J Orthod 2005; 27:274-85.

Instituto Brasileiro de Geografia e Estatística. Censo Demográfico - 2000: nupcialidade de fecundidade: resultados da amostra [online]. 2000.[consultado em 2 jan. 2007] [8 telas] Disponível:

URL:http://www.ibge.gov.br/home/estatistica/populacao/censo2000/nupcialidade_fecun didade/tabela_regioes.shtm\#sudeste.

Kluthcovsky ACGC. Qualidade de vida dos agentes comunitários de saúde de um Município do interior do Paraná [dissertação]. Ribeirão Preto: Escola de Enfermagem de Ribeirão Preto, Universidade de São Paulo; 2005.

Lemme AC, Noronha G, Resende JB. A satisfação do usuário em hospital universitário. Rev Saúde Pública 1991; 25:41-6.

Lima AFBS. Qualidade de vida em pacientes do sexo masculino dependentes de álcool [dissertação]. Porto Alegre: Faculdade de Medicina, Universidade Federal do Rio Grande do Sul; 2002. 
Loffredo LCM, Souza JMP, Yunes J, Freitas JAS, Spiri WC. Fissuras lábio-palatais: estudo caso-controle. Rev Saúde Pública 1994; 28:213-7.

Marcusson A, Akerlind I, Paulin G. Quality of life in adults with repaired complete cleft lip and palate. Cleft Palate Craniofac J 2001; 38:379-85.

Marcusson A, Paulin G, Östrup L. Facial appearance in adults who had cleft lip and palate treated in childhood. Scand J Plast Reconstr Surg Hand Surg 2002; 36:16-23.

Marques LC. Implicações psicossociais da realização da faringoplastia em indivíduos com fissura labiopalatina [dissertação]. Bauru: Hospital de Reabilitação de Anomalias Craniofaciais, Universidade de São Paulo; 2004.

Michelone APC, Santos VLCG. Qualidade de vida de adultos com câncer colorretal com e sem ostomia. Rev Latinoam Enfermagem 2004; 12:875-83.

Minayo MCS, Hartz ZMA. Qualidade de vida e saúde: um debate necessário. Ciênc Saúde Coletiva 2000; 5:7-31.

Minervino-Pereira ACM. Auto-conceito e auto-estima em indivíduos com fissura lábiopalatina: influência do tipo de fissura e do tempo de convivência com a mesma [dissertação]. Bauru: Hospital de Reabilitação de Anomalias Craniofaciais, Universidade de São Paulo; 2000.

Monlleó IL, Lopes VLGS. Anomalias craniofaciais: descrição e avaliação das características gerais da atenção no Sistema Único de Saúde. Cad Saúde Pública 2006; 22:913-22.

Morton RP. Evolution of quality of life assessment in head and neck cancer. $J$ Laringol Otol 1995; 109:1029-35. 
Nahas MV. Atividade fisica, saúde e qualidade de vida: conceitos e sugestões para um estilo de vida ativo. Londrina: Midiograf; 2001.

Neter J, Kutner MH, Wasserman W, Nachtsheim CJ. Applied linear statistical models. $4^{\text {th }}$. ed. Chicago: Irwin; 1996.

Noar JH. Questionnaire survey of attitudes and concerns of patients with cleft lip and palate and their parents. Cleft Palate Craniofac J 1991; 28:279-84.

Norusis MJ. SPSS for windows: based system user's guide relase 9.0. Chicago: Prentice Hall; 1992.

Nucci NAG. Qualidade de vida e câncer: um estudo compreensivo [tese]. Faculdade de Filosofia, Ciências e Letras de Ribeirão Preto , Universidade de São Paulo; 2003.

Omote S. Atratividade física facial e prognóstico. Psicol Teor Pesqui 1997; 13:113-7.

Organización Mundial de la Salud. Promoción de la salud: glosario. Genebra: Organización Mundial de la Salud; 1994.

Paschoal SMP. Qualidade de vida no idoso: elaboração de um instrumento que privilegia sua opinião [dissertação]. Faculdade de Saúde Pública, Universidade de São Paulo; 2000.

Patel Z, Ross E. Reflections on the cleft experience by South African adults: use of qualitative methodology . Cleft Palate Craniofac J 2003; 40:471-80.

Pegoraro-Krook MI. Avaliação da fala de pacientes que apresentam inadequação velofaríngea e que utilizavam prótese de palato [tese]. São Paulo: Universidade Federal de São Paulo, Escola Paulista de Medicina; 1995. 
Pereira ACMM, Mota SAS. Análise da influência do estigma físico nas relações interpessoais em indivíduos com malformações crânio-faciais: fissura lábio-palatina. Mimesis 1997; 18:143-54.

Peter JP, Chinsky R, Fisher MJ. Sociological aspects of cleft palate adults: III. Vocacional and economic aspects. Cleft PalateCraniofac J 1974; 1:371-3.

Peter JP, Chinsky R, Fisher MJ. Sociological aspects of cleft palate adults: IV. Social integration. Cleft Palate Craniofac J 1975; 1:304-11.

Pini JG, Peres SPBA. Alimentação do lactente portador de lesão labio-palatal: aleitamento e introdução alimentar. Rev Nutr 2001; 14:195-9.

Pruzinsky T. Social and psychological effects of major craniofacial deformity. Cleft Palate Craniofac J 1992; 29:579-84.

Quaggio, CMP. Hanseníase: qualidade de vida dos moradores da área social do Instituto Lauro de Souza Lima [dissertação]. São Paulo: Secretaria da Saúde, Coordenadoria de Controle de Doenças; 2005.

Ramstad T, Ottem E, Shaw WC. Psychosocial adjustment in Norwegian adults who had undergone standardised treatment of complete cleft lip and palate. I. Education, employment and marriage. Scand J Plast Reconstr Surg Hand Surg 1995a; 29:251-7.

Ramstad T, Ottem E, Shaw WC. Psychosocial adjustment in Norwegian adults who had undergone standardised treatment of complete cleft lip and palate. II. Self-reported problems and concerns with appearance. Scand J Plast Reconstr Surg Hand Surg $1995 b ; 29: 329-36$.

Richman LC. The effects of facial disfigurement on teacher's perception of ability in cleft palate children. Cleft Palate Craniofac J 1978; 15:155-60. 
Romano BW. Princípios para a prática da psicologia clínica em hospitais. São Paulo: Casa do psicólogo; 1999.

Roque VMN, Forones NM. Avaliação da qualidade de vida e toxicidades em pacientes com câncer colorretal tratados com quimioterapia adjuvante baseada em fluoropirimidinas. Arq Gastroenterol 2006; 43:94-101.

Schestatsky P, Zanatto VC, Margis R, Chachamovich E, Reche M, Batista RG, et al. Quality of life in a brazilian sample of patients with Parkinson's disease and their caregivers. Rev Bras Psiquiatr 2006; 28:209-11.

Segnini LRP. Educação e trabalho: uma relação tão necessária quanto insuficiente. São Paulo Perspec 2000; 14:72-81.

Segre M, Ferraz FC. O conceito de saúde. Rev Saúde Pública 1997; 31:538-42.

Seidl EMF, Zannon CMLC. Qualidade de vida e saúde: questões metodológicas e conceituais. Cad Saúde Pública 2004; 20:580-8.

Sinko K, Jagsch R, Prechtl V, Watzinger F, Hollmann K, Baumann A. Evaluation of esthetic, functional, and quality-of-life outcome in adult cleft lip and palate patients. Cleft Palate Craniofac J 2005; 42:355-61.

Skevington SM, Lotfy M, O'Connell KA, WHOQOL-Group. The World Health Organization's WHOQOL-BREF quality of life assessment: psychometric properties and results of the international field trial. A report from the WHOQOL-Group. Qual Life Res 2004; 13:299-310.

Spina V, Psillakis JM, Lapa FS et al. Classificação das fissuras labiopalatais: sugestão de modificação. Rev Hosp Clin Faculd Med São Paulo 1972; 27:5-6.

Stephan AD. O desenvolvimento psicossocial e educacional de indivíduos com anomalias faciais. Rev Bras Crescimento Desenvolv Hum 2003; 13:53-8. 
Strauss RP. "Only skin deep": health, resilience, and craniofacial care. Cleft Palate Craniofac J 2001; 38:226-30.

Tavano LDA. Análise da integração escolar de uma criança portadora de lesão lábiopalatal [dissertação]. São Carlos: Centro de Educação e Ciências Humanas, Universidade Federal de São Carlos; 1994.

Tavano LDA. Avaliação do desempenho psicossocial de pacientes portadores de fissura lábio-palatina submetidos a tratamento multidisciplinar no Hospital de Reabilitação de Anomalias Craniofaciais-USP [tese] Bauru: Hospital de Reabilitação de Anomalias Craniofaciais, Universidade de São Paulo; 2000.

Thomas PT, Turner SR, Rumsey N, Dowell T, Sandy JR. Satisfaction with facial appearance among subjects affected by a cleft. Cleft Palate Craniofac $J 1997$; 34:22631.

Triviños ANS. Introdução à pesquisa em ciências sociais: a pesquisa qualitativa em educação. São Paulo: Atlas, 1987.

Veronez FS, Tavano LDA. Modificações psicossociais observadas pós-cirurgia ortognática em pacientes com e sem fissuras labiopalatinas. Arq Ciênc Saúde 2005; $12: 133-7$.

Ware JE. Effects of aquiescent response set on patient satisfaction ratings. Med Care 1978; 16:327-36.

The WHOQOL-Group. The development of the World Health Organization quality of life assessment instrument (the WHOQOL). In: Orley J, Kuyken W. Quality of life assessment: international perspectives. Heidelberg: Springer Verlag; 1994. p. 41-60. 
The WHOQOL-Group. Development of the World Health Organization WHOQOLBREF, quality of life assessment. Psychol Med 1998; 28:551-8. 
ANEXOS 
Anexo 1 - Ofício de aprovação pelo Comitê de Ética em Pesquisa

Ofício n² 291/2005-UEP-CEP

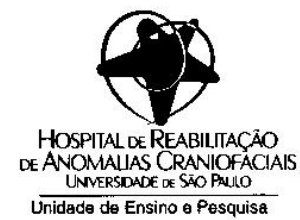

Bauru, 31 de outubro de 2005.

Prezado(a) Senhor(a)

O projeto de pesquisa encaminhado a este Comitê de Ética em Pesquisa em Seres Humanos, denominado "Avaliação da qualidade de vida em pacientes adultos com fissura labiopalatina", de autoria de FULVIA DE SOUZA VERONEZ desenvolvido sob sua orientação, foi enviado ao relator para avaliação.

O parecer do relator, aprovando o projeto, foi aceito pelo Comitê, considerando que nāo existem infraçōes éticas pendentes para início da pesquisa. Solicitamos a V.S ${ }^{\mathbf{a}}$ a gentileza de comunicar o parecer à pesquisadora.

A pesquisadora fica responsável pela entrega na Unidade de Ensino e Pesquisa dos relatórios semestrais, bem como comunicar ao CEP todas as alterações que possam ocorrer no projeto.

Informamos que após o recebimento do trabalho concluído, este Comitê enviará o parecer final para publicação.

\section{Atenciosamente}

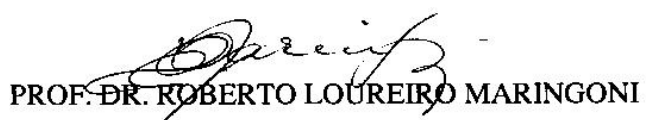

Coordenador do Comitê de Ética em Pesquisa do HRAC-USP

Ilmo. Sr.

Prof. Dr. José Alberto de Souza Freitas

DD. Superintendente do HRAC/USP

Superintendência - HRAC/USP

rua Silvio Marchione, 3-20 Bauru SP Brasi 
Anexo 2 - Carta de Informação ao sujeito da pesquisa

\section{CARTA DE INFORMAÇÃO AO SUJEITO DA PESQUISA}

Prezado participante,

A presente pesquisa intitulada Avaliação da qualidade de vida em pacientes adultos com fissura labiopalatina, será realizada com o objetivo de coletar dados a respeito das condições físicas, psicológicas, sociais, e meio ambiente dos pacientes adultos atendidos pelo HRAC. Desta forma poderemos oferecer aos pacientes melhores condições de tratamento e reabilitação promovendo a qualidade de vida, e atender mais e melhor a população.

Para tanto, os participantes serão reunidos em dia e horário pré determinados, para a aplicação de um questionário sobre a qualidade de vida e entrevista no Hospital de Reabilitação de Anomalias Craniofaciais.

Os pacientes responderão ao questionário sobre qualidade de vida e participarão de uma entrevista sobre formação educacional, interesse vocacional, condições de saúde, sócio-econômicas e convívio familiar.

Vale lembrar que a pesquisa não acarretará nenhum tipo de desconforto ou risco para o participante. A participação do sujeito na pesquisa não requer nenhum gasto adicional para ele.

A pesquisadora estará disponível para qualquer esclarecimento, em qualquer momento.

O sujeito ficará à vontade para se negar a responder, abandonar a pesquisa ou exigir maiores esclarecimentos sobre ela, em todo tempo, sem qualquer prejuízo à continuidade do seu tratamento na Instituição.

Os dados obtidos nas entrevistas e os resultados publicados não identificarão o indivíduo e em hipótese alguma será revelada sua identidade.

Também em qualquer momento da pesquisa o participante poderá solicitar informações respectivas ao estudo, principalmente sobre os resultados finais.

Caso o sujeito da pesquisa queira apresentar reclamações em relação a sua participação na pesquisa, poderá entrar em contato com o Comitê de Ética em Pesquisa em Seres Humanos, do HRAC-USP, pelo endereço: Rua Silvio Marchione, 3-20 na Unidade de Ensino e Pesquisa ou pelo telefone (14) 32358421.

Bauru,

Nome do sujeito:

Assinatura do sujeito:

Nome do pesquisador responsável: Fulvia de Souza Veronez

Assinatura do Pesquisador: 
Anexo 3 - Termo de Consentimento Livre e Esclarecido

\section{TERMO DE CONSENTIMENTO LIVRE E ESCLARECIDO}

Pelo presente instrumento que atende às exigências legais, o Sr. (a)

portador da cédula de identidade:

*responsável pelo paciente , após leitura minuciosa da CARTA

DE INFORMAÇÃO AO SUJEITO DA PESQUISA, devidamente explicada pelas profissionais, em seus mínimos detalhes, ciente dos serviços e procedimentos aos quais será submetido, não restando quaisquer dúvidas a respeito do lido e explicado, firma seu CONSENTIMENTO LIVRE E ESCLARECIDO concordando em participar da pesquisa: Avaliação da qualidade de vida em pacientes adultos com fissura labiopalatina realizada por Fulvia de Souza Veronez CRP: 73329, sob orientação do Dr. José Alberto de Souza Freitas CRO: SP 2021.

Fica claro que o sujeito da pesquisa ou seu representante legal pode a qualquer momento retirar seu CONSENTIMENTO LIVRE E ESCLARECIDO e deixar de participar desta pesquisa e ciente de que todas as informações prestadas tornaram-se confidenciais e guardadas por força de sigilo profissional. (Artigo 16 Código de Ética Profissional do Psicólogo).

Por estarem de acordo assinam o presente termo.

Bauru-SP de de 2005.

$\overline{\text { Assinatura do Sujeito da Pesquisa }}$

Assinatura do Pesquisador

Responsável

Nome do Pesquisador Responsável: Fulvia de Souza Veronez

Endereço do Pesquisador Responsável: Joaquim Fidelis, 2-44

Cidade: Bauru

Estado: SP

CEP: $17.012-180$

Telefone: 9775-3355_Email: fveronez@usp.br

Endereço Institucional (Rua, $\mathrm{n}^{\mathrm{o}}$ ): Silvio Marchione, 3-20

Cidade: Bauru

Estado: SP

CEP: 17.043-900

Telefone: $3235-8000$

Ramal: 8031 
Anexo 4 - Questionário de identificação

Pesquisa: Avaliação da qualidade de vida em pacientes adultos com fissura labiopalatina

Pesquisador: Fulvia de Souza Veronez

INICIAIS

SEXO: Masculino (1)

DATA DE NASCIMENTO

CIDADE:

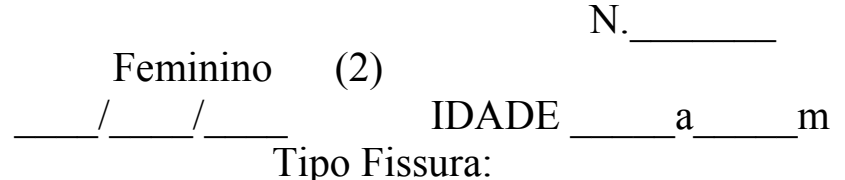

Data de aplicação:

Tipo Fissura:

* Assinale com um X o item que se aplica a você.

ESTADO CIVIL

Solteiro (a)

(1)

Casado (a)

(2)

União estável

(3)

Separado (a)

Divorciado (a)

Viúvo (a)

NÍVEL EDUCACIONAL

Analfabeto

(1)

I grau incompleto

I grau completo

II grau incompleto

II grau completo

III grau incompleto

III grau completo

Pós-Graduação incompleto (8)

Pós-Graduação completo

CONVÍVIO FAMILIAR

Com os pais/familiares

Com parceiro

Sozinho

Com amigos

FILHOS

nenhum

um

De dois a quatro

Mais de cinco

MORADIA

Casa própria

Aluguel

Profissão:

Emprestado

Motivo da escolha da profissão: 
Anexo 5 - WHOQOL - BREF

Iniciais:

$\mathbf{N}^{\mathbf{o}}$

Por favor, leia cada questão, veja o que você acha e circule no número a melhor resposta.

\begin{tabular}{|l|l|c|c|c|c|c|}
\hline & & Muito ruim & Ruim & $\begin{array}{l}\text { nem ruim } \\
\text { nem boa }\end{array}$ & boa & muito boa \\
\hline 1 & $\begin{array}{l}\text { Como você avaliaria sua qualidade } \\
\text { de vida? }\end{array}$ & 1 & 2 & 3 & 4 & 5 \\
\hline & $\begin{array}{c}\text { Muito } \\
\text { insatisfeito }\end{array}$ & Insatisfeito & $\begin{array}{l}\text { Nem } \\
\text { satisfeito nem } \\
\text { insatisfeito }\end{array}$ & satisfeito & $\begin{array}{l}\text { Muito } \\
\text { satisfeito }\end{array}$ \\
\hline 2 & $\begin{array}{l}\text { Quão satisfeito(a) você está com a } \\
\text { sua saúde? }\end{array}$ & 1 & 2 & 3 & 4 & 5 \\
\hline
\end{tabular}

As questões seguintes são sobre o quanto você tem sentido algumas coisas nas ÚLTIMAS DUAS SEMANAS.

\begin{tabular}{|c|c|c|c|c|c|c|}
\hline & & nada & muito pouco & $\begin{array}{c}\text { mais ou } \\
\text { menos }\end{array}$ & bastante & $\begin{array}{l}\text { extremament } \\
\mathrm{e}\end{array}$ \\
\hline 3 & $\begin{array}{l}\text { Em que medida você acha que sua } \\
\text { condição (física) impede você de } \\
\text { fazer o que você precisa? }\end{array}$ & 1 & 2 & 3 & 4 & 5 \\
\hline 4 & $\begin{array}{l}\text { O quanto você precisa de algum } \\
\text { tratamento médico para levar sua } \\
\text { vida diária? }\end{array}$ & 1 & 2 & 3 & 4 & 5 \\
\hline 5 & O quanto você aproveita a vida? & 1 & 2 & 3 & 4 & 5 \\
\hline 6 & $\begin{array}{l}\text { Em que medida você acha que a } \\
\text { sua vida tem sentido? }\end{array}$ & 1 & 2 & 3 & 4 & 5 \\
\hline 7 & $\begin{array}{l}\text { O quanto você consegue se } \\
\text { concentrar? }\end{array}$ & 1 & 2 & 3 & 4 & 5 \\
\hline 8 & $\begin{array}{l}\text { Quão seguro(a) você se sente em } \\
\text { sua vida diária? }\end{array}$ & 1 & 2 & 3 & 4 & 5 \\
\hline 9 & $\begin{array}{l}\text { Quão saudável é o seu ambiente } \\
\text { físico (clima, barulho, poluição, } \\
\text { atrativos)? }\end{array}$ & 1 & 2 & 3 & 4 & 5 \\
\hline
\end{tabular}

Quão completamente você tem sentido ou é capaz de fazer certas coisas.

Quão completamente você tem sentido ou é capaz de fazer certas coisas.
\begin{tabular}{|c|l|c|c|c|c|}
\hline & nada & muito pouco & médio & $\begin{array}{c}\text { muito } \\
\text { completamen } \\
\text { te }\end{array}$ \\
\hline 10 & $\begin{array}{l}\text { Você tem energia suficiente para } \\
\text { seu dia-a- dia? }\end{array}$ & 1 & 2 & 3 & 4 \\
\hline 11 & $\begin{array}{l}\text { Você é capaz de aceitar sua } \\
\text { aparência física? }\end{array}$ & 1 & 2 & 3 & 4 \\
\hline 12 & $\begin{array}{l}\text { Você tem dinheiro suficiente para } \\
\text { satisfazer suas necessidades? }\end{array}$ & 1 & 2 & 3 & 4 \\
\hline 13 & $\begin{array}{l}\text { Quão disponíveis para você estão } \\
\text { as informações que precisa no seu } \\
\text { dia-a-dia? }\end{array}$ & 1 & 2 & 3 & 5 \\
\hline 14 & $\begin{array}{l}\text { Em que medida você tem } \\
\text { oportunidades de atividade de } \\
\text { lazer? }\end{array}$ & 1 & 2 & 3 & 4 \\
\hline
\end{tabular}


Quão bem ou satisfeito você se sentiu a respeito de vários aspectos de sua vida.

\begin{tabular}{|c|c|c|c|c|c|c|}
\hline & & muito ruim & ruim & $\begin{array}{l}\text { nem ruim } \\
\text { nem bom }\end{array}$ & bom & muito bom \\
\hline 15 & $\begin{array}{l}\text { Quão bem você é capaz de se } \\
\text { locomover? }\end{array}$ & 1 & 2 & 3 & 4 & 5 \\
\hline 16 & $\begin{array}{l}\text { Quão satisfeito(a) você está com o } \\
\text { seu sono? }\end{array}$ & 1 & 2 & 3 & 4 & 5 \\
\hline 17 & $\begin{array}{l}\text { Quão satisfeito(a) você está com } \\
\text { sua capacidade de desempenhar as } \\
\text { atividades do seu dia-a-dia? }\end{array}$ & 1 & 2 & 3 & 4 & 5 \\
\hline 18 & $\begin{array}{l}\text { Quão satisfeito(a) você está com } \\
\text { sua capacidade para o trabalho? }\end{array}$ & 1 & 2 & 3 & 4 & 5 \\
\hline 19 & $\begin{array}{l}\text { Quão satisfeito(a) você está } \\
\text { consigo mesmo? }\end{array}$ & 1 & 2 & 3 & 4 & 5 \\
\hline 20 & $\begin{array}{l}\text { Quão satisfeito(a) você está com } \\
\text { suas relações pessoais (amigos, } \\
\text { parentes, conhecidos, colegas)? }\end{array}$ & 1 & 2 & 3 & 4 & 5 \\
\hline 21 & $\begin{array}{l}\text { Quão satisfeito(a) você está com } \\
\text { sua vida sexual? }\end{array}$ & 1 & 2 & 3 & 4 & 5 \\
\hline 22 & $\begin{array}{l}\text { Quão satisfeito(a) você está com } \\
\text { o apoio que você recebe de seus } \\
\text { amigos? }\end{array}$ & 1 & 2 & 3 & 4 & 5 \\
\hline 23 & $\begin{array}{l}\text { Quão satisfeito(a) você está com } \\
\text { as condições do local onde mora? }\end{array}$ & 1 & 2 & 3 & 4 & 5 \\
\hline 24 & $\begin{array}{l}\text { Quão satisfeito(a) você está com o } \\
\text { seu acesso aos serviços de saúde? }\end{array}$ & 1 & 2 & 3 & 4 & 5 \\
\hline 25 & $\begin{array}{l}\text { Quão satisfeito(a) você está com } \\
\text { o seu meio de transporte? }\end{array}$ & 1 & 2 & 3 & 4 & 5 \\
\hline
\end{tabular}

Com que freqüência você sentiu ou experimentou certas coisas nas últimas duas semanas.

\begin{tabular}{|l|l|c|c|c|c|c|}
\hline & & nunca & $\begin{array}{c}\text { Algumas } \\
\text { vezes }\end{array}$ & $\begin{array}{c}\text { freqüenteme } \\
\text { nte }\end{array}$ & $\begin{array}{c}\text { muito } \\
\text { freqüente } \\
\text { mente }\end{array}$ & sempre \\
\hline 26 & $\begin{array}{l}\text { Com que freqüência você tem } \\
\text { sentimentos negativos tais como } \\
\text { mau humor, desespero, ansiedade, } \\
\text { depressão? }\end{array}$ & 1 & 2 & 3 & 4 \\
\hline
\end{tabular}

\section{Muito obrigada.}


Anexo 6- Interpretação gráfica do Boxplot

Fronteira que

determina se o

indivíduo é extremo

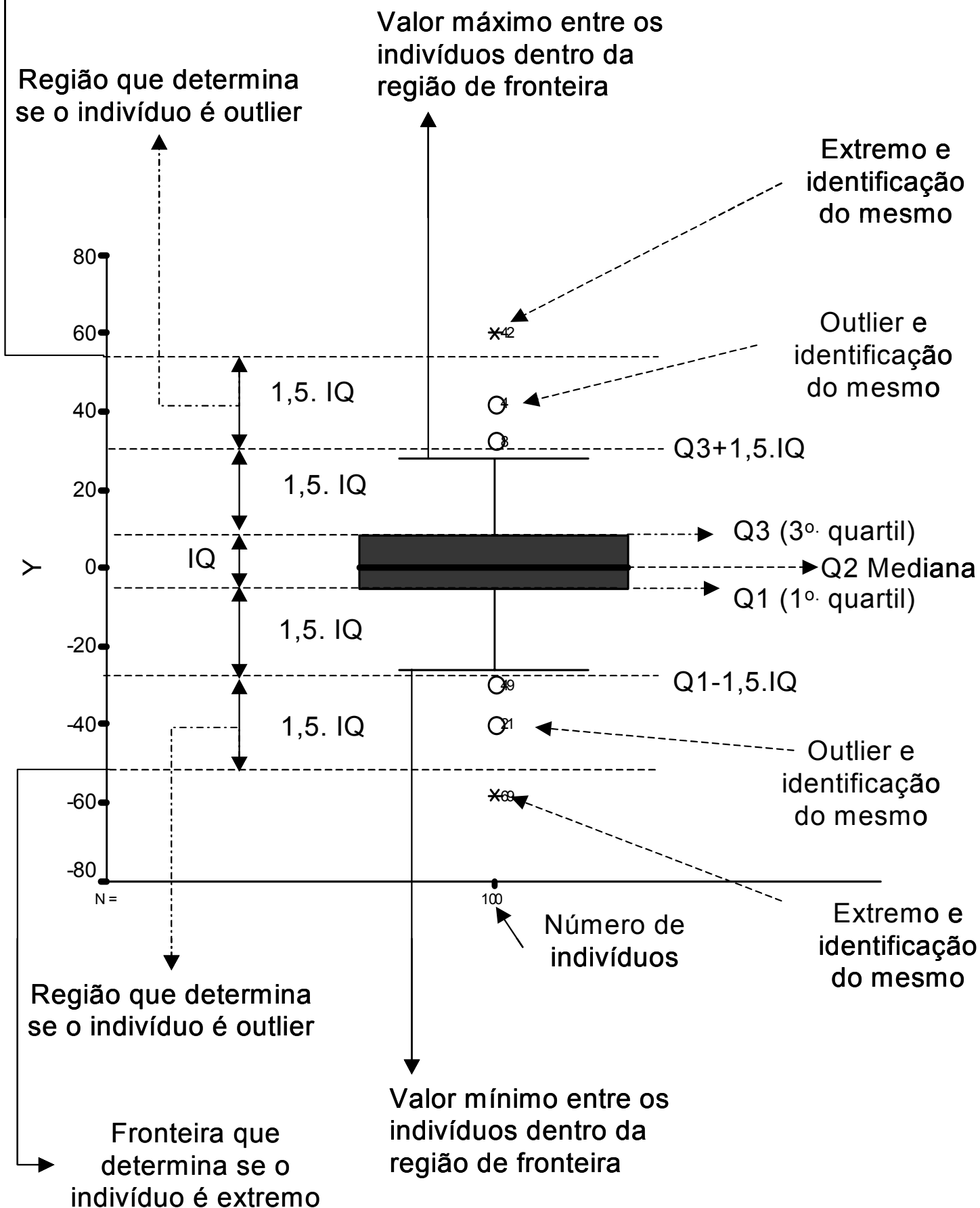

